\section{LA-7399-T}

Thesis

\title{
A Toroidal Fusion Reactor Design Based on the Reversed-Field Pinch
}

옹

¿

$\frac{7}{0}$

. 


\title{
LA-7399-T
}

Thesis

UC-20d

Iserved: July 1978

\section{A Toroldal Fuslon Reactor Design Based on the Reversed-Field Pinch}

\author{
Rendy Lee Haganson
}

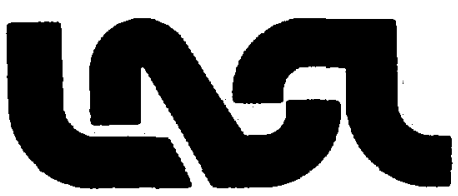




\section{TABLE OF CONIENIS}

Page

ABSTRACT

$\mathbf{x}$

I. INTRODUCTION 1

A. Summary of the Reversed-Field Pinch Concept I

B. Reactor Considerations 5

C. Objectives 9

II . LITERATURE REVIEW 10

$\begin{array}{ll}\text { A. Theory } & 10\end{array}$

$\begin{array}{ll}\text { B. Exper iments } & 17\end{array}$

C. Reactor Studies $\quad 21$

III. DESCRIPTION OF ENERGY BAIANCE

A. General Model $\quad 24$

B. Plasma and Magnetic Field Models 26

C. Plasma Energy Balance $\quad 30$

D. Magnetic Energy Storage and Joule Losses 34

E. Calculational Procedure 37

IY. RESULTS $\quad 39$

A. Reactor Startup Phase 39

B. Thermonuclear Burn Cycles 41

C. Plasma Quench $\quad 49$

D. Operating Point (s) Determination 51 
V. FINAL SYSTEM DESIGN 61

A. General Reactor Description 61

B. Consideration of Major 67 System Coxponents

VI. SUMARY AND CONCLUSIONS

VII. TOPICS FOR FURITIER STUDY : 87

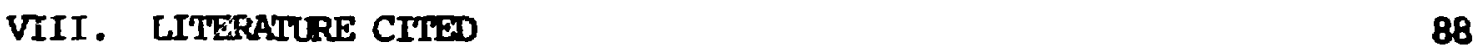

IX. ACKNOWLEDGENIS 95

$\begin{array}{ll}X . & 96 P E N D I X\end{array}$ 


\section{IIST OF TABLES}

Page

Table 1. Sumary of reversed-field pinch parameters 18

Table 2. Dimensions used in RPPR energy-balance study 44

Table 3. Summary of typical RFPR parameters 57

$\begin{array}{ll}\text { Table 4. Hamopolar specifications } & \text { B2 }\end{array}$ 


\section{LIST OF FIGURES}

Page

Fig. 1. In the toroidal system $R$ is taken as the major radius and $r$ as the minor radius The minor axis of the torus is dênoted by $z$, and the angle about $z$ is given by 0 .

Fig. 2. Field profiles of various fusion concepts.

Fig. 3. Cross-sectional drawing of the envisioned RFPR.

Fig. 4. Sample MHD stable pressure and field profiles for a linear pinch showing the effect of increasing the pressure on the location of the conducting wall for stability (13).

Fig. 5. Complete RFPR energy balance used in conjunction with a time-dependent RFP plasma model to evaluate a range of reactor operating points. Refer to text for motation.

Fig. 6. Comparison of assumed poloidal $B_{6}$ and toroidal $B_{2}$ fields and actual MtD stable field profiles (13).

Fig. 7. Generalized pressure-volume diagram for the RFPR. Magnetic field pressures, plasma pressure $p$, and the plasma direct-conversion work $w$. for high-heta plasma expansion against a magnetic fleld are shown for the assumed sharp-boundary plasma model.

Fig. 8. Lines of constant $\mathcal{Q}$ for various first-wall radi $\tau_{y}$ and curves) where a 508-50\% D-T fuel mixture is used. The dotted-dashed curves are lines of constant first-wall $\left((0.3 \mathrm{~mm}) \mathrm{Al}_{2} \mathrm{O}_{3} /(2 \mathrm{~mm}) \mathrm{Nb}-1 \mathrm{Zr}\right)$ surface temperature rise $\Delta T_{W}(k)$.

Fig. 9. Dependence of the engineering $Q$-value $Q_{E}$ on the initial plasma tritium fraction $\mathrm{f}_{\mathrm{T}}$ for 908 burnup of the available tritium in the plasma.

Fig. 10. Lines of constant $Q_{F}$ for various first-wall radi $r_{i}$ and maximum average toroidal current densities $\hat{j}_{z}$ (solid curves) where a 908-10\% D-T fuel mixture is used. The dotted-dashed curves are lines of constant first-wall $\left((0.3 \mathrm{~mm}) \mathrm{Al}_{2} \mathrm{O}_{3} /(5 \mathrm{~mm}) \mathrm{Nb}-1 \mathrm{Zr}\right)$ surface temperature rise $\Delta \mathrm{T}_{\mathrm{W}}(\mathrm{k})$. 
Fig. 11. Time-dependence of plasma and energy quantities for the 53 508-508 D-T operating point sumnarized in Table 3.

Fig. 12. Time-dependence of plasma and energy quantities for the 54 908-10\% D-T operating point sumar ized in Table 3.

Fig. 13. Dependence of $Q_{F}$ on the magnetic energy transfer/ 55 storage efficiency $r_{\text {ETS }}$ for both cases investigated.

Fig. 14. Time-dependence of various plasma parameters and dominant 50 powers for a tokanak-like RFPR startup.

Fig. 15. Plan and elevation view of 750 whe (net) RFPR.

Fig. 16. Schematic diagram of the primary-coolant circuit 63 illustrating the major litinium flow paths.

Fig. 17. Isometric view of 2-m-long RFPR reactor modules (vacuur vessel, blanket, toroidal field $\infty$ ill and asscilated poloidal field coil assembly and iron-core pieces.

Fig. 18. Time dependence of the blanket temperature distribution for the 50z-50\% D-T burn cycle summarized in Table 3.

Fig. 19. Time dependence of lithium coolant flow in the RFPR 71 blanket for the 508-508 D-T fuel mixture case.

Fig. 20. Dependence of first-wall temperature and stress during the ignition, burn, quench, and plasma cooling periods associated with the 508-508 D-T burn cycle given in Table 3.

Fig. 21. Dependence of first-wall temperature and stress during the ignition, burn, quench, and plasma cooling periods associated with the $908-108 \mathrm{D}-\mathrm{T}$ burn cycle given in Table 3 .

Fig. 22. Schernatic diagram of hamcpolar-generator òriven circuit for boch TFC and PFC systems. The voltage $V \sim 4-5 k \mathrm{k}$, the rise time $\tau_{R} \sim 100 \mathrm{~ms}$, and $\tau_{B} \sim 1-6 \mathrm{~s}$. 


\section{A TOROIDAL FUSION REACIOR DESIGN BASED \\ ON THE REVERSED-FIELD PINCH}

$$
\text { by }
$$

Randy Lee Hagensor,

RTIACT

The toroidal reversed-field pinch (RFP) achieves gross, equilibrium and stability with a combination of high shear and wall stabilization, rather than the imposition of tokamak-like q-constraints. Consequently. confinement is provided primarily by poloidal magnetic fields, poloidal betas as large as $\sim 0.58$ are obtainable, the high ohmic-heating (toroidal) current densities promise a sole means of heating a D-T plasma to ignition, and the plasma aspect ratio is not limited by stability/equilibrium constraints. A reactor-like plasma model has been developed in order to quantify and to assess the general features of a power system based upon RFP ounfinement. An "operating point" has been generated on the basis of this plasma model and a relatively detailed engineering energy balance. These results ara used to generate a conceptual engineering model of the reversed-field pinch reactor (RFPR) which includes a general description of a 750 we power plant and the preliminary consideration of vacuum/fueling, first wall, blanket, magnet coils, iron core, and the energy storage/transfer system. 


\section{TNIRODUCTION}

\section{A. Sumary of the Reversed-Field Pinch Concept}

The desire for power production from fusion reactions has lead to the pursuit of many plasma confinement schemes. The present experimental goal of containing a reacting plasma for a sufficient time to achieve a net energy output has been difficult to attain. Even when plasma physics problems are overcome, the economics of the reactor system may be unfavorable and render a particular concept useless. The purpase of this thesis is to determine the potential of a fusion reactor system based on reversed-field pinch confinement. Theoretical predictions (Sec. II.A) and exper imental observation (Sec. II.B) provide the basis for the pres.nt optimisn that stabie plasma confinement may be achievable for time periods sufficient to make an economic reactor system.

Toroidal pinch systems confine the plasma using an azimuthal field $B_{0}$ produced by a toroidal current flowing through the plasma and a toroidal field $\mathrm{B}_{2}$ applied from external coils where the coordinate notation is shown in Fig. 1. Two basic approaches have energed that seek to obtain stable configurations. The first achieves magnetohydrodynamic (MHD) stability by operating beiow the Kruskal-Shafranov current limit $(1,2)$ which implies that unstable modes would require magnetic field wavelengths langer than the major circumference of the torus. This translates into $q>1$ where

$$
q=\left(B_{z} / B_{\Theta}\right) / A
$$




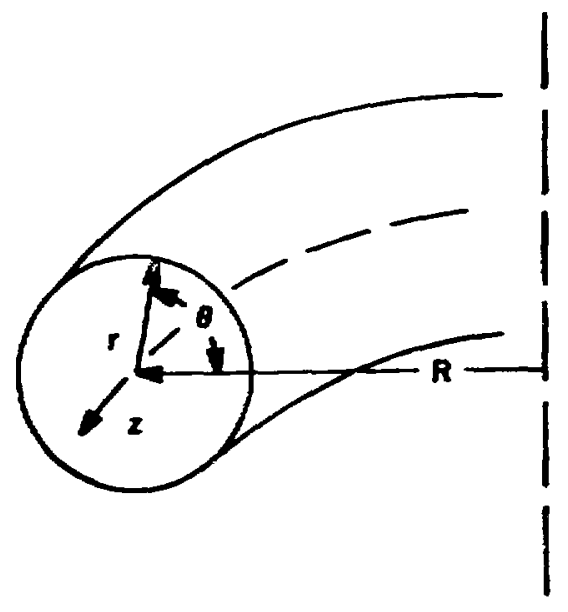

Fig. 1. In the toroidal system $R$ is taken as the major radius and $r_{w}$ as the minor radius The minor axis of the torus is denoted by $z$, and the angle about $z$ is given by 0 .

The aspect ratio $A$ is $R / r_{w}$ where $r_{w}$ is the first-wall radius. The major device utilizing this concept is the tokamak (3-6) whose field profiles are also shown in Fig. 2. Maintaining $q>1$ requires small values of $\mathrm{B}_{\Theta} / \mathrm{B}_{\mathbf{z}}$ which leads to low values of total $B$ (p).asma pressure/total magnetic pressure). It is desirable, however, to have a high total $B$ because the power density is proportional to the square of the number density and $n \propto B \mathrm{~B}^{2}$, so for a constant magnetic field the power output is directly related to $B^{2}$. Present tokamak designs for increasing the total plasma beta are based upon the noncircular plasma concept $(5,6)$ and the flux conservirg tokamak (6). These techniques are envisioned to allow $\beta=3-108$ and still maintain MFD stability. Belt pinches $(7,8)$ shown in Fig. 2 and high-beta tokimaks $(8,9)$ also seek to increase $B$ values. The screw pinch $(8-10)$ shown in Fig. 2 is theoretically stable for $q \sim 0.7-1.5$ with total $B$ up to $25 \%$. The stabilizing influence of 

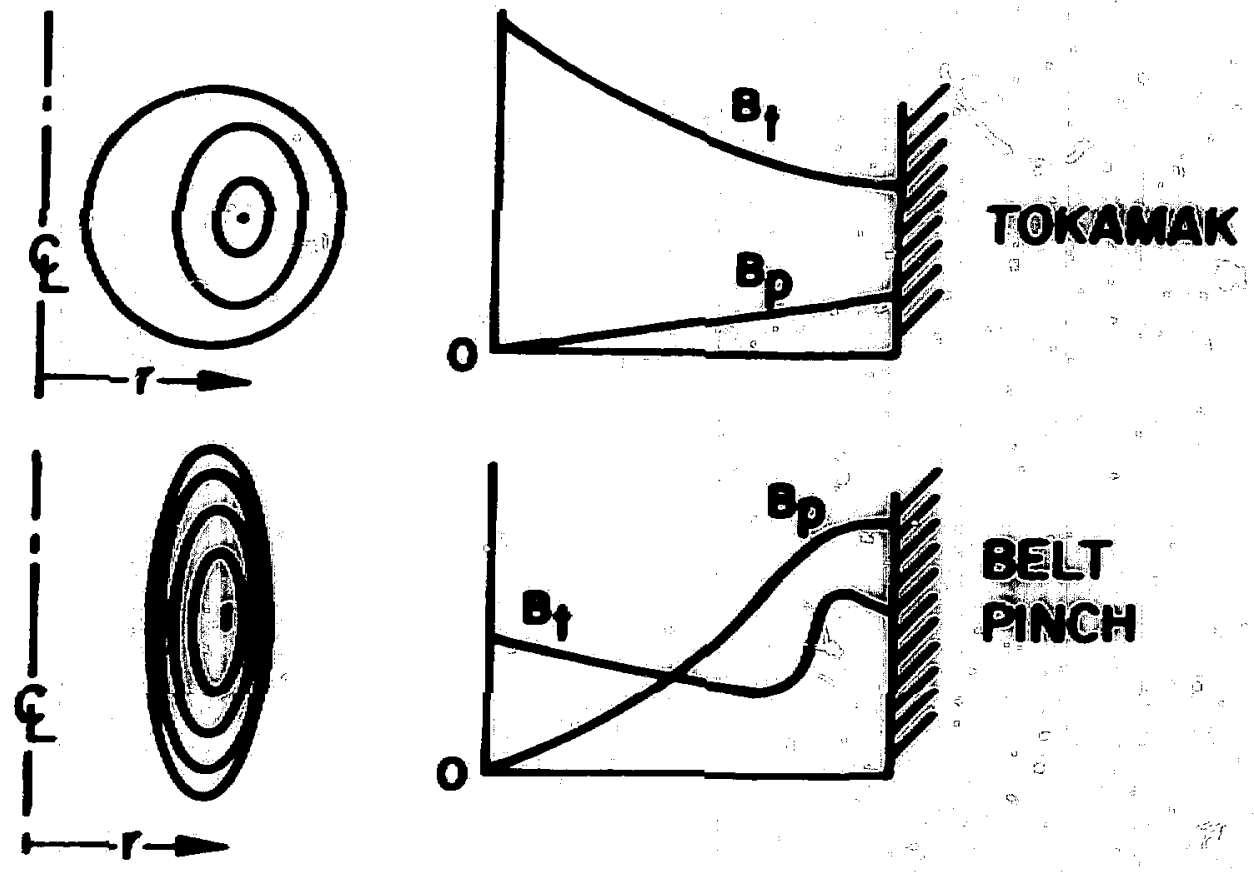

BELT
Pinder
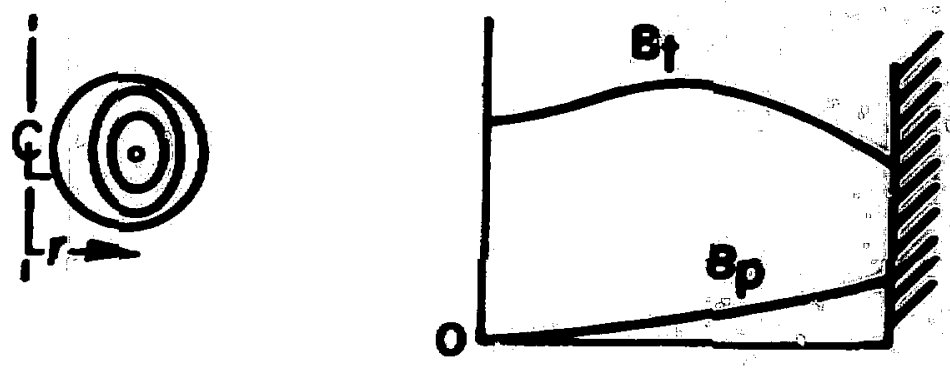

SCRISH

Prower
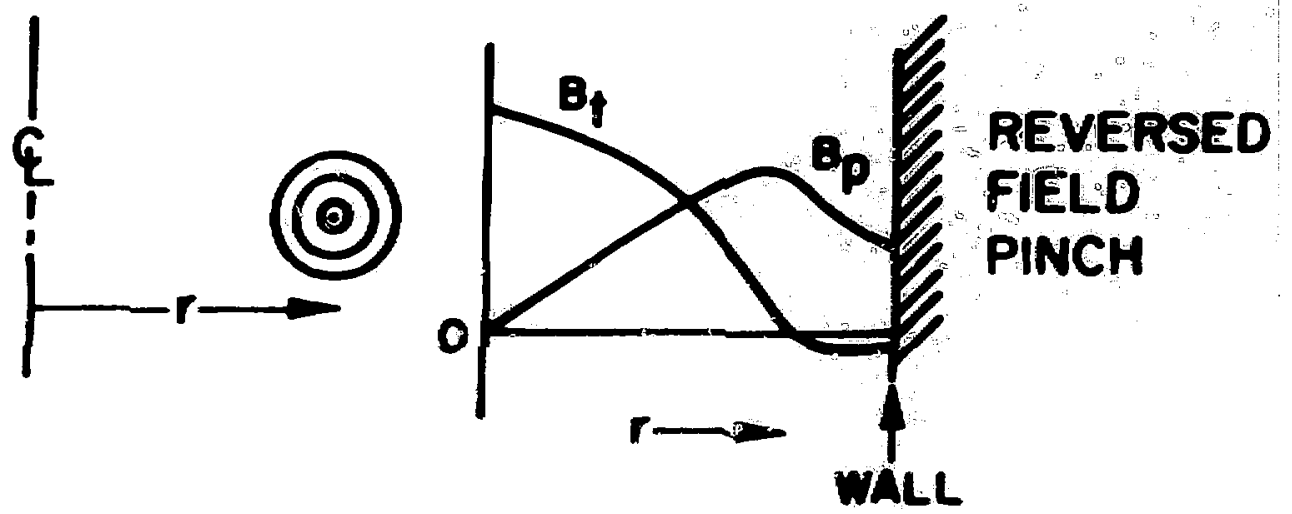

Fig. 2. Field profi.les of various fusion concepts. 
pressureless plasma currents outside the plasma colum achieve these high values of $B$.

As seen from Eq. (1.1), small aspect ratios are also desirable for $q>1$. This implies "tight" tor $i$ leading to inhomogeneous toroidal $\mathrm{B}_{2}$ fields which produces many trapped particle instabilities and enhances the particle and energy diffusion rates $(3,4)$.

In the second inajor approach a onducting shell for external onductors) eliminates grossly unstable modes with magnetic field wavelengths that are now greater than the minor radius of the device. Localized modes are avoided by using a strongly sheared magnetic field. The reversed-field pinch (RFP) utilizes this approach (11-13) and is shown in Fig. 2. The Kruskal-Shafranov limit $(1,2)$ no longer applies and large ohmic heating currents are possible. The restrictions of small aspect ratios and small values of $B_{\theta} / B_{z}$ are therefore, removed. Theoretical values of total $\beta$ equal to $\sim 40 \%$ are predicted.

Numerous methods (11-13) of producing the desired RFP profiles have been considered. Simply inducing a plasma current in the presence of an initial bias field $B_{z o}$ produces a discharge which is initially unstable. Wail contact and unstable MHD modes allow the plasma to spontaneously produce a reversed toroidal field in the outermost region of the discharge. This phenomena of self-field reversal relaxes the plasma into a quiescent mode of operation.

The RFP may also be generated by programing the currents in the toroidal field windings. The reversed field is thereby imposed on the plasma, and the desired profiles can be produced without the initial turbulent phase that characterizes the self-reversal mode. Many of the 
present experiments (Sec. II.B) use this approach, however, the field risetimes must be comparable to the growth rates ( sound speed in the plasma) of the unstable plasma modes. These times are too short for reactor. systems in which rotating machinery is used to store the magnetic field energy between pulses. Aiding the self-reversal process with field programing is considered feasible for relatively slow risetime systems. The device is often started as a tokamak discharge with an initial toroidal $\mathrm{B}_{z 0}$ field and $\mathrm{q}>1$. As the plasma current is increased, the toroidal field outside the plasma colum is reversed and the plasma likely passes through many unstable states as $q$ falls below one until a stable RFP field profile is established. Other methods of field programing such as increasing the toroidal bias field as the current is increased to give $\mathrm{q}<1$ during startup are also postulated. A combination of self-reversal and field progranming will hopefully minimize the wall interaction during the plasma initiation and burn.

\section{B. Reactor Considerations}

The reversed-field pinch reactor (RFPR) offers many advantages when compared to q-stabilized systems. The RFPR would operate wel.l above the Kruskal-Shafranov current limit $(1,2)$ and may, therefore, achieve ignition utilizing the high ohric heating rates. The main confining field, $B_{\Theta^{\prime}}$ varies as $1 / r$ outside the plasma, reducing magnetic energy storage requirements and magnet stresses when oxmpared to devices which have uniform toroidal fields outside the plasma. The unrestricted 
aspect ratio should lead to more open systems and reduced construction and maintenance problems.

The operating scheme investigated here for a RFPR is that of a pulsed, high-e system, in which the burn time is a fraction of the energy confinement time. This "batch" burn process implies that no refueling is needed during the burn. The problem of wall interaction with a diffuse plasma edge is minimized by the short burn periods, and divertors are not required. The vigorous plasma burn is not easily degraded by the influx of impurities.

Pulsed systems allow the use of room-temperature coils because the output power (proportional to $\mathrm{B}^{2}$ for a constant confining field) can be made much larger than joule losses in a high- $B$ system. The need for large superconducting coils outside of thick blankets and blanket shields is obviated, which represents considerable cost reductions. The energy balance is enhanced by alpha-particle reaction products expanding against the magnetic field and forcing flux out of the magnet coils. This direct-conversion of $\sim 608$ of the alphi-particle energy to electrical energy through the magnet coils occurs with $\sim 100$ o efficiency.

Varying the burn pulre in frequency and amplitude allows control of the output power. Thermal fluctuations in the primary coolant 100p and blanket structure are small because "off" times less than $10 \mathrm{~s}$ are short compared to the thermal time constants. Liquid lithium can be utilized for breeding tritium and providing cooling with little pumping energy loss. In steady-state systems the lithium must be pumped across strong magnetic fields, whereas pulsed systems may be operated with small lithium flows during the burn when fields are present. 
Operation in a pulsed mode also presents inherent disadvantages when compared to quasi-steady-state systems. Cyclic thermal/mechanical loading of the first-wall and blanket imposes operational constraints. Thermal fatigue of the first wall is a particularly crucial problem. The magnetic energy must be switched into the reactor each burn cycle, and recovered by the energy storage device with high efficiency to actieve an acceptable energy balance. Efficient energy transfer requires reliable switching and puised energy power supplies such as homopolar generators. This pulsed mode of operation implies that the highly energetic plasma must be nondestructively contained and quenched without excessive magnetic field dissipation. Feedback control of the plasma may be required at high- $\beta$ to achieve the required stable configurations.

A schematic drawing of the envisioned RFPR in Fig. 3 shows the location of the major system components. A reference first-wall systen (14) of $\mathrm{Al}_{2} \mathrm{O}_{3}$ bonded to $\mathrm{Nb}-182 \mathrm{r}$ structural alloy is used for first-wall heat transfer calculations. The alumina provides protection against high-z impurities due to sputtering. The blanket utilizes a lead multiplying region followed by ${ }^{6} \mathrm{Li}$, resulting in tritium breeding ratios of 1.10 for a $0.35-m$ thick blanket (15). A conventional stean cycle converts the thermal blanket energy into electrical energy with an assumed 408 efficiency. The room temperature poloidal and toroidal field coils are outside of the lithium cooled blanket. An iron core couples the poloidal coil current from the homopolar energy store (16) to the plasma with nearly unity coupling, accomplished by not saturating the iron core. 


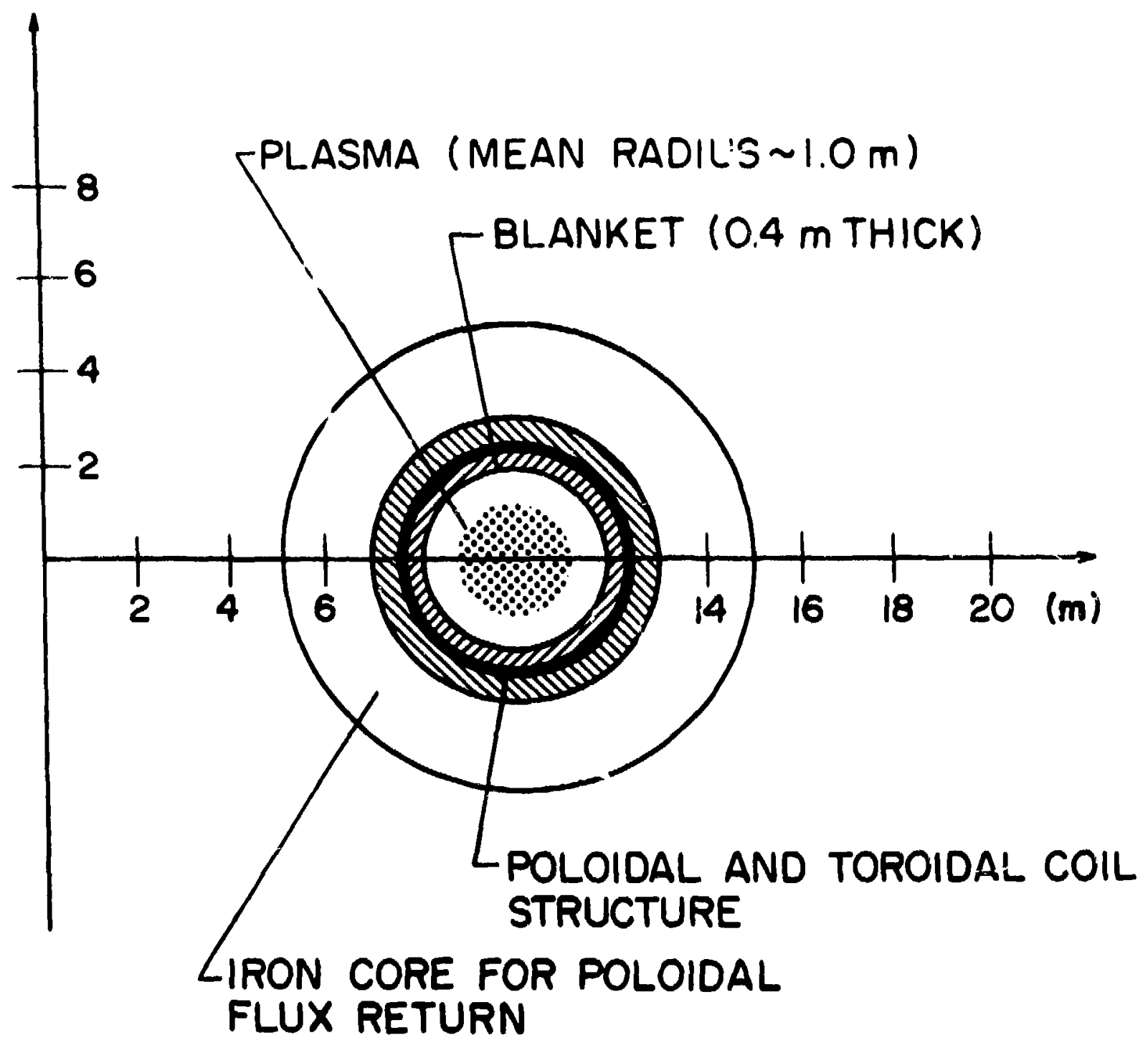

Fig. 3. Cross-sectional drawing of the envisioned RFPR, 


\section{Objectives}

This thesis investigates passible operating schemes for a RFPR. A realistic energy balanoe defines the irmortant energy flows throughout the system. The reactor performance is then evaluated for various first-wall radii, plasna current densities, plasma number densities, anc: deuterium-tritium DT fractions. A zero-dimension plasma engineering code is developed to calculate the burn dynamics for a plasma confined by ideal poloidal and toroidal fields modeled by Bessel functions. Alpha-particle thermalization using Foiker-Planck formulism, classical particle diffusion and thermal conduction, ohnic heating, and radiation losses are included.

Potential operating points for the fFPR are presented which include startup and pre-quench phases. The final system design includes a general reactor description, including preliminary considerations of the required energy storage systems with associated circuits, magnet $\infty i 1 s$, lithium blanket, and the first wall. The results of the analyses preserted herein are used to identify a physics operating point for the RFPR rather than to generate a detailed engineering design for the system. 


\section{LITERATURE REVIEN}

\section{A. Theory}

The pinch discharge is one of the earliest fusion concepts to be proposed. The simple pinch is a resistively heated current-carrying conductor being radially compressed by the azimuthal field generated by the current. The theory of a constricted gas current was initially developed in 1934 and is presented in Glasstone and Lovberg (17). The simple pinch is, however, very unstable to both sausage and kink-type instabilities. A local constriction of the plasma colum enhances the field pressure $\left(\propto 1 / \mathrm{r}^{2}\right)$ at that point causing further contraction and complete current disruption as the sausage mode progresses. The plasma may also remain circular in cross section and develop a kink. The lines of force due to the current in the plasma are brought closer together on the inside of the kink and farther apart on the outside. Once a slight kink develops, the mode grows until the plasma strikes the walls. Theories were then developed that quantitatively explained the behavior of instabilities and predicted the fields necessary to produce a stable pinch.

Early theoretical work on pinch discharges utilized normal mode analysis (17-24) which describes small-amplitude perturbations of the plasma in terms of Fourier components. Small amplitude displacenent.s ;. are represented by

$$
\xi=\xi(r) \exp [i(m \Theta+k z+\gamma(t)]
$$

where $\mathrm{m}$ is the azimuthal periodicity of a particular deformation mode, $k$ is the longitudinal wave number, and $\gamma$ determines the growth rate of the 
perturbation. If $\gamma^{2}$ is positive, the perturbation is periodic in time and stable. For $\gamma^{2}$ negative, the disturbance grows exponentially in time and the system is unstable.

In 1954 Kruskal and Schwarzschild (19) applied the above analysis to a cylindrical sharp-boundary plasma carrying a toroidal current, $I_{z^{\prime}}$ in an infiniteiy thin surface layer. Using no bias field $B_{z}$, it was found that the system was unstable foc $m=0$ (sausage instability) and $I$ (kink instability). Tayler (20) showed in 1957 that all mode numbers $m$ were unstable in this simple pinch, and the growth rates $1 / \gamma$ were of the same magnitude as the sound speed in the plasma.

The sharp boundary model was then extended (1956-1958) to include an axial field $B_{z}$ both inside and outside of the plasma, and a conducting shell encircling the pinch (21-24). The $m=0$ and $m=2$ modes were stabilized using only an axial field, whereas a conducting shell was needed to stabilize the $m=1$ mode. The sharp boundary stability criteria is given approximately by

$$
x>\frac{1}{5\left(1-\beta_{\theta}\right)}, \beta_{\theta}<0.5 \text {, }
$$

where $\beta_{\Theta}$ is the plasma pressure inside the pinch divided by the poloidal field pressure at the surface of the pinch, and $x$ is the plasma radius $r_{p}$ divided by the first-wall radius $r_{w}$

Sharp boundary pinches were not encountered experimentally, and a model which allowed current to permeate the plasma region was needed. A necessary, although not sufficient, condition for a diffuse linear pinch given in 1958 is the Suydam criteria (25) 


$$
\frac{r}{4}\left(\frac{1}{v} \frac{d u}{d r}\right)^{2}+\frac{2 \mu_{0}}{B_{z}^{2}} \frac{d p}{d r}>0
$$

where

$$
u=\frac{\mathbf{B}_{\Theta}}{\mathrm{rB}_{\mathbf{z}}}
$$

represents the number of rotations of a field line per unit length along the $\mathrm{z}$-coordinate. The localized plasma pressure is $\mathrm{p}$ and $\mu_{0}=$ $4 \pi \times 10^{-7} \mathrm{~h} / \mathrm{m}$. The quantity $(1 / U)(d u / d r)$ is the rate of change in pitch angle with radial distance and is called the "shear" of the field. As seen in Eq. (2.3) high shear is desirable for stability. Sample stable pressure and field profiles which satisfy this criteria are show in Fig. 4. As $r \rightarrow 0$ the shear of the fields vanishes, and Eq. (2.3) is satisfied by a positive pressure gradient $d p / d r$. Clearly the pressure gradient must be negative near the outer edge of the discharge as the pressure is reduced to near zero at the wall. This destabilizing effect is cancelled by highly sheared fields in the outer regions resulting from the reversed toroidal field.

Using ideal MD theory, necessary and sufficient conditions were found by Newcomb (26) in 1960 for a linear diffuse pinch. Stability occurs for all $m$ and $k$ values if and only if the pinch is stable for $m=0, k \rightarrow 0$ and $m=1,-\alpha<k<\infty$. The application of this criteria involves the solution of the Euler-Lagrange equation (18). This formulism finds the displacement $\xi(r)$ which minimizes the systems' potential energy. The stability criteria predicts that any displacement from the equilibrium configuration yields an increase in potential 


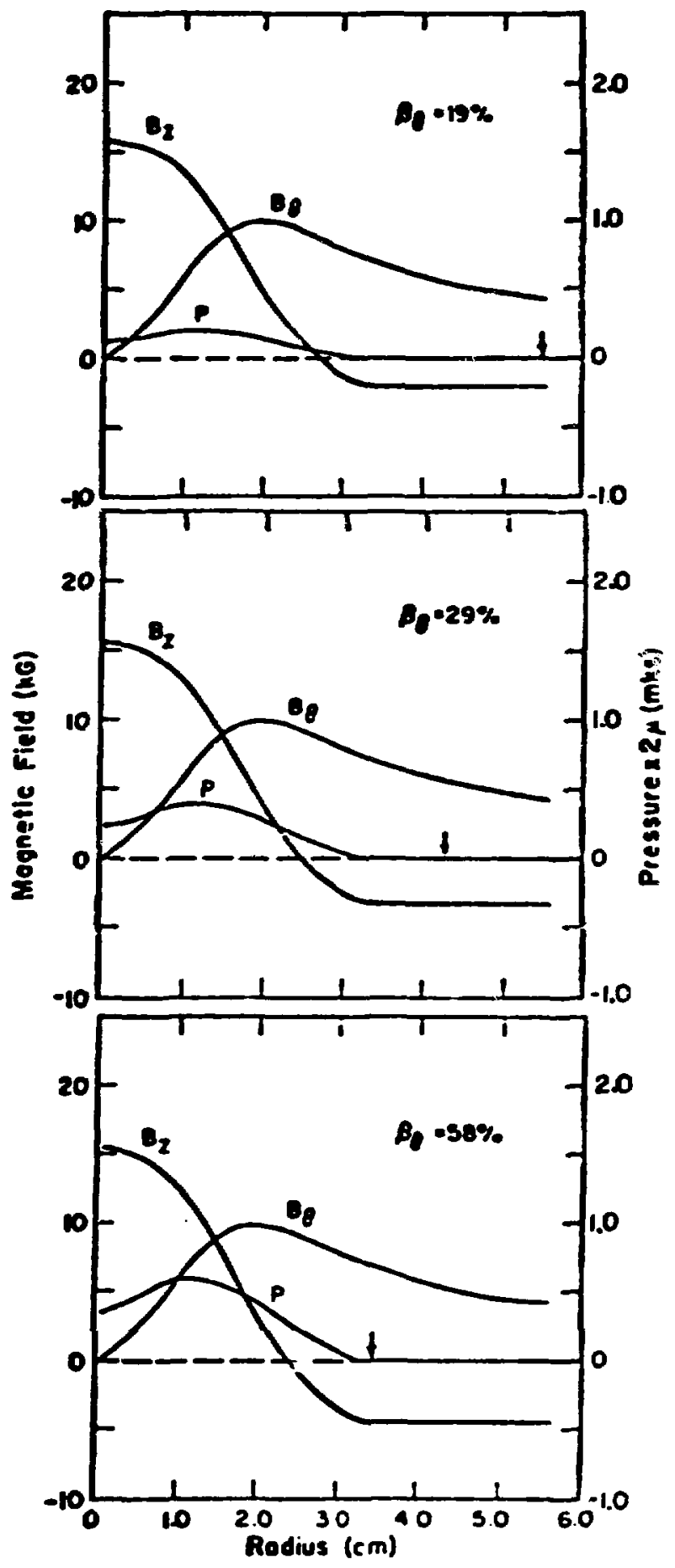

Fig. 4. Sample MDD stable pressure and field profiles for a linear pinch showing the effect of increasing the pressure on the location of the conducting wall for stability (13). 
energy, i.e., requires work to be done on the system. This calculation and other methods used in 1960 by Furth and Suydam $(27,28)$ of investigating stability generally require numerical computer solutions. Recent (1971-1974) calculations (29-31) yield stable reversed-field profiles as shown in Fig. 4. The important conditions for stability are positive total axial flux, $\beta_{\Theta} \leq\left(0.5+100 a l B\right.$ value, where $\left.B_{z}=0\right)$ and the profile must satisfy Suydam's criteria. The first two conditions are important for reactor considerations and are monitored in this stu't by the zero-dimensional models. The last condition would require a onedimensional MrD code, however, so the precise shape of a stable plasma profile is not included when a reactor energy balance is being considered.

Robinson (31) noted in 1971 that a stable configuration also requires that no minimum in the pitch $1 / v=\mathrm{rB}_{z} / \mathrm{B}_{\theta}$ versus radius be present (31). The pitch $1 / u$ must fall monotonically from $r=0$ to the conducting wall. In the vacuum region, $B_{2}=$ constant, $B_{0} \propto 1 / r$ and the resultant pitch varies as $r^{2}$. If both $B_{z}$ and $B_{0}$ are positive, the pitch is increasing in the vacuum region and a pitch minimum will occur. Reversing the $\mathrm{B}_{2}$ field in the vacuum region allows the pitch to continue to fall outside the plasma. A current-free vacuum region is then allowed in a RFP between the plasma and the wall.

The calculation of MHD stable equilibria has been extended to toroidal coordinates (32-34) in 1972 using numerical techniques, vhere the stability of localized modes is determined by the Mercier (32) criterion (toroidal analog of the Suydam criterion) published in 1960. The RFP toroidal configuration produces enhanced stability margins for 
aspect ratios (major radius/minor radius) of 1-5, when compared to a linear device. For aspect ratios approaching 1.0, however, extreme toroidal effects induce instabilities. Stable equilibria exist when $B_{\Theta} \leq 0.6$ for aspect ratios greater than $\sim 2$. Aspect ratios greater than $\sim 5$ allow the use of linear pinch stability theory with substantially the same results.

The stability criteria predicted by ideal wD theory is used for the physics constraints in the reactor calculations. A large body of additional information has been added to the theory of pinches since 1970. Nonideal MTD theory has been used to investigate resistive instabilities using a time-dependent oode that solves the linearized equations of motion $(35,36)$. Including compressibility, finite resistivity, viscosity, and thermal conductivity, unstable resistive tearing modes are possible for ideal MAD stable profiles. Theoretically stable resistive configurations have been found (37) for total $B \sim 308$. A Vlasov-fluid model (38) has also been used to study RFP configurations. This model predicts better stability margins than does ideal MoD theory. Microinstability theory is also being actively pursued and is surmarized in Reference 12.

The behavior of a RFP during startup and operation has been investigated analytically and numerically. The self-reversal of the outer toroidal field, observed in RFP experiments (SeC. II.B), hais been predicted theoretically $(39,40)$. For a slight energy dissipation, the pinch will naturally relax to a state of minimum energy. For $\Theta>1.2$ $\left(\Theta=B_{\theta}\langle\right.$ wall $\left.) /\left\langle B_{z}\right\rangle,\left\langle B_{z}\right\rangle=2 r_{w}^{-2},{ }^{r_{w}} B_{z} r d r\right)$ the lowest energy state 
inside a perfectly conducting wall has a force-free region with a reversed field. For very fast field programmed systems, a global energy and pressure balance has produced the following theorem (41): If the plasma current risetime is much faster than the flux diffusion time, static equilibrium cannot be achieved after the poloidal field has diffused to a uniform current distribution unless losses or plasma pressure at the wall are present. This situation implies that the localized plasma pressure may become too high ouring a very fast startup, and a turbulent phase may result.

Numerical modeling of the experimental plasma behavior in ZT-I (Sec. II.B) has also been performed. A time-dependent, one-dimension MHD code (34) with anisotropic electrical resistivity, heat conduction, and impurity radiation has been used to investigate the postimplosion phase of ZT-I. The electrical resistivity appears to be nearly classical on axis and must increase by two orders of magnitude from the axis to the discharge tube wall in order to approximate the experimental results. If this increase is interpreted to be classical (resistivity $r_{1} \propto T^{-3 / 2}$ ) then the temperature must fall from $\sim 20 \mathrm{eV}$ on axis to a few ev at the wall. More precise temperature measurements are needed to answer the question of anomalous versus classical resistivity. The energy loss to the wall can be taken into account by enhanced transport or by impurity radiation, assuming 18 oxygen and 18 carbon. For the same problem, a hybrid code (42) that treats ions as particles and electrons as a fluid has been used to model the discharge. The field diffusion during the pinch phases has been matched well using an enhanced resistivity. These 
simulatims are carried out for the 5-15 $\mathrm{s}$ containment times of the experimental discharge.

\section{B. Exper iments}

A large number $(17,18,43)$ of linear pinch devices were constructed during the years 1957-1958 in which the electrodes were inserted directly into the plasma at the ends of the tube. Current $r$ ise rates of $10^{10}$ to $10^{11} \mathrm{~A} / \mathrm{s}$ and initial gas pressures of 2 to $10^{3}$ mitore were readily obtainable in devices with lengths from a few inches to several feet and diameters up to two feet. Neasurements performed away from the ends appeared not to be dominated by end effects such as impurities and electrode cooling due to the short confinement times. These experiments were in general agreement that the expected instabilities discussed in Sec. II.A. propagated with the sound speed in the plasma. Many of these experiments $(17,18,43)$ also included a bias field which suppressed the $\mathrm{m}=\mathbf{0}$ mode. Accocding to sharp-boundary theory (Sec. II.A), using a bias field and a conducting shell around the plasma may provide a stable plasma configuration. This theory was insufficient to predict the behavior of a diffuse plasma and the $m=1$ mode persisted. Using Suydam's criteria for a diffuse-current layer, the possibility of improved stability by imposing a reversed field $\mathrm{B}_{z}$ outside the plasma column, or utilizing self-reversal during the current initiation, led to the toroidal RFP experiments listed in Table 1.

One of the first experiments to impose a reversed field, by Ohkawa et al. (44) in 1963, is designated as RFPI in Table 1. By using an 
initial bias field $\mathrm{B}_{\mathrm{zO}} \sim 0.1 \mathrm{~T}$ and programing the magnetic and electric fields to reverse outside of the pinch during the current rise, the plasma lasted for 10 to 15 ws at ion temperatures up to $130 \mathrm{eV}$. Plasma compression increased the density by a factor of $\sim 5$ which resulted in peak ion densities of $3 \times 10^{22} \mathrm{~m}^{-3}$. Without programing, WD instabilities forced the plasma to the wall within $3 \mu \mathrm{s}$.

Table 1. Summary of reversed-field pinch parameters ${ }^{a}$

\begin{tabular}{|c|c|c|c|c|c|}
\hline $\begin{array}{l}\text { Exper iment } \\
\text { Designation }\end{array}$ & $\begin{array}{l}\text { Composition } \\
\text { of } \\
\text { First Wall }\end{array}$ & $\begin{array}{c}\text { First-Wall } \\
\text { Radius } \\
r_{w}(\mathrm{~cm})\end{array}$ & $\begin{array}{l}\text { Major } \\
\text { Radius } \\
\text { R(cm) }\end{array}$ & $\begin{array}{c}\text { Plasia } \\
\text { Current } \\
I_{z}(k A)\end{array}$ & $\begin{array}{l}\text { Filling } \\
\text { Pressure } \\
\mathbf{P}_{\mathbf{A}} \text { (ntrorr) }\end{array}$ \\
\hline RFPl & Alumina & 3.5 & 25 & 20 & $90-100$ \\
\hline \multirow[t]{2}{*}{ ZEPA } & Stainless & 50 & 150 & $100-900$ & $0.25-2.0$ \\
\hline & Steel & & & & \\
\hline HBTX & Quartz & 6.5 & 100 & $40-110$ & 40 \\
\hline EMA-BEIA & Quartz & 5 & 40 & $30-150$ & $20-80$ \\
\hline EL-TPE-1 & Pyrex & 5 & 40 & $80-120$ & $30-50$ \\
\hline STP & Quartz & 4 & 12 & 50 & $20-30$ \\
\hline ZTLI & Alumina & 5 & 37 & $30-200$ & $10-100$ \\
\hline zT-S & Alumina & 7.7 & 40 & $30-140$ & $10-100$ \\
\hline
\end{tabular}

axper iments described in text.

The relatively slow current risetime $(\sim 1 \mathrm{~ms})$ for the ZETA device (45-49), initially operated in 1958, induced voltages of only $\sim 100 \mathrm{v} / \mathrm{m}$ 
and allowed the use of a metallic first wall. Sustaining plasma currents for 1-3 ms through a low pressure gas in the presence of a stabilizing field $\mathrm{B}_{z 0}(0.02-0.1 \mathrm{~T})$ produced plasma temperatures of 10-50 eV and energy confinemerit times of $\tau_{E} \sim 100 \mu \mathrm{s}$. Values of $\Theta_{0}=2-5$ $\left(A_{0}=B_{\theta}(\right.$ wall $\left.) / B_{20}\right)$ were achieved with $B_{\theta}$ up to 108 . A reversed field was not imposed on the outside of the plasma. Continuing experimental studies (47) made from 1965-1968 exhibited a period of improved stability for times up to $3 \mathrm{~ms}$ at electron temperatures of $100-200 \mathrm{eV}$. The quiescence occurred only when both the magnetic and electric fields were reversed in the outer regions of the plasma with $\theta_{0}>1.8$. Recent analysis of old ZEIA experimental data (48) has produced substantially the same conclusions where energy containment times were estimated to be 3-10 ms during the quiescent state at $\beta_{\Theta} \sim 108$. In this experiment no reverse field was imposed on the plasma; self-reversal cocurred when the plasma relaxed to a state of minimum potential energy.

In HBTX $(50,51)$, reversed-field configurations were produced by fast programming. Using $\Theta \sim 2$ suppressed the $m=1$ kink instability under all experimental conditions. Energy confinement times of $\tau_{E} \sim 15 \mu \mathrm{s}$ were predicted during the 20 us stable configuration. The peak temperature increased as the square of the current up to $110 \mathrm{eV}$ with $B_{\theta}=0.4-0.6$.

Experimentally stable RFP configurations were found in ETA-BETA $(52,53)$ for currents up to $60 \mathrm{kA}$, whereas instabilities cocurred at higher currents. Stable discharges were obtained for 10 is containment times and plasma compressions of $x \sim 0.6$. The plasma was characterized by an average temperature of $10 \mathrm{eV}$ and $B_{\theta}=0.2-0.3$. Self-reversal has 
also been exhibited using $x=0.4-0.5$, yielding, plasma decay times of 25-30 is.

The ETL-TPE-1 $(54,55)$ device has been run as a screw pinch and a RFP. Electron temperatures of $\sim 10 \mathrm{eV}$ were maintained for $\sim 20$ ws as $b_{\mathrm{U}}$ rises above 0.6 when the oolumn develops an $m=1$ helical motion and touches the wall. Preliminary RFI operation of the STP (operated primarily as a high-beta tokamak) experiment has also showed improved stability using reversed-field programing (56).

The ZT-I experiment $(57,58)$ was initially designed with a rapid current risetime, $\dot{\mathrm{I}} \sim 1.4 \times 10^{12} \mathrm{~A} / \mathrm{S}$, using inductive energy storage with fuse interrupters. Ion temperatures of $\sim 1 \mathrm{keV}$ and electron temperatures of $\sim 40 \mathrm{eV}$ were obtained. Reversed-field programing was slow compared to the pinch time and completely stable MH profiles were not obtained. Derating the device to currents of 40-70 kA and $i$ to $10^{11} \mathrm{~A} / \mathrm{s}$ allowed field programing. The ion'temperatures were decreased an order of magnitude and favorable stability was obtained. Confinement times of 10-15 is resulted from the reversed-field programing compared to 3-4 $\mathrm{ks}$ with no reversed field. Loss of contaimment appeared to be caused by $B_{\Theta}$ increasing above the stability limit $(\sim 0.5)$.

The major purpose of $\mathrm{Z}^{\mathrm{r}} \mathrm{-S}$ is to examine confinement time scaling by increasing the bore from $10 \mathrm{~cm}$ on ZT-I to $15 \mathrm{~cm}$ on $\mathrm{ZT}-\mathrm{S}$. The confinement time is expected to scale as the field diffusion time, $\tau_{f} \sim r_{w}^{2} D$, where $D$ is the field diffusion osefficient. The confinement time was increased from 10-15 $\mu \mathrm{s}$ in ZT-I to $25-30 \mu \mathrm{s}$ in ZT-S. The increased time scales approximately as the square of the minor radius. 
These promising results have led to the proposal of many new experiments, which include (12) a 24-cm bore experiment (ETA BETA II, University ot Padua, Italy) and a 40-cm bore device (ZT-40, Los Alamos Scientific Laboratory, Los Alamos, NM), both utilize field programing techniques. A 120-cm bore self-reversal experiment (RFX, Culham Laboratory, United Kingdom) is also planued. It is hoped that the above experiments will produce favorable scaling that will extrapolate to the reactor regime.

\section{Reactor Studies}

The few reactor stidies that exist for the RFPR were done at the Los Alamos Scientific Laboratory in 1975 (1.3) and the Culham Laboratory at a low level of effort from 1969-1975 (59-61) leading to the much larger program presently in progress (62). All. of these calculations use a steady-state plasma burn model (plasma temperature and density assumed constant throughout the burn) and were primarily interested in the plasma parameters necessary for a reactor with no consideration of the associated engineering; although, the present Culham program (62) will ultimately lead to a consistent engineering design.

Reactor calculations performed at Los Alamos (13) assumed the plasma is held at constant temperature $(15 \mathrm{keV})$, poloidal beta $\left(B_{\Theta}=0.5\right)$, and plasma compression $(x=0.4)$ for a specified time. The reactor power multiplication was assumed and plasma current limits were calculated based upon the total allowable neutrons incident on the first wall which will result in a specified first-wall lifetime. 
Calculations performed at Culhan used tokamak codes with appropriate RFPR resistivities and classical losses (59-61). In these studies MHD stability is determined by a limiting pcloidal beta, $B_{O L}=0.075 \mathrm{H}^{3}$ (63). This is a result of an increase in the shear of the fields as the plasma current is increased, and must not be used above $\Theta \sim 2$. This general trend of supporting more plasma pressure as the pinch moves away fran the stabilizing wall is in opposition to the results obtained for configurations with the field shear already established. (Sec. II.A)

Using this limiting $\beta_{O L}$, when $B_{O}<\beta_{O L}$ the behavior is assumed classical; when $\beta_{\theta}>B_{\theta L}$ instabilities grow and supposedly saturate, appearing as enhanced loss mechanisms proportional to exp $\left(\left(\beta_{O}-\beta_{O L}\right) k\right)$. The value of $k$ is sufficiently large for $\hat{n}_{\partial L}$ not to be exceeded by more than a few percent. For a 3-m device, $I=25 \mathrm{MA}, \boldsymbol{\theta}=1.75$, and $n_{i}=$ $4 \times 10^{19} \mathrm{~m}^{-3}$, the plasma ohmically ignites in $1.0 \mathrm{~s}$. Cold particles are then injected to maintain the plasma temperature at $20 \mathrm{keV}$ for $20 \mathrm{~s}$. This steady-state system operates at $\vdots=0.46$, and is achieved by the assuned turbulent loss mechanisms. The stability of the configuration during this process is difficult to assess. Energy balance calculations are not performed, although a thermal output of $2000 \mathrm{MN}$ is calculated for arı aspect ratio of 5 .

The reactor study currently in progress at Culham (62) invokes the same postulated plasma loss mechanisms described above where an enhanced thermal conduction maintains a steady-state burn. For a 1.75-m device the parameters of the ohmically heated plasma $(4.5 \mathrm{~s}$ heating phase for 
$I=19 \mathrm{MA})$ are $T=10 \mathrm{keV}, \mathrm{n}_{i}=2.5 \times 10^{20} \mathrm{~m}^{-3}$ and $\beta_{\Theta}=0.35$ during the $27.5 \mathrm{~s}$ burn phase resulting in a 308 fuel burnup. Using a full cycle of $40 \mathrm{~s}$ and normal conducting coils require a 428 recirculating electric power fraction resulting in a net output power of 600 whe from a reactor of $16-\mathrm{m}$ major radius at an estimated capital cost of $\$ 2000 / \mathrm{kWv}$. 


\section{DESCRIPTION OF ENERGY BAIANCE}

\section{A. General Model}

Evaluation of possible operating cycles for the RFPR requires a model of the reactor which allows a realistic energy balance. Such a model is shown schematically in Fig. (5). The plasma has an initial plasma energy $w_{\text {INT }}^{O}$. The total stored energy $W_{B O}$ is then transferred into the RFPR magnets and $w_{B O}\left(1-n_{\text {EIS }}=w_{\text {ETS }}\right.$ is assumed lost externally (outside of the magnet ooil leads), where $r_{\text {EIS }}$ is the magnetic energy transfer/storage efficiency. The remaining magnetic energy ${ }^{\mathrm{BO}}{ }_{\mathrm{E}}$ ETS is partitioned between vacuum field energy, transwort losses $W_{T^{\prime}}$ eddy current losses in the blanket $W_{\mathrm{EB}}$ and magnet coil $\mathrm{W}_{\mathrm{EC}^{\prime}}$ ohmic heating energy $W_{\mathrm{OHM}^{\prime}}$ and field energy trapped inside the plasma $w_{B}^{\mathrm{IN}}$. The high- $\beta$ plasma expansion restores some of the field energy by direct-conversion work $w_{D^{*}}$ The plasma also produces neutron $w_{N^{\prime}}$ radiation $W_{R_{A D}}$ conduction $w_{\text {CaNd }}$ internal plasma $w_{\text {INT }}$, and field $w_{B}^{I N}$ energies which are thermally dissipated and eventually appear as thermal energy in the blanket. All of the field trapped in the plasma at the end of the burn $\mathrm{W}_{B}^{\mathrm{IN}}$ is assumed to be thermally lost to the first wall. The blanket energy is then converted with a themal efficiency $\eta_{\text {TH }}$ to produce a gross electric energy $w_{E T}$. Auxiliary energy $w_{A}$ requirements (pumps, plant operation, etc.), given as a fraction $f_{A}$ of $W_{E T}$ complete the energy balance. Some fraction $\varepsilon$ must be recirculated as makeup energy $W_{C}=E W_{E T}$ the net electric energy is then $W_{E}=(1-\varepsilon) W_{E T}$ and the overall plant efficiency is $(1-E) \eta_{\mathrm{TH}^{\circ}}$ 


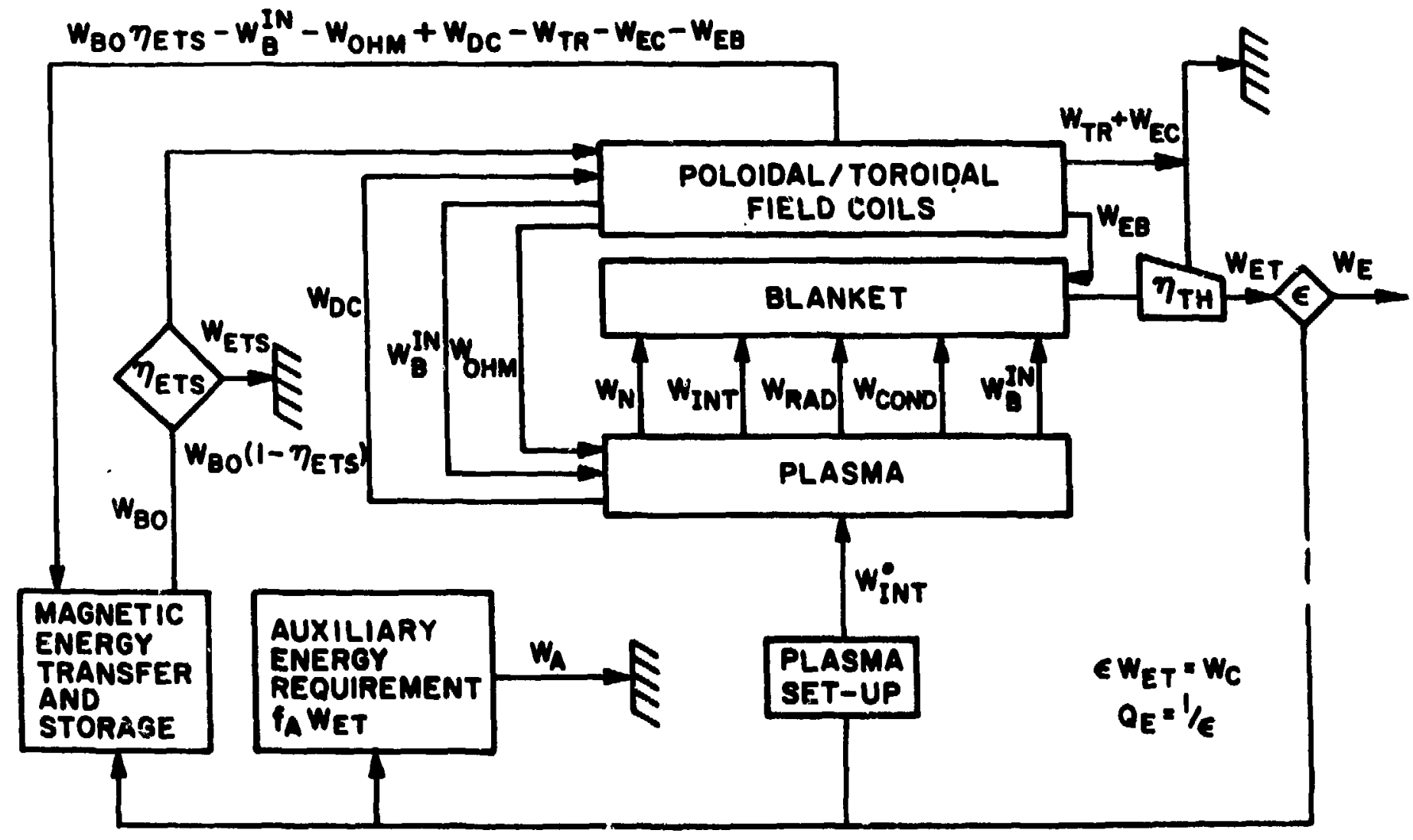

Fig. 5. Complete RFPR energy balance used in conjunction with a timedependent RFP plasma model to evaluate a range of reactor operating points. Refer to text for notation. 
An engineering $Q$-value $Q_{E}$ is defined as

$$
\begin{aligned}
Q_{E} & =\frac{w_{E T}}{W_{C}}=\frac{1}{\varepsilon} \\
& =\frac{r_{I H}\left[w_{N}+w_{I N T}+w_{R A D}+w_{C O N}+w_{B}^{I N}+w_{E B}\right]}{w_{I N I}^{O}+w_{C M}+w_{B}^{I N}+w_{T R}+w_{E B}+w_{B C}-w_{D C}+w_{E H S}+w_{A}}
\end{aligned}
$$

and is used as a major performance indicator for the RFFR. Ecomnic performance indicators have not been used to date, although ultimately economic considerations must be used to provide a final evaluation of a fusion power concept.

\section{B. Plasma and Magnetic Field Models*}

The radial dependence of both poloidal $\mathrm{B}_{\Theta}$ and toroidal $\mathrm{B}_{2}$ fields are assumed to be described by

$$
\begin{aligned}
& B_{\theta}(r)=\left\{\begin{array}{l}
A_{\theta} J_{1}(\alpha r), r<r_{p} \\
\frac{\mu_{0} I_{z}, r>r_{p}}{2 \pi r}
\end{array}\right. \\
& B_{z}(r)=\left\{\begin{array}{l}
A_{z} J_{0}(\alpha r), r<r_{p} \\
B_{R^{\prime}} r>r_{p}
\end{array}\right.
\end{aligned}
$$

iuls units are used throughout, although plasma temperature is expressed in keV units, $k T(J)=T(k e V) \times 10^{3} \mathrm{e}$, where $e=1.602 x$ $10^{-19} \mathrm{~J} / \mathrm{ev}$. 
where $J_{0}(\alpha r)$ and $J_{1}(\alpha r)$ are Bessel functions of the first kind, $A_{\Theta}$ and $A_{z}$ are constants to be determined, $\mu_{0}=4 \pi \times 10^{-7} \mathrm{H} / \mathrm{m}, I_{z}$ is the toroidal plasma current, and $B_{R}$ is the uniform toroidal field outside the plasma. The good agreement between the assumed fields and actual MfD stable field profiles (13) is shown in Fig. (6), which gives the radial dependence of $B_{\Theta}$ and $B_{z}$.

Throidal flux conservation is assumed irside the plasma, which implies that the initial toroidal flux $\left(\pi r_{w}^{2} B_{z 0}\right)$ must equal $B_{z}(r)$ integrated over the plasma area $(2 \pi r d r)$. Performing the integration gives

$$
A_{z}=\frac{\alpha r_{p} B_{z o}}{2 x^{2} J_{1}\left(\alpha r_{p}\right)}
$$

where $x$ is the plasma radius $r_{p}$ divided by the wall radius $r_{w^{\prime}}$ and $B_{z 0}$ is the initial toroidal field. The radius of the plasna is taken as the point of zero $B_{z}$ field for $x<1\left(\alpha r_{p}=2.405\right)$, and $x$ must be determined for $x=1$.

From Maxwell's equations, assuming a static electric field,

$$
\mu_{0} \vec{j}=\vec{\nabla} \times \vec{B} \text {, }
$$

the plasma current densities are given by

$$
\begin{aligned}
& j_{z}(r)=\frac{\alpha A_{\theta} J_{0}(\alpha r)}{\mu_{0}} \\
& j_{\theta}(r)=\frac{\alpha A_{2} J_{1}(\alpha r)}{\mu_{0}}
\end{aligned}
$$




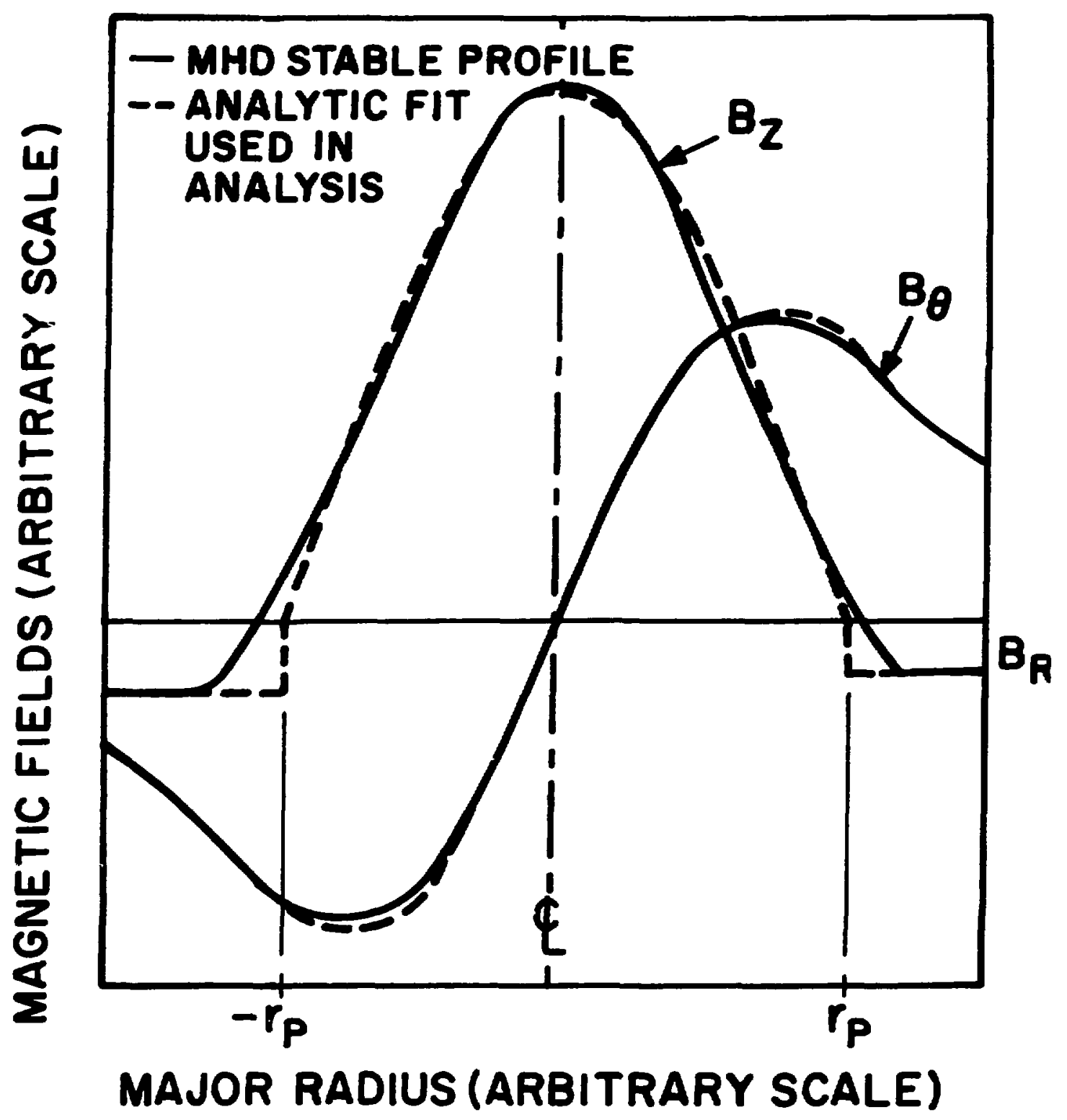

Fig. 6. Comparison of assumed poloidal $B_{9}$ and toroidal $B_{z}$ fields and actual MFD stable field profiles (13). 
The toroidal plasma current $I_{z}$ must equal the integral of $j_{z}$ over the plasma cross section, which leads to

$$
A_{0}=\frac{{ }_{0}^{\mu_{0} I_{2}}}{2 \pi r_{p} J_{1}^{\left(x_{r_{p}}\right)}}
$$

From Maxwell's equations (static electric field) the pressure balance is given by

$$
\frac{1}{\mu_{0}}(\vec{\nabla} \times \vec{B}) \times \vec{B}=\vec{\nabla} p(r)
$$

Substituting the magnetic fields into Eq. (3.9) and integrating over the plasma radius gives the plasma pressure as a function of radius

$$
p(r)=\frac{A_{\Theta}^{2}-A_{z}^{2}}{2 \psi_{0}}\left[J_{0}^{2}(\alpha r)-J_{0}^{2}\left(\alpha r_{p}\right)\right] \text {. }
$$

Within the constraints of the global (zero-dimensional) plasma model use of the average integrated plasma pressure is desirable. Integrating Eq. (3.10) over the plasma area gives

$$
p=\frac{p(r)}{J_{0}^{2}(\alpha r)-J_{0}^{2}\left(\alpha r_{p}\right)} J_{1}^{2}\left(\alpha r_{p}\right)
$$

The average plasma pressure $p$ is given by a sumation of nkT over all plasma species, where an isothermal plasma is generally assumed. Substituting Eq. (3.10) into Eq. (3.11) and utilizing the expressions for $A_{\theta}$ and $A_{2}$ gives

$$
P=\frac{1}{2 \mu_{0}}\left[\frac{I_{z}^{2} \mu_{0}^{2}}{\left(2 \pi r_{p}\right)^{2}}-\frac{B_{z 0}^{2}\left(\alpha r_{p}\right)^{2}}{4 x^{4}}\right] \text {. }
$$


For $x=1, \mathrm{Eq} .(3.12)$ is solved for $\alpha$ which defines the field and pressure profiles during the initial current rise.

A poloidal beta $B_{(}$, is defined as the average plasma pressure divided by the poloidal field pressure at the plasma radius $r_{p}$ which gives

$$
B_{\Theta}=\frac{p}{B_{\Theta}^{2} / 2 \mu_{0}}=\frac{A_{\theta}^{2}-A_{Z}^{2}}{A_{\theta}^{2}}
$$

This expression is used to monitor stability criteria during the thermonuclear burn.

\section{Plasma Energy Balance}

The time-rate-of-change of plasma energy is

$$
\frac{d\left(3 p \pi r_{p}^{2} / 2\right)}{d t}=P_{\alpha}+P_{C A M}-P_{R A D}-P_{C O N D}-P \frac{d\left(\pi r_{p}^{2}\right)}{d t}(N / m) .
$$

where the per meter powers are alpha-particle, ohmic, radiation, and thermal conduction. The last term in Eq. (3.14) represents directconversion work done by high-B plasma expansion against confining magnetic fields. Substituting Eq. (3.12) into Eq. (3.14), and solving for $\mathrm{dx} /$ dt gives

$$
\frac{d x}{d t}=\frac{P_{\alpha}+P_{\alpha E M}-P_{R A D}-P_{C O N D}-3 \cdot \frac{B_{\theta}^{2}}{2 \mu_{0}} \frac{I_{z}}{d t} \frac{d I_{z}}{\pi r_{p}^{2}}}{\frac{1}{x}\left[\frac{3}{2 \mu_{0}} \frac{B_{z O}^{2}}{x^{4}} \frac{(2.405)^{2}}{4}+2 p\right]}
$$

where $B_{\Theta}$ is defined at the plasma radius $r_{p}$. 
The spatially dependent alpha-heating power $\left(\alpha n^{2}\right)$ is numerically integrated over the plasma area using Eq. (3.11) and assuming an isothermal plasma. The result is

$$
P_{\alpha}=5.64 \times 10^{-13} n_{D} n_{T}\langle\sigma v\rangle A
$$

where $n_{D}$ and $n_{T}$ are the spatially averaged deuterium and tritiun number densities, and $\mathrm{A}$ is approximated by an analytic function (within 1 ? accuracy) given by

$$
A=\left\{\begin{array}{cc}
{\left[1.333+0.039 \alpha r_{p}\left(1+0.21\left(\alpha r_{p}\right)^{4}\right)\right] \pi r_{p}^{2},} & x=1 \\
2.098 \pi r_{p}^{2} & , x<1
\end{array}\right.
$$

Bremsstrahlung, line, and cyclotron radiation contribute to the radiation power $P_{\mathrm{RAD}}$. Impurity radiation is incorporated for ongen and utilizes fitted functions given in Ref. 64. The average brensstrahlung power is (18)

$$
\mathrm{P}_{\mathrm{BR}}=5.35 \times 10^{-37} \mathrm{n}_{\mathrm{e}}^{2} \mathrm{z}_{\mathrm{eff}} \mathrm{T}_{\mathrm{e}}^{1 / 2} \mathrm{~A}
$$

where $z_{e f f}$ is the sum of $n_{k} z_{k}^{2}$ divided by the sum of $n_{k} z_{k}$ over all ion species $k$. The cyclotron radiation leaving a nonabsorbing plasma (18) is numerically integrated over the plasma cross section for $\alpha r_{p}=2.405$ to give

$$
\mathrm{P}_{c y}^{\mathrm{T}}=6.20 \times 10^{-17} \mathrm{n}_{\mathrm{e}} \overline{\mathrm{B}}^{2} \mathrm{~T}_{\mathrm{e}}\left(1+\frac{\mathrm{T}_{\mathrm{e}}}{204}\right) \pi \mathrm{r}_{\mathrm{p}}^{2},
$$


where an effective magnetic field $\bar{B}$ has been defined as

$$
\overline{\mathrm{B}}^{2}=\frac{2.098}{3}\left[\mathrm{~B}_{\ominus}^{2}+3 \frac{(2.405)^{2} \mathrm{~B}_{\mathrm{zO}}^{2}}{4 \mathrm{x}^{4}}\right] \text {. }
$$

The poloidal field $B_{\odot}$ is evaluated at the plasna radius. The fraction of $\mathrm{P}_{\mathrm{CY}}^{\mathrm{T}}$ leaving the plasma, accounting for absorption and assuning nonreflecting walls, is (18)

$$
k_{L}=2.1 \times 10^{-3} \mathrm{~T}_{\mathrm{e}}^{7 / 4}\left[\frac{\mathrm{c} \overline{\mathrm{B}} \varepsilon_{\mathrm{o}}}{2 \mathrm{r}_{\mathrm{p}} \mathrm{n}^{\mathrm{e}}}\right]^{1 / 2}
$$

The fraction of $\mathrm{P}_{\mathrm{CY}}^{\mathrm{T}}$ leaving the plasma when plassa absorption and $a$ reflecting cylindrical first wall is present is given as $k_{c}$ in Ref. 65. Thus, given a first wall with a fraction $f$ formed by holes, the cyclotron radiation power leaving the plasma and escaping through these holes is $P_{C Y}^{H}=P_{C Y}^{T} k_{L}$. The power leaving the plasma and absorbed by the first wall is $P_{C Y}^{W}=P_{C Y}^{T} k_{C}(1-f)$ for a reflecting metallic wall and $P_{C Y}^{W}=P_{C Y}^{T} k_{L}$ (1-f) for a nonreflecting wall. The total power leaving the plasma is $P_{C Y}=P_{C Y}^{H}+P_{C Y}^{W}$. In this study a low-z ceramic coating $\left(A_{2} O_{3}\right)$ on the first wall is taken to be nonreflecting.

The ohmic heating power $\mathrm{P}_{\mathrm{OHM}}$ is first calculated for ${ }_{\alpha \mathrm{p}}=\mathbf{2 . 4 0 5}$. From Eqs. $(3.5,9)$, the current perpendicular to $B$ must support the plasma pressure or

$$
j_{\perp}(r) B(r)=\frac{\partial p(r)}{\partial r}
$$

and the remaining current is directed parallel to field lines

$$
j_{i i} \quad(r)=\left(j_{z}^{2}+j_{\ominus}^{2}-j_{\perp}^{2}\right)^{1 / 2} \text {. }
$$


Numerically integrating the ohmic heating power $\left(n_{11} j_{11}^{2}(r)+n_{1} j_{L}^{2}(r)\right)$ over the plasma cross section, and fitting the result to an analytic function (within 18 accuracy) gives

$$
\begin{aligned}
\mathbf{P}_{\mathrm{QTM}}= & \frac{\mathrm{I}_{\mathrm{z}}^{2}}{\pi \mathrm{r}_{\mathrm{p}}^{2}}\left(\frac{2.405}{2}\right)^{2}\left\{\eta_{i}\left(2-\beta_{0}\right)+\left(\eta_{1}-r_{i}, \varepsilon_{0}^{2}\right.\right. \\
& \left.\left.\mid 1-1.13\left(1-\beta_{0}\right)^{1 / 2}+0.43\left(1-\beta_{\theta}\right)\right]\right\} .
\end{aligned}
$$

where the plasma resistivities are assumed classical and are given in the Appendix. During the early startup phase (iir $p \times 2.405)$, the relatively cool plasma yields $B_{O} \sim 0$, and only the parallel resistivity need be considered. The integrable ohmic heating power is then

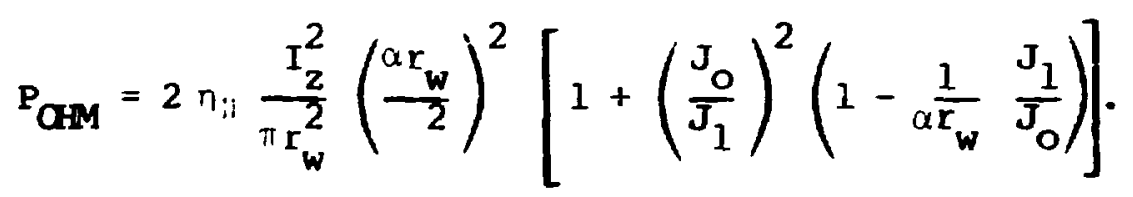

Conductive losses fram the plasma can be properly treated as a function of time by a one-dimensional MHD code. Such a calculation is beyond the scope of this study and an approximate expression is used to describe the dominant ion thermal conduction losses. The conductive power loss is taken as

$$
P_{\text {COND }}=K_{1} \quad(\partial T / \partial r) 2 \pi r_{w}=4 \pi T_{i} K_{1}
$$

where $\mathrm{T}$ is taken as $\left(1-r^{2} / r_{w}^{2}\right) \mathrm{T}_{i}$ (steady-state solution for an infinite circular cylinder with uniform properties) and the thermal conductivity 
$\mathbf{K}_{\perp}$ is given in the Appendix. This power loss term is generally very small and has no impact on the energy balance.

D. Magnetic Energy Storage and Joule Losses

The toroidal and poloidal fields in the plasma and between the plasma and the oil are given by Eqs. $(3.2,3)$. The respective field profiles in the coil are given by

$$
\begin{aligned}
& B_{\Theta}(r)=\frac{\mu_{0} I_{z}}{2 \pi r} \frac{\delta_{p}^{2}-\left(\frac{r}{r_{c p}}\right)^{2}}{\delta_{p}^{2}-1} \\
& B_{z}(r)=-B_{R} \frac{r_{C z}}{\Delta r_{C z}}\left(\delta_{z}-\frac{r}{r_{C z}}\right) .
\end{aligned}
$$

where $r_{C p}$ is the inside radius of the coil, $\Delta_{C p}$ is the coil thickness, $\delta_{p}=1+\Delta r_{q p} / r_{c p}$, and the toroidal $\infty i l$ parameters are defined in an analogous manner. The dependence of $B$ in the coil assumes a uniform current density (i.e. fully litzed and transposed windings). Integrating $\left(B^{2} 2 \pi r d r\right) / 2 \mu_{0}$ over each region (assuming the poloidal energy stored in the iron core is negligible) results in the following expressions for the energy stored in the RFPR:

$$
\begin{aligned}
W_{B O}(J / m)= & \frac{\mu_{o} I_{2}^{2}}{4 \pi}\left[\left(\frac{1}{2}-\frac{J_{o}}{\alpha r_{p} J_{1}}+\frac{J_{o}^{2}}{2 J_{1}^{2}}\right)+\ln \left(\frac{r_{c o}}{r_{p}}\right)\right. \\
& \left.+\frac{\delta^{\delta_{p}}\left(\ln \delta_{p}-\frac{3}{4}\right)+\delta_{p}^{2}-\frac{1}{4}}{\left(\delta_{p}^{2}-1\right)^{2}}\right]
\end{aligned}
$$




$$
\begin{aligned}
& w_{B z}(J / m)=\frac{B_{z o}^{2}}{2110} \frac{\left(\alpha r_{p}\right)^{2} \pi r_{p}^{2}}{4 x^{4}} \quad\left[1+\frac{J_{o}^{2}\left(\alpha r_{p}\right)}{J_{1}^{2}\left(\alpha r_{p}\right)}\right] \\
& +\frac{\mathrm{B}_{\mathrm{R}}^{2}}{2 \mu_{\mathrm{o}}} \pi \mathrm{r}_{\mathrm{z}}^{2}\left[\left(1-\frac{\mathrm{r}_{\mathrm{p}}^{2}}{\mathrm{r}_{\mathrm{cz}}^{2}}\right)+\left(\delta_{\mathrm{z}}-1\right)\left(\frac{1}{6} \delta_{\mathrm{z}}+\frac{1}{2}\right)\right] \text {. }
\end{aligned}
$$

The first, second, and third terms for both fields are, respectively, the energy stored in the plasma, between the plasma and the coil (i.e. in the vacuum region and blanket structure), and in the coil, per se.

A uniform poloidal current distribution is assumed around the minor radius of the torus. The required distribution for stability and equilibrium must ultimately be determined by a MFD calculation. The coil transport is then

$$
\mathrm{P}_{\mathrm{TR} O}(\mathrm{~W} / \mathrm{m})=\frac{\mathrm{r}_{\mathrm{CP}}}{\pi\left[\left(\mathrm{r}_{\mathrm{CP}}+\Delta \mathrm{r}_{\mathrm{CP}}\right)^{2}-\mathrm{r}_{\mathrm{CP}}^{2}\right] \lambda_{\mathrm{CP}}} \mathrm{I}_{\mathrm{z}}^{2} \text {. }
$$

where $n($ ohm-m) is the coil electrical resistivity and $\lambda$ is the filling fraction of conductor in the ooil. The transport losses in the toroidal field coil are expressed as

$$
\mathrm{P}_{\mathrm{TRZ}}(\mathrm{N} / \mathrm{m})=\frac{{ }^{n} \mathrm{cz} 2 \pi\left(\mathrm{r}_{\mathrm{cz}}+\Delta \mathrm{r}_{\mathrm{cz}} / 2\right)}{\Delta \mathrm{r}_{\mathrm{cz}} \lambda_{\mathrm{cz}}} \frac{\mathrm{R}_{\mathrm{R}}^{2}}{\mathrm{ii}_{\mathrm{O}}^{2}}
$$

Parallel plate leads are assumed where the thickness of one plate is $\mathrm{p}_{\mathrm{t}}$ and a gap between the plates is $\mathrm{p}_{\mathrm{g}}$, so that the total lead thickness 
is $2 p_{t}+p_{g}$. Specifying the lead width $p_{w}$, lead length $p_{\ell}$, and length of coil fed by lead as $\ell$, the energy storage and transport losses are

$$
\begin{aligned}
& W_{B L D}(J / m)=\frac{B_{L}^{2}}{2 \mu_{0}} \frac{p_{w} p_{l}}{l}\left[p_{g}+\frac{2}{3} p_{t}\right] \\
& P_{\text {TRLD }}(W / m)=\frac{2 p_{l} p_{w}}{P_{t}^{\lambda l} \frac{B_{L}^{2}}{\mu_{L}^{2}}} .
\end{aligned}
$$

where $\mathbf{N}$ is the turns ratio, $\lambda$ is the fraction of conductor in the lead, $\eta$ is the resistivity and

$$
\begin{aligned}
& B_{L}=\frac{\mu_{0} I_{z}}{P_{w} N_{C P}} \\
& B_{L}=\frac{\ell B_{R}}{P_{w} N_{C z}}
\end{aligned}
$$

for the poloidal and toroidal coils, respectively.

Eddy current losses in the coils are incurred during the current rise and fall corresponding to a total time of $2 \tau_{R^{\circ}}$ Taken as a fraction of the transport losses incurred during the plasma burn $\tau_{B^{\prime}}$ these losses are estimated to be (66)

$$
\frac{W_{\mathrm{EC}}}{\bar{W}_{\mathrm{T}}} \sim 0.02 \mathrm{n}^{2}\left(\frac{d}{\delta}\right)^{4} \frac{\tau_{R}}{\tau_{B}}
$$

The $n$ layers of thickness $d$ constitute a coil of total thickness $n d / \lambda$ having an electrical skin depth of $\delta=\left(0.5 \times 10^{6} n \tau_{R}\right)^{1 / 2}$ Using roam temperature copper $\left(n=1.8 \times 10^{-8_{\Omega-m}}\right), \tau_{R}=0.1, \tau_{R} / \tau_{B}=0.1$, 
$\mathrm{d}=0.607, \mathrm{n}=100, \lambda=0.7$ gives a total coil thickness of $1 \mathrm{~m}$ and $W_{E C} W_{T R} \sim 0.05$

Eddy current losses (66) in the lithium blanket ontaining a fraction $f_{w}$ of the total stored energy $w_{B O}$ are

$$
\frac{\tilde{w}_{\mathrm{EB}}}{\overline{\mathrm{W}}_{\mathrm{BO}}} \sim \mathrm{f}_{w} \frac{\pi h^{2}}{20 \dot{\delta}^{2}}
$$

for segments of width h. For lithium at $1000 \mathrm{~K}\left(n \sim 2 \times 10^{-6}{ }_{\zeta-\mathrm{m}}\right)$, $\mathrm{f}_{\mathrm{w}} \sim 0.05(0.15 \mathrm{~m}$ lithium length in blanket), $\mathrm{h}=0.1 \mathrm{~m}$, the losses are $\mathrm{W}_{\mathrm{EB}} / \mathrm{H}_{\mathrm{BO}} \sim 0.001$

The eddy current losses are then taken as 58 of the transport losses for a coil constructed of $7 \mathrm{~mm}$ layers, plus 0.18 of $\mathrm{H}_{\mathrm{BO}}$ for a segmented $10 \mathrm{~cm}$ blanket. These quantities are used for all parameter studies and may be achieved by adjusting the thickness indicated above.

\section{E. Calculational Procedure}

The initial bias field $\mathrm{B}_{\mathrm{zO}}$ is calculated from $\mathrm{Eq}$. (3.12) based upon a desired minimum plasma compression $x_{m}$. The value of $\alpha r_{p}$ is then calculated from Eq. (3.12) as the current rises sinusoidally, which defines the field profiles. When $\alpha r_{p}$ reaches 2.405 , a numerical integration of $\mathrm{Eg}$. (3.15) gives the plasma radius variation. 
Alpha particle heating is treated by a Fokker-Planck calculation (67), which allows for the possible non-Maxwellian phase-space distributions for both electron and fuel ion species. The addition of particles to the alpha-particle distribution function is given by

$$
\Delta f_{\alpha}\left(n / v^{3}\right)=\frac{\Delta n_{\alpha}}{\sqrt{\pi} \Delta_{d}\left(4 \pi v_{\alpha}^{2}\right)} e^{-\left(\frac{v-v_{\alpha}}{\Delta_{d}}\right)^{2}}
$$

where $\mathrm{v}_{\alpha}$ is the velocity correspanding to the $3.52 \mathrm{MeV}$ alpha particle, $\Delta n_{\alpha}$ is the number density of alphas added at each time step $\Delta t$, and the doppler broadening due to the background ion species is $\Delta_{d}=\left(k T_{i} / 2 m_{i}\right)^{1 / 2}$

During each time step the electron termerature is adjusted according to the varying plasma volume and plasma powers $\mathrm{P}_{\mathrm{OHM}}$ and $\mathrm{P}_{\mathrm{RAD}}{ }^{\circ}$ Similari$l_{y}$, the ion temperatures must reflect the volume change and power loss $P_{\text {COND }}$. At the end of each time step the alpha velocity distribution is modified to account for plasma expansion, and the energy equipartition between plasma species is followed by the Fokker-Planck calculation. Numerically integrating plasma powers and oil transport losses completes the energy balance calculation. 


\section{RESULTS}

\section{A. Reactor Startup Phase}

Establishing the field profiles necessary for stable operation of an RFPR appears" to be a formidable problem. The initial constant toroidal field $\mathrm{B}_{z O}$ and increasing current results in a field configuration similar to that in a tokamak. This q-stabilized system must then be transformed into a RFP by proper programing of the fields. The achieving of stability during this phase seems unlikely, and turbulence similar to that exhibited by tokamaks may result. Pressure balance is assumed, however, and the approximate field profiles during startup are modeled by the equations in section III. This startup sequence is one of the major uncertainties in the reactor design.

Preionization is assumed to be achieved uniformly to a density of $n_{e}=10^{-6} n_{0}$ by a RF-heating source $(64,68)$. The electric field applied to the plasma by the homopolar machine must then be sufficient to sustain breakdown. This electric field is taken as $I_{z} R_{p} /(2 \pi R)$ where $R_{p}$ is the resistance of the plasma. This ignores the inductive spike $(\sim 1$ usec) at time $t \rightarrow 0$ when the plasma current is near zero (64). The minimum field for breakdown is $\sim 5 \mathrm{~V} / \mathrm{m}-\operatorname{mi}$ torr for densities above $\sim 0.5$ mTorr for reactors with a minor radius an the order of a meter $(64,68)$. Electron runaway is observed $(69-71)$ above $20 \mathrm{~V} / \mathrm{m}$ - mTorr which may be taken as a maximum allowable field $(64,68)$. When a significant fraction of the neutral population is ionized $(\sim 108)$ electron-ion collisions dominate and determine the conditions for electron runaway. A critical electric field $E_{c}=1.6 \times 10^{-11} n_{e^{r_{1}}} T_{e}^{1 / 2}(72)$ divided by the 
electric field imposed on the plasma $E=\eta_{11} I_{z} / \pi r_{p}^{2}$ gives $E_{C} / E=$ $2 \times 10^{-7}\left(N_{e} B_{\theta}\right)^{1 / 2}$, where the line density $N_{e}$ and pressure balance is used. Having $E_{C} / E>50$ results in an insignificant loss due to runaway electrons (72). Very low $\beta_{\theta}$ values result during the low plasma temperatures at startup, however, the initial $20 \mathrm{~V} / \mathrm{m}$-milorr is then the limiting constraint. Electron runaway at higher temperatures is apparently not a problem. Taking typical values of $\mathrm{N}^{-10^{21} \mathrm{~m}^{-1} \text { and }}$ $\mathfrak{B}_{\Theta} \sim 0.01$ (during startup) gives $\mathrm{E}_{\mathbf{C}} / \mathrm{E} \sim 630$.

Assuming the aforementioned preionization, plasma breakdown is then modeled with a tokanak startup code (64) until the plasma temperature reaches $\sim 0.1 \mathrm{keV}$. The discharges are typically started at relatively low densities ( 0.5-1 mTorr) which minimizes the power loss due to line radiation at low temperatures $(\sim 0.01 \mathrm{keV})$. The line radiation power is proportional to $n_{e} n_{i m}\left(n_{i m}\right.$ is the inpurity number density), and may be difficult to overcome if the initial density is too high. The final density is then achieved by gas injection after the resonance line radiation of low-z. impurity ions has decreased. For oxygen the peak resonance occurs at $\sim 0.01 \mathrm{keV}$, and neutral. gas is allowed to flow into the system for $\mathrm{T}>0.02 \mathrm{keV}$ until the required density is achieved.

Only with further laboratory experimentation using large radius plasmas and long startup times $(\sim 0.1$ s) can the true behavior of the plasma during the initiation phase be seen. The scheme used herein provides an estimate of plasma parameters and powers during the startup phase. 


\section{B. Thermonuclear Burn Cycles}

The pressure balance equation (Fg. (3.12)) is plotted on the P-V diagram in Fig. (7), which is used to illustrate the operational modes and limitations anticipated for pulsed, high- $B$ operation. The dependence of $\beta_{\ominus}$ with respect to $x$ is also given by Eq. (3.12) as $\beta_{0}=$ $1-\left(x_{m} / x\right)^{2}$ where a constant $I_{z}$ current and negligible plasma pressure at $x=x_{m}$ is assumed. Starting at $x=1$ the plasma is compressed to $x=0.4$, which is taken as the minimum stable plasma radius (29-31). Ohmic heating rapidly brings the plasma to ignition. Noting from Fig. (7) that all solid curves pertain to lines of constant $I_{z}$ current throughout the burn, alpha-particle heating subsequently raises the plasma pressure to a maximum at $x^{2}=0.32$ corresponding to $B_{n}=0.5$. The plasma continues to heat and expands to the wall. The inside toroidal field $\mathrm{B}_{\mathrm{zI}}$ reversibly increases to a maximum at $\mathrm{x}^{2}=0.16$ and then decreases according to the laws of flux conservation. The directconversion work $W_{D C}$ associated with plasma expansion against the magnetic field is given by the area enclosed by the plasma pressure-volume curve. Stable profiles are known to exist up to $B_{0} \sim 0.58$, but as the hot plasma continues to expand to the wall, $\beta_{\theta}$ continues to $r$ ise to a maximum of $\beta_{\theta}=0.84$ at $x=1$.

To remedy this unstable situation, the plasma pressure must be much lower before expansion to the wall occurs. For a constantly rising plasma temperature the $B_{\theta}$ field must be decreased before the plasma nears its maximum pressure. This case, denoted by the dashed curves, indicates that the direct-conversion work is now compromised and the 


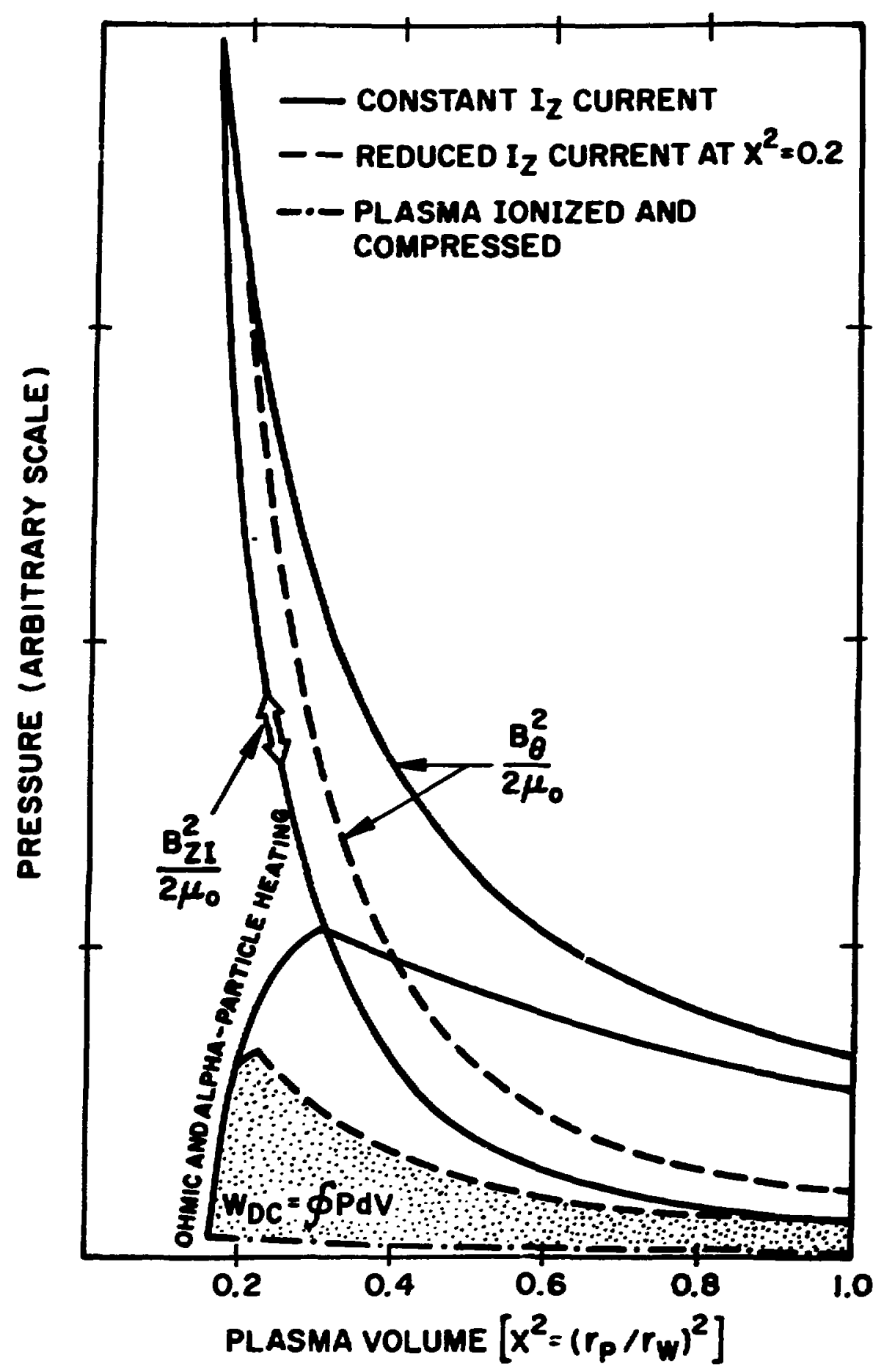

Fig. 7. Generalized pressure-volume diagram for the RFPR. Magnetic field pressures, plasma pressure $p$, and the plasma directconversion work $W_{D C}$ for high-beta plasma expansion against a magnetic field are shown for the assumed sharp-boundary plasma model. 
lower average plasma $f$ will result in a lower power output. However, if the plasma temperature can be controlled, then the plasma pressure can be brought to $\beta_{f} \sim 0.5$ and maintained at that point throughout the burn. Near the end of the burn the plasma temperature is decreased, giving a lower $F_{i}$ and permitting the dashed curves to be followed; a stable plasma $\left(E_{0} \leq .58\right)$ results as it expands to the wall.

The dynamic plasma and energy-balance models described in sec. III were used to perform a parametric systems analysis of a wide range of RFPR burn cycles. The engineering $Q$-value $Q_{E}$ served as the object function for this system optimization. Reactor dimensions used in this study are summarized in Table 2. The initial plasma conditions (temperature, D-T ratio, filling pressure), initial toroidal bias field, magnitude and wave form of the toroidal current and the total burn time were varied over a wide parameter rangr.. The magnitude of the first-wall temperature rise and associated thermal stresses, both of which were computed as a function of time by the RFP systens model, and the total plasma beta were continually monitored and used as major constraints. The toroidal current I was increased sinusoidally with a rise time $\tau_{\mathbf{R}}$ ' held constant (crowbarred) for a time $\tau_{B}$, and then was sinusoidally decreased with a fall time equal to ${ }^{\top} \mathbf{R}$.

For a 50\%-508 D-T fuel mixture the plasma ignites and can reach $\beta_{\Theta} \sim 0.35$ before the plasma must be expanded to the walls; plasma expansion occurs with a half-cycle fall time approximately 108 that of the burn time. This scenario maintains a stable plasma $\left(\beta_{\theta}<0.5\right)$ throughout the burn cycle. The initial filling pressure is varied until 
Table 2. Dimensions used in RFPR energy-balance study

Symbol Definition value

\begin{tabular}{lll}
\hline$r_{w}$ & first-wall radius $(\mathrm{m})$ & variable \\
first-wall $\mathrm{Nb}-18 Z \mathrm{Zr}$ thickness $(\mathrm{m})$ & $0.002(0.005)^{\mathrm{a}}$ \\
first-wall $\mathrm{Al}_{2} \mathrm{O}_{3}$ coating thickness $(\mathrm{m})$ & $3.0 \times 10^{-4}$ \\
blanket thickness $(\mathrm{m})$ & 0.4
\end{tabular}

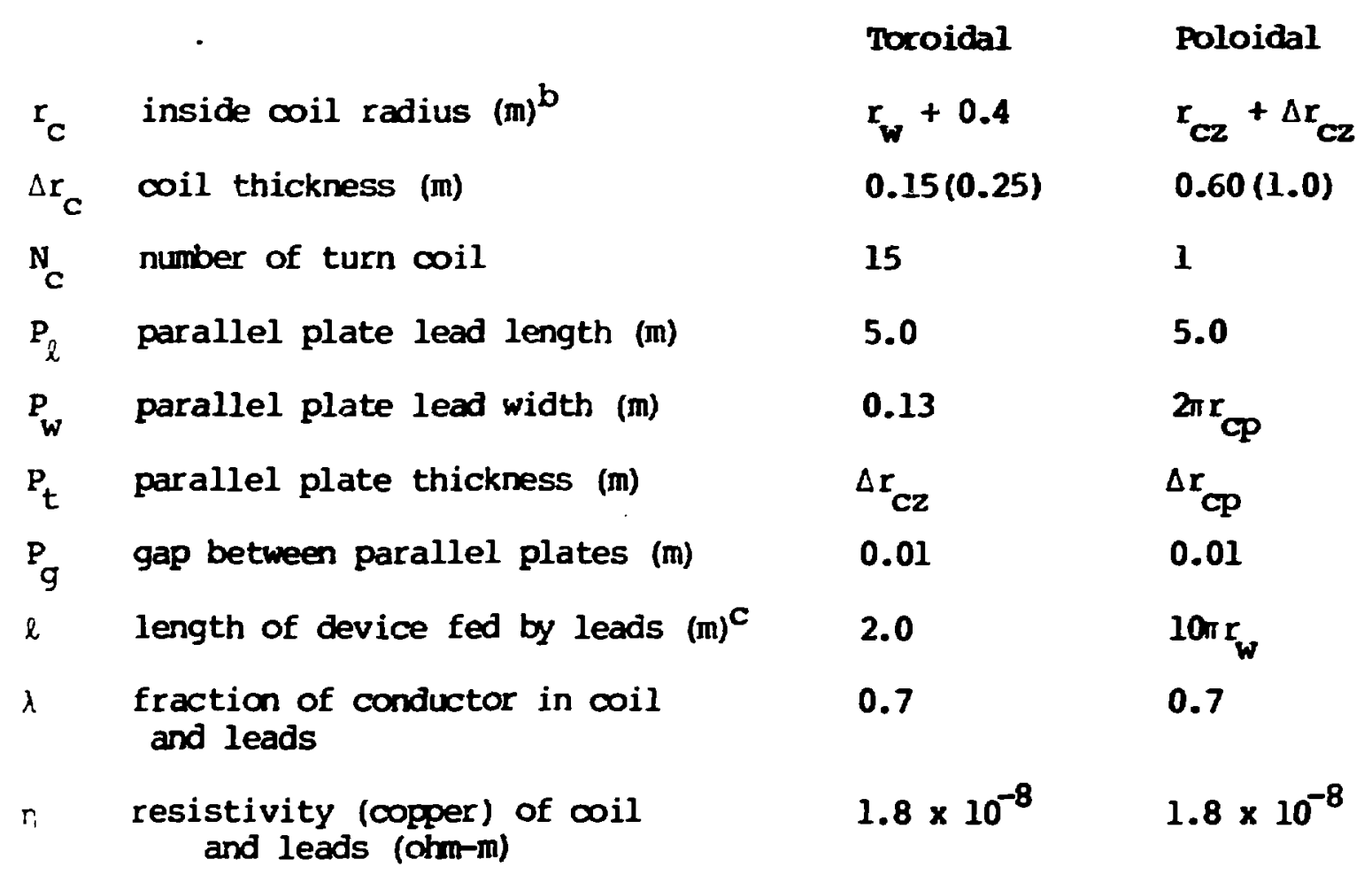

Dimensions in parentheses used for the longer burn times associated ith the case which controls $B_{\odot}$ by D-T burnout (908-108 D-T fuel mixture).

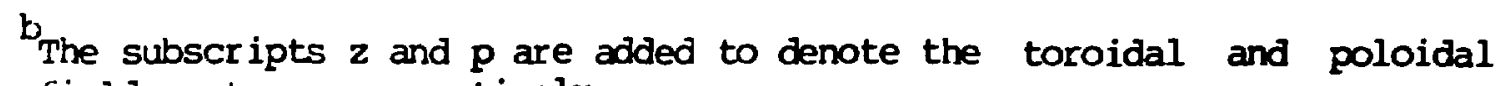
field systems, respectively.

Aspect ratio taken to be 5.0 . 
the maximum $Q_{E}$ is obtained. In Fig. 8 the first-wall radius $r$ versus the average maximum toroidal current density $\hat{j}_{z}$ is shown as a function of $Q_{E}$ for the $50 \%-50 \%$ D-T fuel mixture case $\left(B_{\Theta}\right.$ control by early quench). Superimposed upon the $Q_{E}$ curves are lines of constant firstwall surface temperature rise $\Delta \mathrm{T}_{w}(k)$ where the first wall $(0.3 \mathrm{~mm}) \mathrm{Al}_{2} \mathrm{O}_{3} /(2 \mathrm{~mm}) \mathrm{Nb}-1 \mathrm{zr}$ is cooled by a stagnant pool of lithium. Attempting to achieve higher values of $\mathrm{C}_{\mathrm{E}^{\prime}}$ plasma control using oold fuel injection or impurity addition was consids but the alpha-heating power must be balanced by losses to the firstet in order to maintain a constant plasma temperature. since the tat heating power is $\sim 28$ times that of bremsstrahlung radiation at 20 the surface heat flux to the wall would be correspondingly increas For typical initial ion densities $(508-508 \mathrm{D}-\mathrm{T}$ fuel mixture, $2-\mathrm{m}$ f fis wall radius, and $\hat{j}_{z}=20 \mathrm{~mA} / \mathrm{m}^{2}$ of $1.4 \times 10^{20} / \mathrm{m}^{3}$ compressed $8.6 \times 10^{21} / \mathrm{m}^{3}$ at the minimum compression $x=0.4$, a heat removal ratep. of $\sim 10 \mathrm{MN} / \mathrm{m}^{2}$ at the first wall would be necessary to achieve a constant plasma temperature $20 \mathrm{kev}$. This exceedingly high surface heat flux would be intolerable over the $1.14 \mathrm{~s}$ burn time anticipated for the aforementioned case. The actual bremsstrahlung power $\sim 0.3 \mathrm{~m} / \mathrm{m}^{2}$ produces a $163 \mathrm{~K}$ degree surface temperature $\mathrm{rise}$ for a $(0.3 \mathrm{~mm})$ Al ${ }_{2} \mathrm{O}_{3} /(\mathrm{lm}) \mathrm{Nb}-1 \mathrm{zr}$ first wall. For these methods of plasma temperature control, the plasma density must be decreased by $\sim 5$ to lower the alpha-heating power a factor of 25; a corresponding increase in burn time would result. The potential technical difficulties associated with the injection of cold fuel or impurities and questions of plasma 


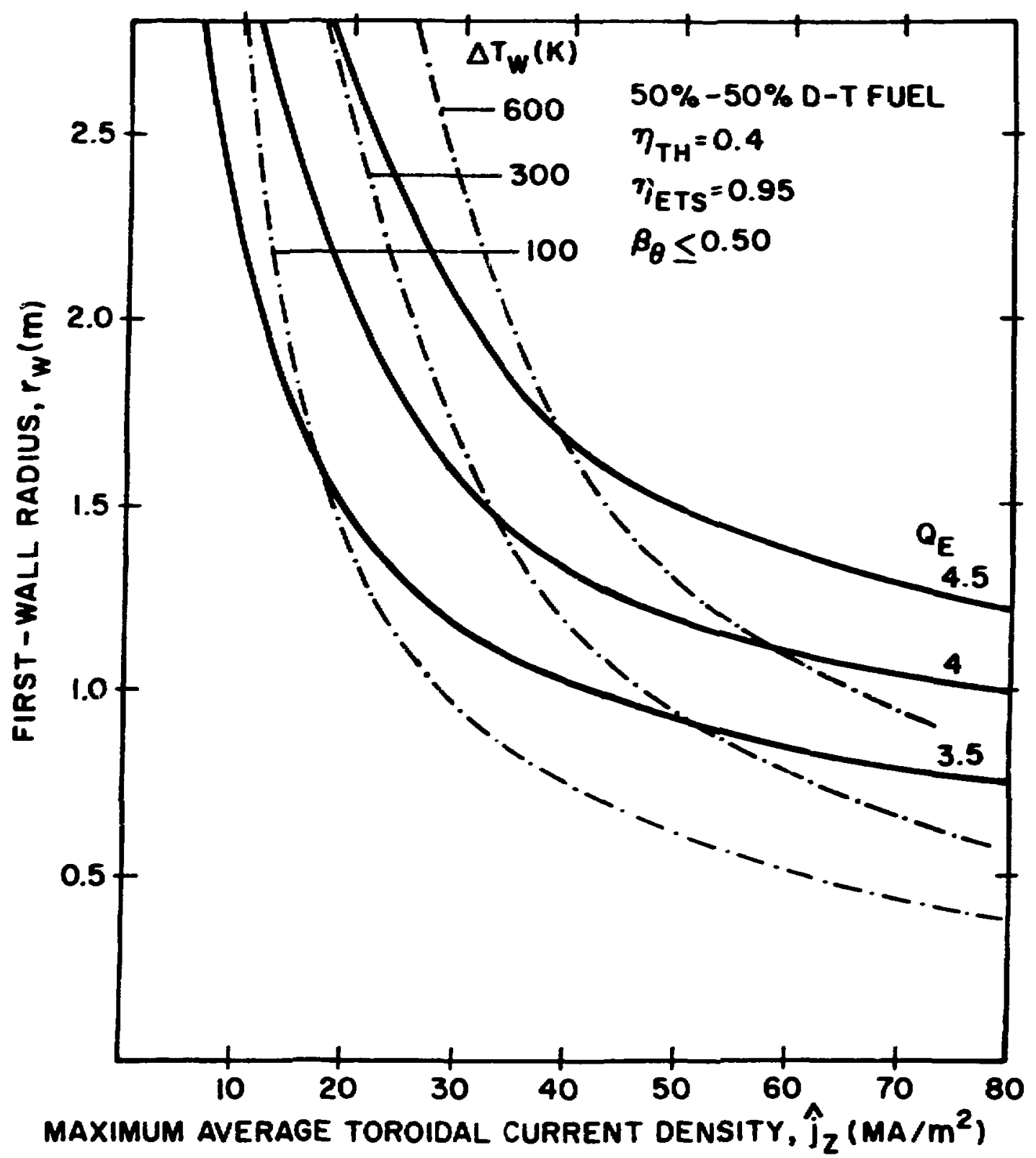

Fig. 8. Lines of constant $Q_{E}$ for various first-wall radii $x_{w}$ and maximum average toroidal current densities $\hat{j}_{z}$ (solid curves) where a 508-508 D-T fuel mixture is used. The dotted-dashed curves are lines of constant first-wall $\left((0.3 \mathrm{~mm}) \mathrm{Al}_{2} \mathrm{O}_{3} \mathcal{\prime}^{\prime}(\mathrm{mm})\right.$ $\mathrm{Nb}-12 \mathrm{r}$ ) surface temperature rise $\Delta \mathrm{T}_{\mathrm{w}}(\mathrm{k})$. 
stability incurred by the use of such processes were also major factors leading to the decision not to utilize injection techniques for plasma temperature control.

A method of temperature control utilized in this study lawers the initial tritium loadings below 50\%. Through this scheme, the plasma provides automatic temperature control by tritium burnup, decreased alpha-particle heating, and natural radiative losses. In Fig. $9 Q_{E}$ versus the initial tritium fraction $f_{T}$ is shown for a first-wall radius of $2 \mathrm{~m}$ and maximum average toroidal plasma current density $\hat{j}_{z}=I_{z} / \pi$ $\left(r_{w} x_{m}\right)^{2}=15 \mathrm{MA} / \mathrm{m}^{2}$. The plasma is expanded to the wall after 908 of the available tritium has been consumed. The half-cycle rise and fall time of $I_{2}$ was taken to be $0.1 \mathrm{~s}$. The filling pressure $P_{A}$ is varied until $\left(\beta_{\theta}\right)_{\text {MAX }} \sim 0.43$ before expansion, resulting in $\beta_{\Theta} \sim 0.5$ at the first wall after expansion. Shown in Fig. 9 are the required filling pressures, associated burn times and maximum ion temperatures for each initial tritium fraction $\mathrm{f}_{\mathrm{T}}$. As the tritium fraction $\mathrm{f}_{\mathrm{T}}$ is increased, high ion temperatures result in a reduction of the alpha-particle heating power $\left(P_{\alpha} \sim\langle C v\rangle_{D T} / T^{2}\right.$ decreases by one e-fold of the peak value at $T=50 \mathrm{keV})$. Much langer burn times, therefore, are required to achieve high burnups at higher ion temperatures. The plasma temperature reaches $T=50-60 \mathrm{keV}$ for $f_{T}=0.08-0.10$ and since the burn times are greatly increased beyond $f_{T}=0.1$ and $Q_{E}$ is not, $f_{T}=0.1$ is chosen. Longer burn times at high ion temperatures results in higher coil transport losses and a decreasing thermonuclear output, respectively, thereby resulting in the saturation and eventual decrease in $Q_{E}$ as $f_{T}$ is 


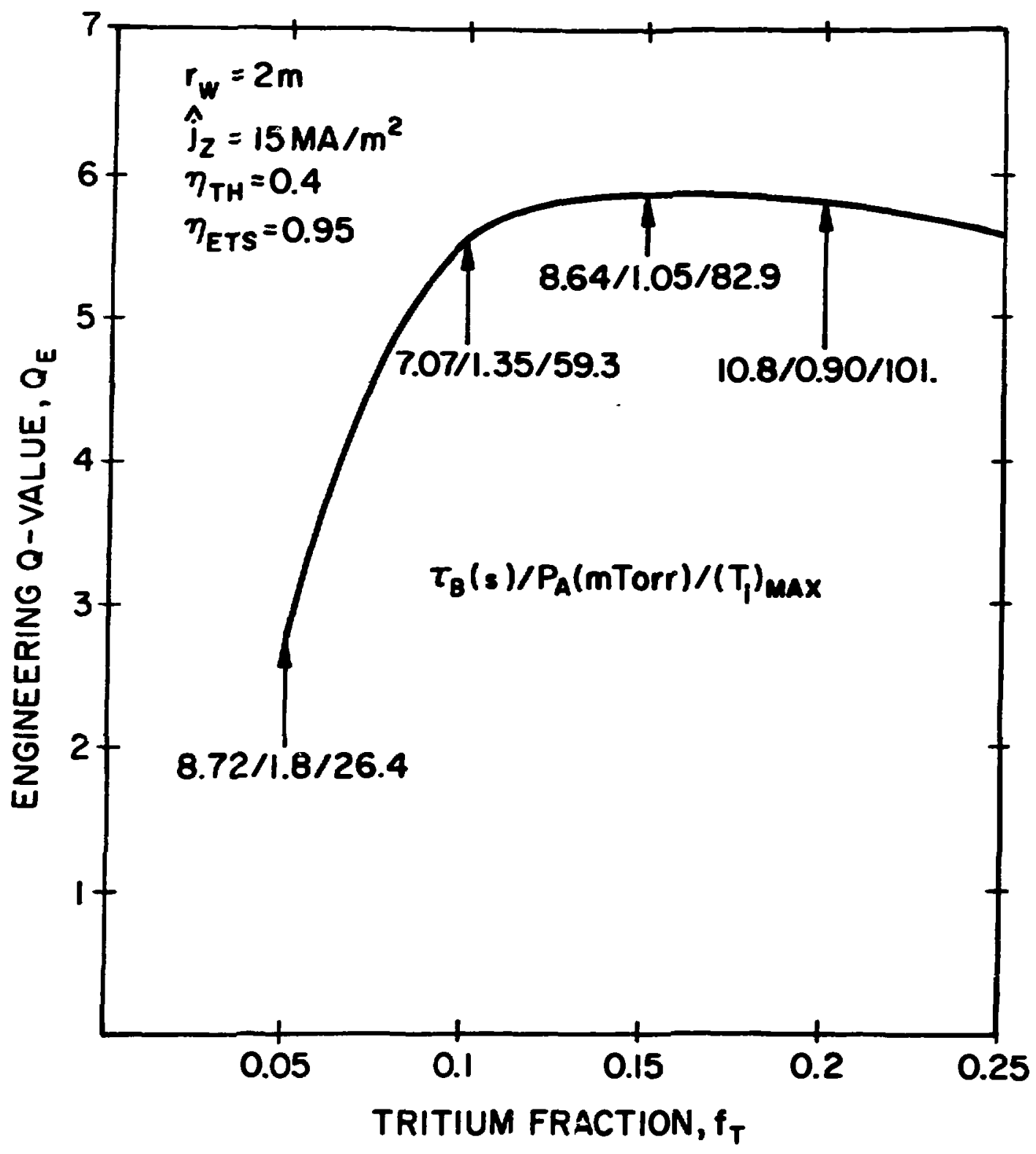

Fig. 9. Dependence of the engineering $Q$-value $Q_{T}$ on the initial plasma tritiun fraction $f_{T}$ for 908 bumup of the available tritium ir. the plasma. 


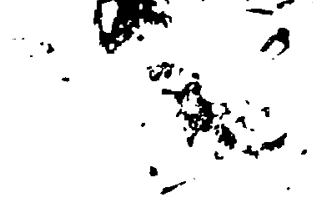

increased. In Fig. (10) curves of constant $Q_{E}$ and first-wall temperature rises are shown for the 908-108 D-T fuel mixture case $\left(\beta_{0}\right.$ control by tritium burnout) using a thicker first wall $(0.3 \mathrm{~mm}) \mathrm{Al}_{2} \mathrm{O}_{3} /$ (5 $\mathrm{mm}) \mathrm{Mb}-1 \mathrm{Zr}$ (Table 2) and increased thickness of the magnet coil (fram 0.6 to $1.0 \mathrm{~m}$ ). The longer burn times associated with the lower tritium loadings necessitate thicker first walls to maintain approximately the same temperature drop across the wall (a measure of the internal mechanical stress, typically $<50 \mathrm{~K}$ ) and bulk temperature $\mathrm{rise.} \mathrm{The}$ joule losses in the ooil are also increased by the longer burn times and are offset by the thicker coil. Increasing the coil thickness increases $Q_{E}$ but the trade-off between coil size, complexity and cost versus higher $Q_{E}$ must eventually be considered.

\section{Plasma Quench}

At the end of the burn the $I_{z}$ current is lowered sinusoidaliy with a half-cycle fall time $\tau_{R}$ and the plasma expands to the wall. The plasma is then assumed to be wall confined, where heat loss is controlled by heat conduction across the fields inside the plasma. For a plasma of negligible resistivity and classical thermal conductivity, the rate of heat transfer to a cold wall is

$$
q=2.62 \times 10^{-21}\left[\frac{T^{3 / 2} n_{i}^{3} \ln !}{B^{2} t}\right]^{1 / 2} w / m^{2}
$$

For typical post-burn parameters $\left(T=20 \mathrm{keV}, n_{i}=10^{20} / \mathrm{m}^{3}, \ln \Lambda=20\right.$, and $B=1 \mathrm{~T})$, the heat loss to the wall is $1.1 / \mathrm{t}^{1 / 2} \mathrm{kw} / \mathrm{m}^{2}$ which, 


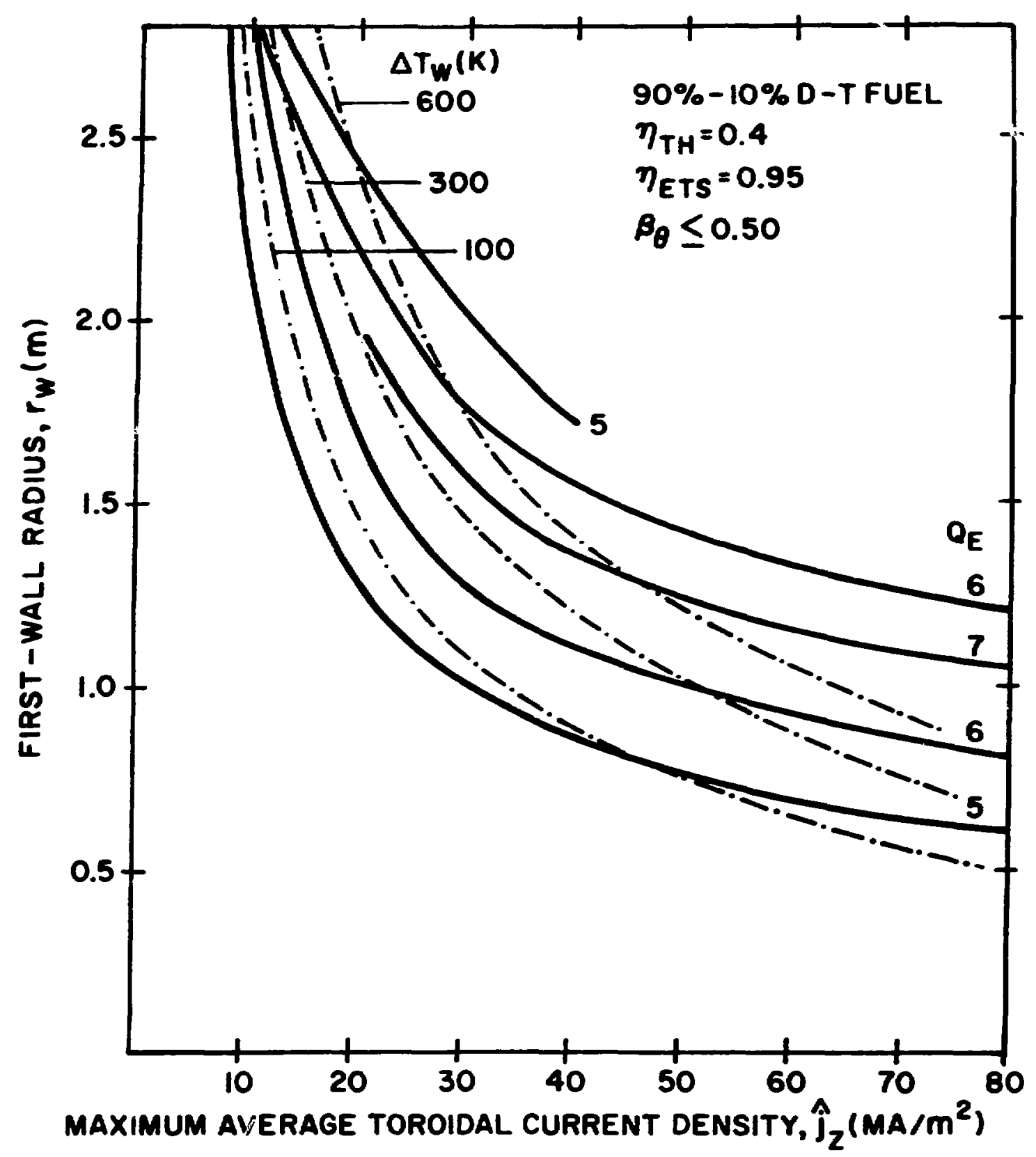

Fig. 10. Lines of constant $Q_{E}$ for various first-wall radii $r_{w}$ and maximum average toroidal current densities $\hat{j}_{\text {. }}$ (solid curves) where a 908-10\% D-T fuel mixture is used. The dotted-dashed curves are lines of constant first-wall $\left((0.3 \mathrm{~mm}) \mathrm{Al}_{2} \mathrm{O}_{3} /(5 \mathrm{~mm})\right.$ $\mathrm{Nb}-1 \mathrm{Zr}$ ) surface temperature rise $\Delta \mathrm{T}_{\mathrm{w}}(\mathrm{k})$. 
generally, is small compared to the radiation heat flux during the burn $\left(\sim 250 \mathrm{kw} / \mathrm{m}^{2}\right)$. The inclusion of a neutral gas between the plasma and the wall could prevent the wall from being damaged before the cool buffer layer is set-up within the plasma and could enhance the seemingly slow classical heat loss rate. For the tritium burnout case no energy is produced in the plasma during quench. In the 508-508 D-T case no additional plasma energy is assumed by the energy balance to be added after plasma expansion to the wall, but a significant increase in $Q_{E}$ may result because of additional alpha-heating power cocurring during the quench phase.

The proposal of wall confinement at the end of the burn is preliminary, however, and must be studied in much greater detail. Of primary importance are transient effects which may determine the heat transport and surface damage to the first wall during the set-up phase of the wall-confined plasma.

\section{Operating Point(s) Determination}

Uncertainties in the plasma physics including plasma field profiles, resistivities, diffusion, achievable current densities, and stability makes the choice of any operating point for the RFPR questionable at this point. The two specific operating points shown below, therefore, are intended only to illustrate possible operating regimes.

An experimentally determined (12) value of the maximum achievable average toroidal current density is taken to be about $20 \mathrm{~mA} / \mathrm{m}^{2}$. Using this constraint and imposing a reasonable limit on the first wall 
temperature rise $\left(\Lambda T_{w}(k)<200\right)$ leads to a reactor size of about $2 \mathrm{~m}$ for both cases. The time response of major variables is shown in Fig. 11 and Fig. 12, and reactor parameters and energies are given in Table 3.

An energy transfer and srorage (EIS; system efficiency "ETS of 0.95 was used in all the studies. The variation of $q_{E}$ versus $r_{E T S}$ for the chosen reactor operating points is shown in Fig. 13. The characteristically efficient use of magnetic field energy by reversed-field pinches is reflected by the low values of ${ }^{r_{F}}$ FTs allowed for $Q_{E}=1$.

For both cases the field annihilated inside the plasma $w_{B}^{\mathbb{I N}}$ constitutes $\sim 508$ of the total losses in the system. Hence, although the efficient use of magnetic field energy in a RFP configuration results in an energy balance which is less sensitive to ' $\mathrm{r}$ ETs' this strong advantage is weakened somewhat by the need to provide for losses associated with trapped flux.

The startup for the two operating points proceeds as described in Sec. IV.A. A sinusoidal voltage of $10 \mathrm{kV} /$ turn with a quarter period of $0.1 \mathrm{~s}$ appears virtually constant during the initial $0.012 \mathrm{~s}$ modeled by the tokamak startup code, or until $\mathrm{T}_{E}$ reaches $0.1 \mathrm{keV}$. The resultant plasma response is shown in Fig. 14. The initial rapid decrease in electric field to $6 \mathrm{~V} / \mathrm{m}$-mTorr involves the transition from the avalanche region $\left(n_{e}<0.01 n_{0}\right)$ with $T_{e} \sim 0.01 \mathrm{keV}$ to a Maxwellian electron distribution of lower temperature $\left(T_{e}=0.003 \mathrm{keV}\right)$ where the high energy "tail" (energy above $0.015 \mathrm{keV}$ ) of the distribution ionizes the D-T 


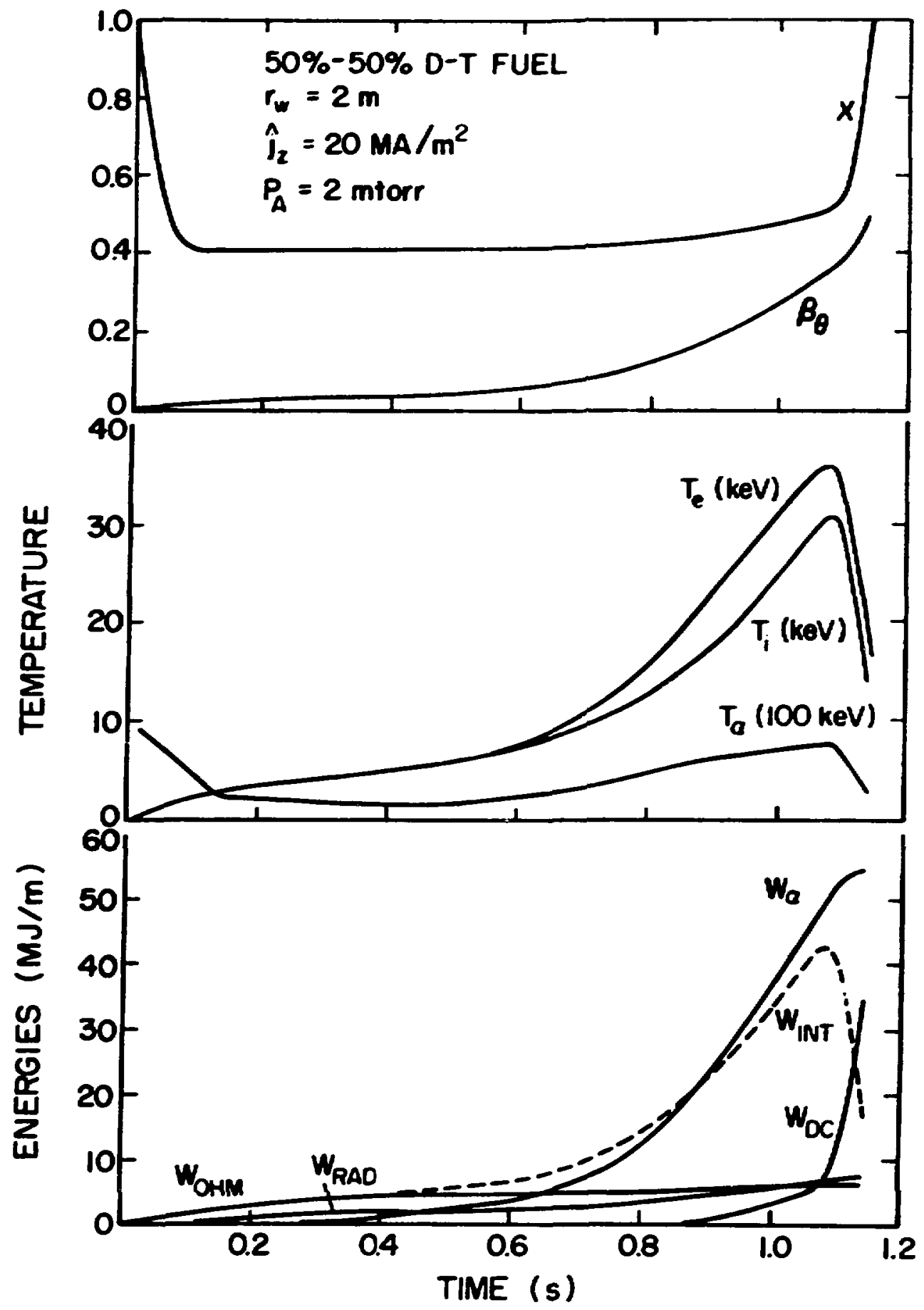

Fig. 11. Time-dependence of plasma and energy quantities for the 508-508 D-T operating point sumarized in Table 3. 


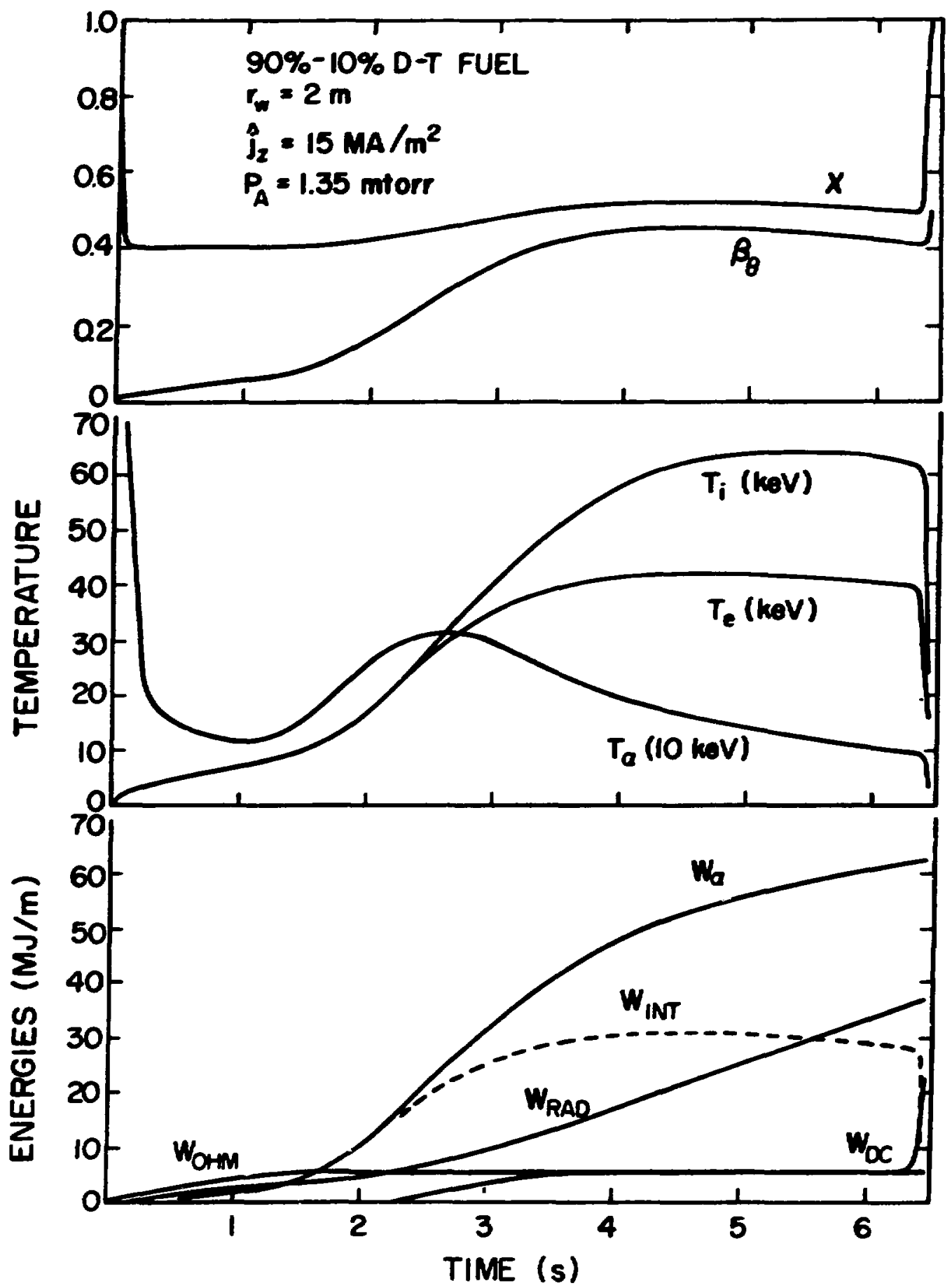

Fig. 12. Time-dependence of plasma and energy quantities for the 908-108 D-T operating point summarized in Table 3. 


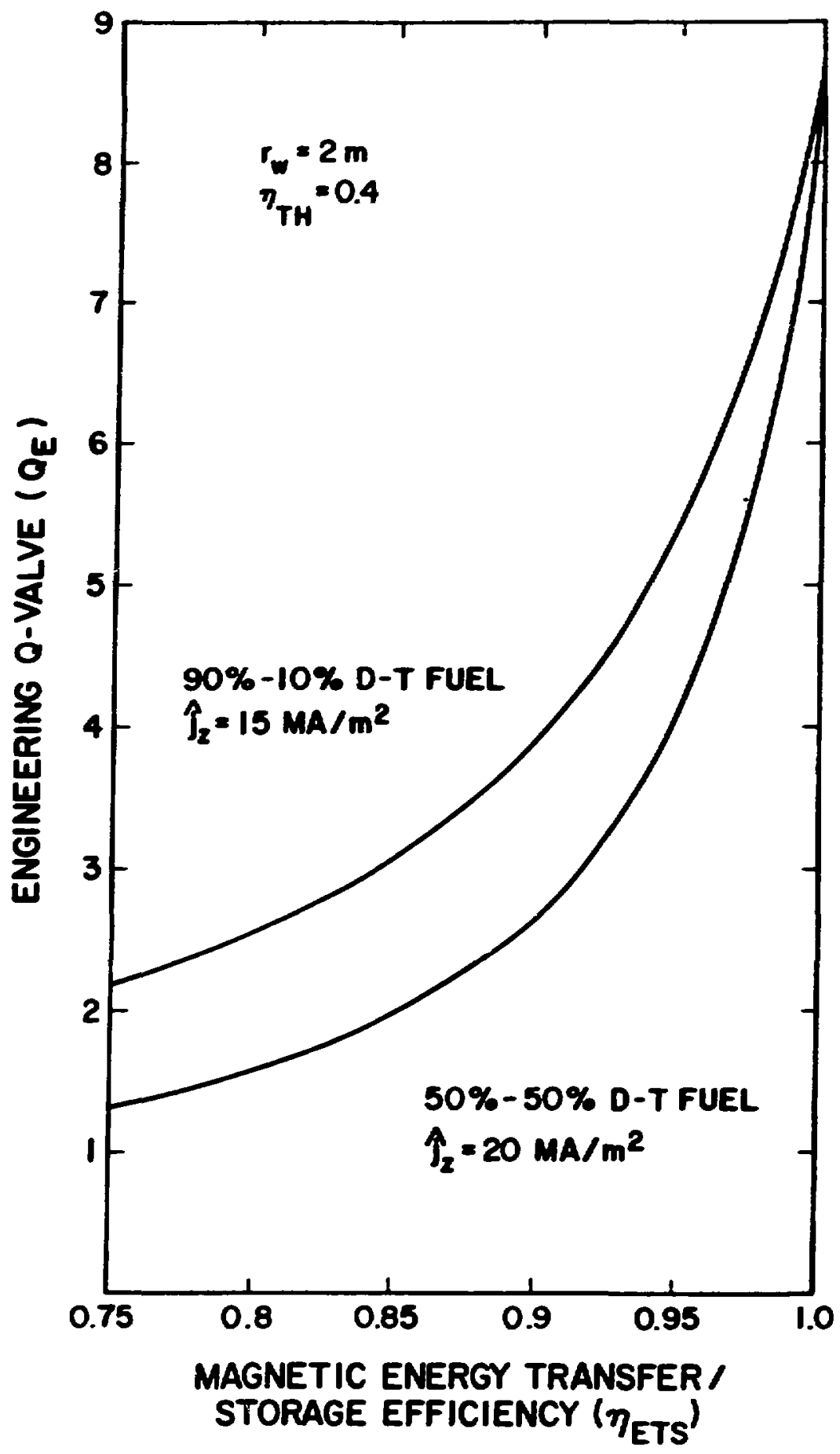

Fig. 13. Dependence of $Q_{E}$ on the magnetic energy transfer/storage efficiency $n_{E T S}$ for both cases investigated. 


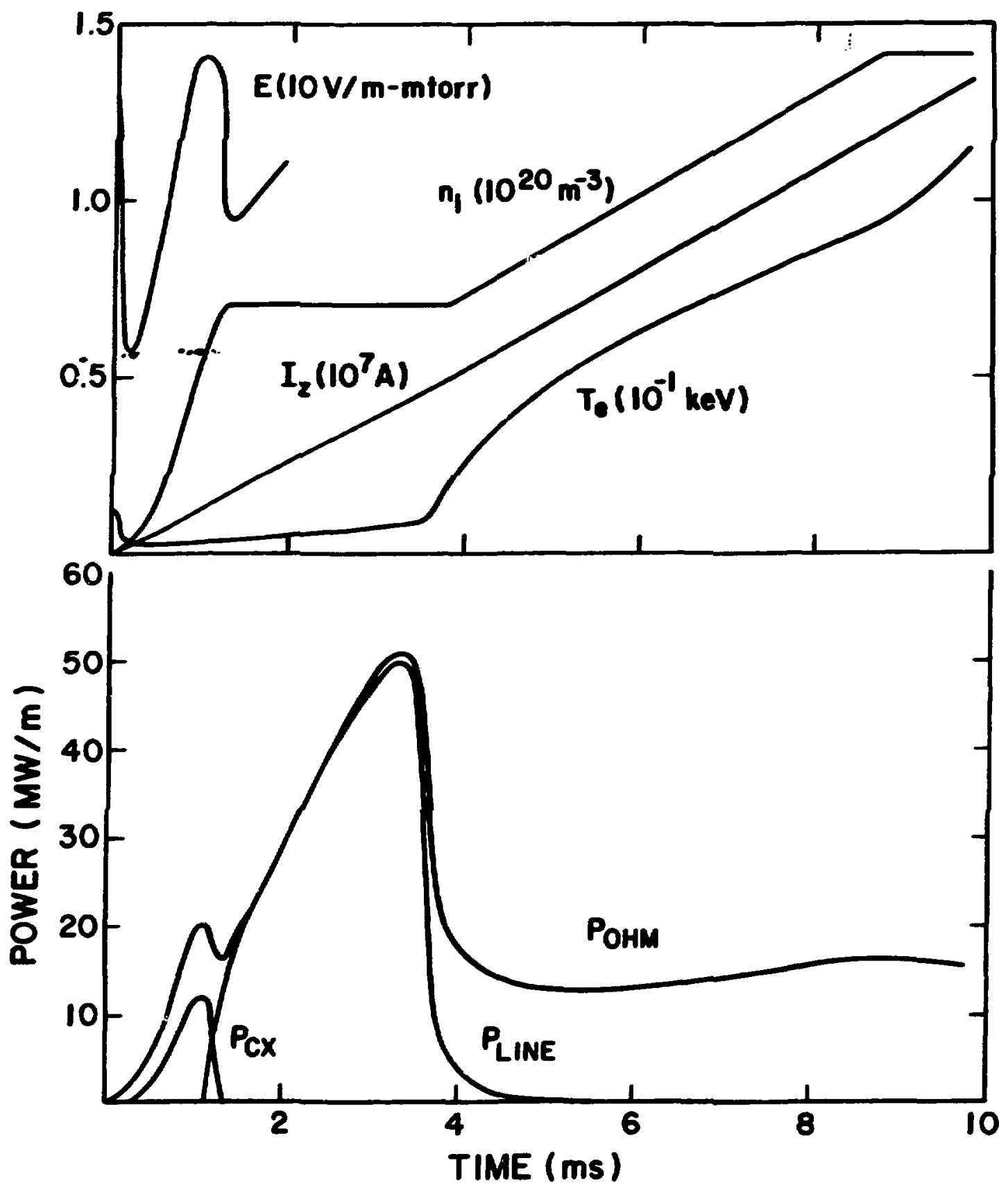

Fig. 14. Time-dependence of various plasma parameters and dominant powers for a tokamak-like RFPR startup. 
Table 3. Sumnary of typical RFPR parameters

\begin{tabular}{|c|c|c|c|}
\hline Symbol & Definition & $508-508 \mathrm{DT}$ & $908-108 \mathrm{DT}$ \\
\hline $\mathbf{r}_{\mathbf{w}}$ & first-wall radius (m) & 2.0 & 2.0 \\
\hline$x_{m}$ & minimm plasma compression & 0.4 & 0.4 \\
\hline & peak toroidal plasma current (MA) & 40.0 & 30.0 \\
\hline$\hat{j}_{z}$ & $\begin{array}{l}\text { average toroidal current density at } \\
\text { minimum compression ( } \mathrm{Mg}^{\mathrm{m}} \mathrm{\textrm {m } ^ { 2 } )}\end{array}$ & 20.0 & 15.0 \\
\hline $\mathbf{P}_{\mathbf{A}}$ & ambient D-T filling pressure (mTorr) & 2.0 & 1.35 \\
\hline $\mathbf{n}_{\mathbf{i}}$ & ion density at ignition $\left(1 / \mathrm{m}^{3}\right)$ & $8.52 \times 10^{20}$ & $5.82 \times 10^{20}$ \\
\hline nt & $\begin{array}{l}\text { time-iqtegrated Lawson parameter } \\
\left(s / m^{3}\right)\end{array}$ & $8.41 \times 10^{20}$ & $2.64 \times 10^{21}$ \\
\hline $\mathbf{f}_{\mathbf{T}}$ & initial tritium atom fraction & 0.5 & 0.1 \\
\hline $\mathbf{f}_{\mathbf{B}}$ & fractional burnup & 0.109 & 0.184 \\
\hline $\mathbf{T}_{\text {if }}$ & $\begin{array}{l}\text { ion temperature prior to quench } \\
\text { (keV) }\end{array}$ & 14.4 & 23.8 \\
\hline $\mathbf{T}_{\text {ef }}$ & $\begin{array}{l}\text { electron temperature prio to } \\
\text { quench (keV) }\end{array}$ & 16.3 & 15.3 \\
\hline$(\mathrm{dT} / \mathrm{dt})_{Q}$ & $\begin{array}{l}\text { post-burn plasma reactivity } \\
(\mathrm{keV} / \mathrm{s})\end{array}$ & 18.5 & -0.41 \\
\hline $\mathrm{w}_{\mathrm{INT}}^{0}$ & initial plasma energy ( $(\mathrm{MJ} / \mathrm{m})$ & 0.086 & 0.058 \\
\hline W $\mathbf{N T}$ & final plasma energy $(\mathrm{MJ} / \mathrm{m})$ & 18.9 & 11.0 \\
\hline $\boldsymbol{w}_{\text {BR }}$ & bremsstrahlung energy $(\mathrm{MJ} / \mathrm{m})$ & 5.38 & 19.9 \\
\hline $\mathrm{w}_{\mathrm{CY}}$ & $\begin{array}{l}\text { cyclotron energy into first wall } \\
\text { (nonreflecting) ( } \mathrm{MJ} / \mathrm{ma})\end{array}$ & 1.72 & 16.9 \\
\hline $\mathbf{w}_{\mathrm{N}}$ & $\begin{array}{l}\text { fusion neutron energy (18 } \mathrm{MeV} / \mathrm{n}) \\
(\mathrm{MJ} / \mathrm{m})\end{array}$ & 279.6 & 317.7 \\
\hline$w_{\alpha}$ & $\begin{array}{l}\text { total-alpha particle energy } \\
(\mathbf{M J} / \mathrm{m})\end{array}$ & 54.7 & 62.1 \\
\hline${ }^{W}$ OFM & $\begin{array}{l}\text { plasma chmic heating energy } \\
(\mathrm{MJ} / \mathrm{m})\end{array}$ & 5.11 & 5.85 \\
\hline${ }^{1}$ ond & $\begin{array}{l}\text { thermal conduction energy } \\
(\mathbf{M J} / \mathrm{m})\end{array}$ & 0.036 & 0.24 \\
\hline$W^{W}$ & direct-conversion energy $(\mathrm{MJ} / \mathrm{m})$ & 34.7 & 21.3 \\
\hline $\mathbf{w}_{\mathrm{BZ}}$ & $\begin{array}{l}\text { energy requirements of toroidal } \\
\text { field system }(\boldsymbol{M J} / \mathrm{m})\end{array}$ & 13.3 & 7.3 \\
\hline
\end{tabular}


Table 3 (Continued)

\begin{tabular}{|c|c|c|c|}
\hline Symbol & Definition & 508-508 DT & $908-1 C 8 \mathrm{DT}$ \\
\hline $\mathrm{w}_{\mathrm{BP}}$ & $\begin{array}{l}\text { energy requirements of poloidal } \\
\text { field system }(\mathrm{MJ} / \mathrm{m})\end{array}$ & 345.4 & 205.0 \\
\hline${ }^{W_{B O}}$ & $\begin{array}{l}\text { total magnetic energy in EIS } \\
\text { system }(\mathbf{M J} / \mathrm{m})\end{array}$ & 358.7 & 212.3 \\
\hline $\mathrm{w}_{\mathrm{TR}}$ & $\begin{array}{l}\text { transport losses in } \infty i l \text { and } \\
\text { leads }(\mathrm{MJ} / \mathrm{m})\end{array}$ & 6.23 & 11.5 \\
\hline$\omega_{\text {ED }}$ & $\begin{array}{l}\text { eddy current losses in oil, } \\
\text { leads, and blanket }(\mathbf{M J} / \mathrm{m})\end{array}$ & 0.67 & 0.79 \\
\hline $\mathbf{w}_{\mathrm{B}}^{\mathbf{I N}}$ & $\begin{array}{l}\text { field in plasma at end of burn } \\
(\mathrm{MJ} / \mathrm{m})\end{array}$ & 37.1 & 19.6 \\
\hline$w_{\text {ETS }}$ & 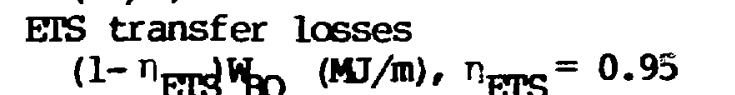 & 17.9 & 10.6 \\
\hline $\mathbf{w}_{\mathrm{IH}}$ & $\begin{array}{l}\text { total recoverable thermal energy } \\
(\mathrm{MJ} / \mathrm{m})\end{array}$ & 342.7 & 385.5 \\
\hline$W_{E T}$ & $\begin{array}{l}\text { gross electr ic energy } n_{\mathrm{TH}} \mathrm{w}_{\mathrm{TH}} \\
(\mathbf{M J} / \mathrm{m}), n_{\mathrm{TH}}=0.4\end{array}$ & 137.1 & 154.2 \\
\hline$Q_{E}$ & engineering Q-value & 4.06 & 5.39 \\
\hline$w_{C}$ & total circulating energy $(\mathrm{MJ} / \mathrm{m})$ & 33.8 & 28.6 \\
\hline$\varepsilon$ & recirculating power fraction $1 / Q_{E}$ & 0.25 & 0.19 \\
\hline$w_{E}$ & $\begin{array}{l}\text { net electric energy } \\
(1-\varepsilon) W_{\mathrm{FT}}(\mathrm{MJ} / \mathrm{m})\end{array}$ & 103.3 & 125.6 \\
\hline$\eta_{p}$ & $\begin{array}{c}\text { overall plant efficiency } n_{\mathrm{TH}}(1-\varepsilon) \text {, } \\
n_{\mathrm{TH}}=0.4\end{array}$ & 0.30 & 0.33 \\
\hline $\mathbf{R}$ & major radius $(m)$ & 10.0 & 10.0 \\
\hline$\tau_{\mathbf{C}}$ & cycle time (s) & 8.65 & 10.5 \\
\hline$\tau_{\mathbf{B}}$ & burn time (s) & 1.14 & 6.44 \\
\hline$I_{w}$ & $\begin{array}{l}14 \mathrm{MeV} \text { neutron wall loading } \\
\left(\mathrm{MN} / \mathrm{m}^{2}\right)\end{array}$ & 2.00 & 1.87 \\
\hline $\mathrm{P}_{\mathrm{TH}}$ & total thermal power (MNt) & 2490. & 2300 \\
\hline$P_{\text {ET }}$ & system gross electric power (Mie) & 995. & 921. \\
\hline $\mathbf{P}_{\mathbf{C}}$ & $\begin{array}{l}\text { system circulating electric } \\
\text { power ( } \mathrm{N} \text { (N)) }\end{array}$ & 245. & 171. \\
\hline$P_{E}$ & net system electric power (Mie) & 750. & 750. \\
\hline
\end{tabular}


neutrals. The electric field on the plasma then varies between 6-14 $v / m-m$ rorc as the bulk of the neutrals are ionized.

The major power contributions are also shom in Fig. 14. The difference between the ohnic-heating power $\mathrm{P}_{\mathrm{CP}}$ and ion-neutral chargeexchange power $P_{C X}$ is the power required to ionize the $D-T$ neutrals. The large line radiation power $P_{\text {InN }}$ at $0.01 \mathrm{keV}$ is apparent where a If oxygen fraction is assumed. After the resonance line is overocme (T> $0.02 \mathrm{keV})$, the initial density corresponding to 1 morr is increased to 2 morr in $0.005 \mathrm{~s}$ for the 508-508 D-T case while holding the impurity fraction constant. The bremsstrahlung power during this early phase increases to a maximum of only $0.3 \mathrm{kN} / \mathrm{m}$ at $0.012 \mathrm{~s}$, and the cyclotron radiation is insignificant. The ion and electron diffusive energy loss terms are less than $0.01 \mathrm{MN} / \mathrm{m}$.

The impurity fraction used above for illustrative purposes during startup was taken to be zero curing the burn to recuce the paraneter space. The initial starting density may be reduced until electron runaway becomes serious. The initial inductive spike begins at $\sim 75 \mathrm{~V} /$ $m$-mMorr and drops to $20 \mathrm{~V} / \mathrm{m}$-mitorr after $15 \mu \mathrm{s}$ for 1 minorr. As the density is decreased the initial large electric field is maintained for longer periods of time and, for ionization below 10s, continues to increase until large numers of electrons runaway and the discharge fails to develop. An experimentally determined filling pressure of 0.1-0.2 miorr (46) for a radius of $\sim 0.5 \mathrm{~m}$ gives an estimate of the minimum value. The startup code predicts an electric field $>20 \mathrm{~V} / \mathrm{m}-\mathrm{m}$ torr auring the period when $\mathrm{n}_{\mathrm{e}}<0.1 \mathrm{n}_{0}$ at these minimm 
densities. Changing the applied voltage on the system proportionally varies the time scale, however the magnitude of all quantities plotted in Fig. 14 remain virtually unchanged. Doubling the voltage would then decrease the time scale by one-half. 


\section{v. FTNAL SYSTEM DESIGN}

\section{A. General Reactor Description}

The toroidal reversed-field pinch reactor investigated here is a pulsed-plasma device using a lithium-sodium-steam heat transport system with a thermal cycle efficiency of 408 to produce 750 whe at an overall plant efficiency of 30-338. The major reactor parameters are listed in Table 3 for the two chosen operating points. The design given herein is based primarily on the 508-508 D-T fuel mixture case although both cases are similar. A plan view of the reactor system containing key RFFR subsystems is given in Fig. 15. The details of the heat removal and thermal conversion systems are described in Reference 73 for the Reference Theta Pinch Reactor. Two coolant loops of $\sim 1250 \mathrm{kHt}$ each transport the heat from the reactor to the single turbine/generator set. The schematic diagram of the primary-colant circuit in Fig. 16 illustrates the major lithium flow paths. The jrimary lithium oolant removes heat from the reactor blanket (lines denoted 1-7 in Fig. 16) and provides the tritium breeding necessary for the deuterium-tritium fusion burn cycle. Because of the cyclic nature of the plasma fusion, the lithium flow is reduced to near zero when magnetic field is present in the reactor blanket. During this period of the burn cycle the lithium flow must be shunted to an upstream surge tank while a downstream surge tank continues to flow lithium to the intermediate heat exchanger. When the magnetic field is zero, the lithium flows through the blanket, and the upstream tank empties while the downstream tank refills. The 

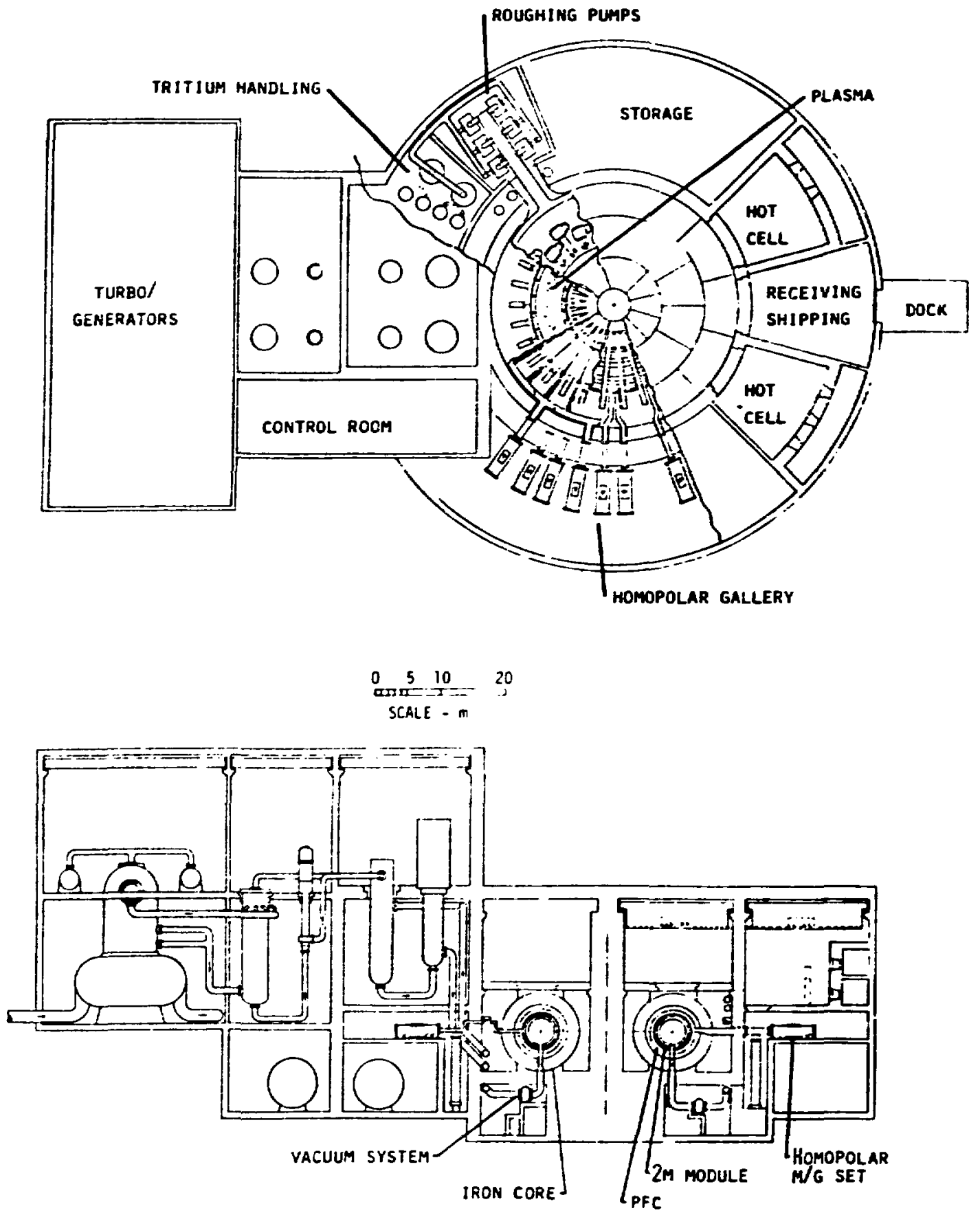

Fig. 15. Plan and elevation view of $750 \mathrm{MNe}$ (net) RFPR. 


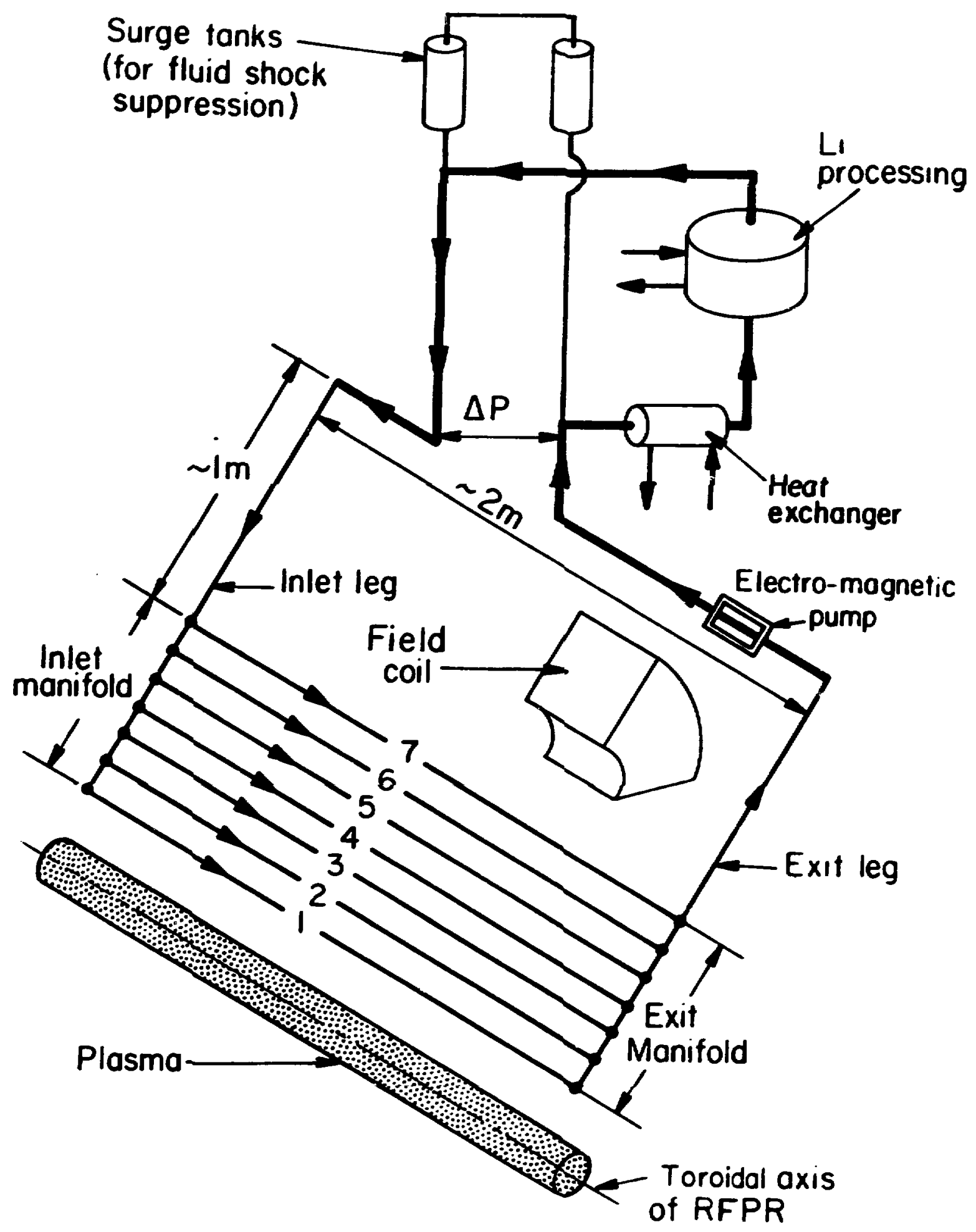

Fig. 16. Schematic diagram of the primary-coolant circuit illustrating the major lithium flow paths. 
lithium which flows from the heat exchanger is purified and the tritium extracted (73).

A lithium exit temperature of $820 \mathrm{~K}$ produces a sodium exit temperature of $810 \mathrm{~K}$ from the Li-Na heat exchangers. The remainder of the plant is then similar to the Liquid-Netal Fast-Breeder Reactor designs. The plant operates at $755 \mathrm{~K}$ maximm stean temperature which is similar to the design temperatures of many fossil-fuel plants presently in operation. An overall thermal cycle efficiency of $\eta_{T H}=0.40$ results and is used for all calculations.

As shown in Fig. 15, the reactor is comprised of $30,2.1-\pi-10 n$ toroidal sections resulting in a torus of $10-\mathrm{m}$ major radius. An isometric view of a RFPR segment, given in Fig. 17, shows the placement of major reactor components. The first wall also acts as the vacuum wall where the flanges at the ends of the 2.1-m modules are welded to form a vacuum seal. The lithium-cooled blanket, and toroidal field coil (TFC) is then encircled by a structural ring which is used to lift the $2.1-m$ module. The blanket/first-wall assembly and vacuum ducting for each module is mechanically separate and supported by the iron core structure. Outside of the modules are the poloidal field coils, divided into 4-m-long toroidal sections, and the iron cores, divided into top and bottam semicircular sections. The actual amount of iron necessary to reduce the externally stored energy to near zero is much more than shown in Figs. 15 and 17 and is discussed in Sec. V.B.

Referring to Fig. 17 a vacuum pump and associated ducting is provided for each 2.1-m-long module with the vacuum tunnel underneath 


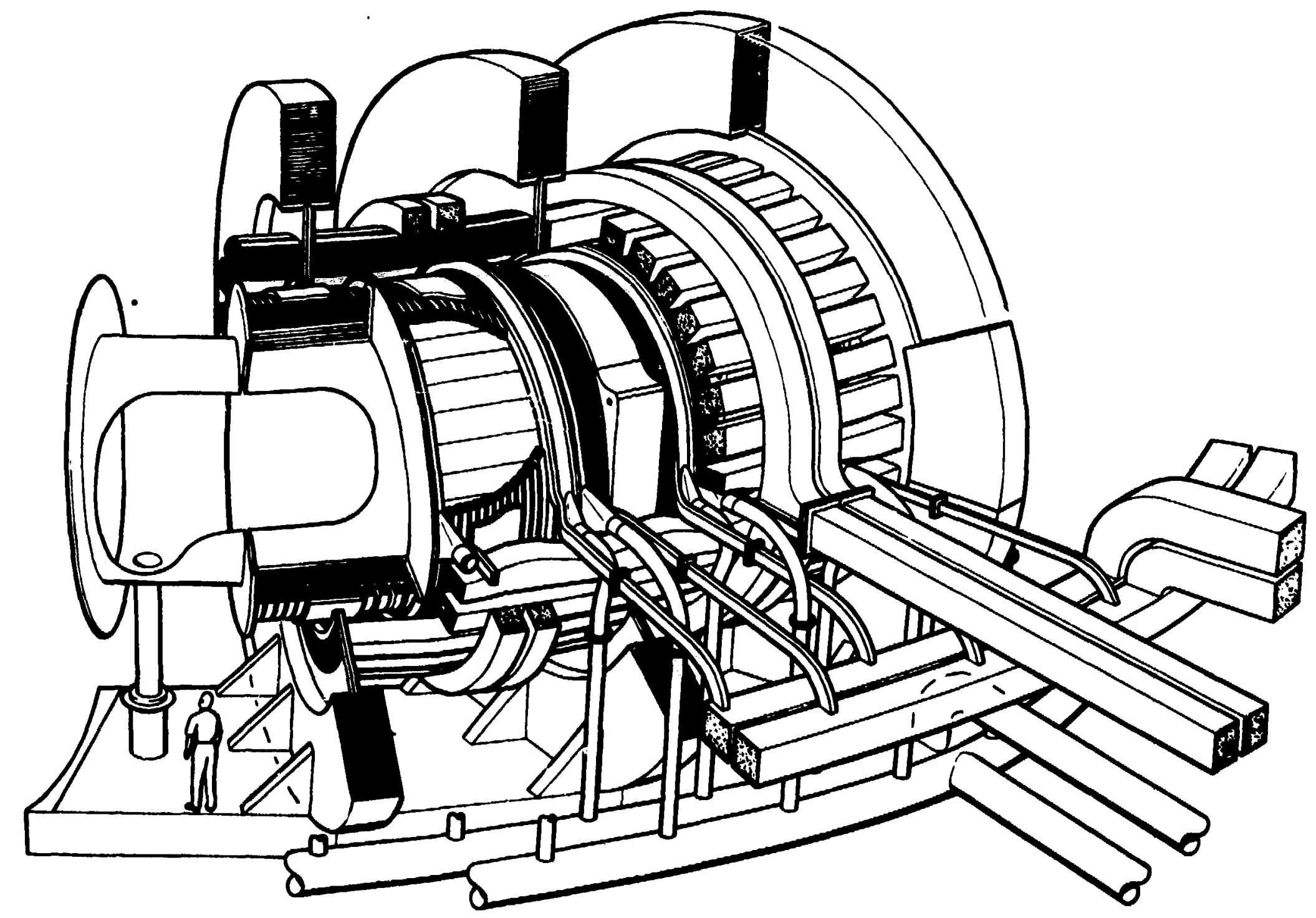

Fig. 17. Isometric view of 2-m-long RFPR reactor modules (vaculm vessel, blanket, toroidal

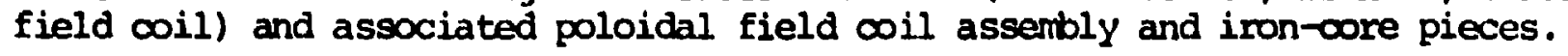


the floor of the reactor. The inlet and outlet lithium coolant pipes encircle the torus at the reactor floor level and separate connections are made to each module. The IFC's are connected electrically in parallel to a bus which also encircles the machine and is energized by two center-grounded homopolar machines. The poloidal field coil (PFC) consists of wedge-shaped segments where $1 / 15$ of the conductors in each wedge are energized at each 4-m-lang section, resulting in a single turn transformer oil when the 15 sections are connected. Each of the PFC leads is then connected to two center-grounded homopolar machines.

The plant layout given in Fig. 15 depicts the general scheme envisaged for repair and maintenance of the RFPR. All major coprations on the reactor torus must be made remotely with the aid of a -200-Tonne-capacity overhead crane. Aocess to a given 2-m-long $x$ 5.5-m diameter $\times 100-$ Tonne module is achieved after renoval of the overhead shielding blocks, the top halves of three adjacent iron-core pieces, and the top half of the associated 4-m-long $\times 175$-Tonne PFC assembly after disconnecting the electrical leads and associated coil (He-gas) coolant leads. The bottcm halves of both iron-core pieces and PFC assembly need not be removed to replace a RFPR module. Disconnection of TPC leads and associated coolant lines, and revote grinding of welded vacuun joints between the adjacent modules as well as joints connecting the module to the vacuum downocmer allows the module under repair to be removed from the torus and placed in an appropriate repair or salvage area. 
The 20-30 homopolar generators used to energize the coils would be mounted on rails and could easily be decoupled from the massive hut permanent lead structure. A similar arrangement is envisaged for the banks of vacum pungs with the additional difficulty of remote maintenance due to the intense neutron boubardment of the vacuum systea. The technology associated with the large number of remote manipulations of massive equipment will require considerable develognent. Other required reactor subsystems such as tritium handling/processing, He-gas coolant system for the coils, cryogenic facility for the superconducting homopolar energy stores, plant control system, and associated maintenance machinery have not been investigated and must be addressed in future RFPR design studies. The balance of plant appears "standard" except for the $\mathrm{Na} / \mathrm{Li}$ primary heat exchangers and Li pumps.

\section{B. Consideration of Major System Components}

The major compcnents to be described are the fuel supply and removal system, first wall and blanket, magnet coils, iron core, homopolar energy storage devices, and switches. This design has not progressed into the detailed engineering stage, and specific structural analysis of these subsystems is not addressed.

The fuel supply and removal system must provide a DT mixture at the pressure required for the plasma burn phase ( 1-2-mitorr), supply a sufficient amount of neutral gas (DT mixture) to quench the plasma, and reduce the concentrations of reaction products (helium) and other impurities between plasma burn pulses. The fuel supply will use 
straight-forward gas-puff methods through small tubes $(\sim 1 \mathrm{~nm})$ at a few locations around the torus providing $\sim 1600$ l-Torr $(\sim 0.6 \mathrm{~T})$ fuel charge (2 mitorr) for a burn pulse and an additional amount for the plasma quench. Given that each $25 \mathrm{~m}^{3}$ module is equipped with a vacurm "downcomer" which represents the minimum vacuum conductance, the maximum pumping speed is then determined by this conductance. Under the anticipated condition of molecular flow, the downcomer conductance is given by (74)

$$
c=\frac{651 \pi a^{2}}{1+\frac{3}{8} \frac{1}{a}} \mathrm{~m}^{3} / \mathrm{s}
$$

where $a$ is the duct radius taken as $0.2 \mathrm{~m}$ and the length 1 is $1 \mathrm{~m}$, resulting in a $28.5 \mathrm{~m} / \mathrm{s}$ conductance. Dividing the conductance into the module volume yields an e-folding time of $\sim 0.9 \mathrm{~s}$, and a few seconds of pumping through this conductance will reduce the concentration by ten. This ideal situation does not account for the added gas load which may be incurred by the as yet unresolved requirements of the quench and plasma cooling phases of the burn cycle. A Roots blower (with associated roughing pumps) is envisaged for the primary pumping system and when impedanced matched with a $25,000 \mathrm{l} / \mathrm{s}$ conductance would be $\sim 1.6 \mathrm{~m}$ diameter $\times 3.6-\mathrm{m}-\mathrm{lang}$ and consume $100 \mathrm{kWe} /$ module (73).

The lithium-cooled (99\% enriched $\left.{ }^{7} \mathrm{Li}\right)$, Nb-1Zr blanket system is described in References 15 and 75 and is shown schematically in Fig. 18. The 0.4-m-thick blanket with 1 to 2-mm-thick niobium structural walls uses stagnant lead for neutron multiplication in the hard-spectrum regions, stagnant ${ }^{6} \mathrm{Li}$ (958 enriched) for tritium production leading to 


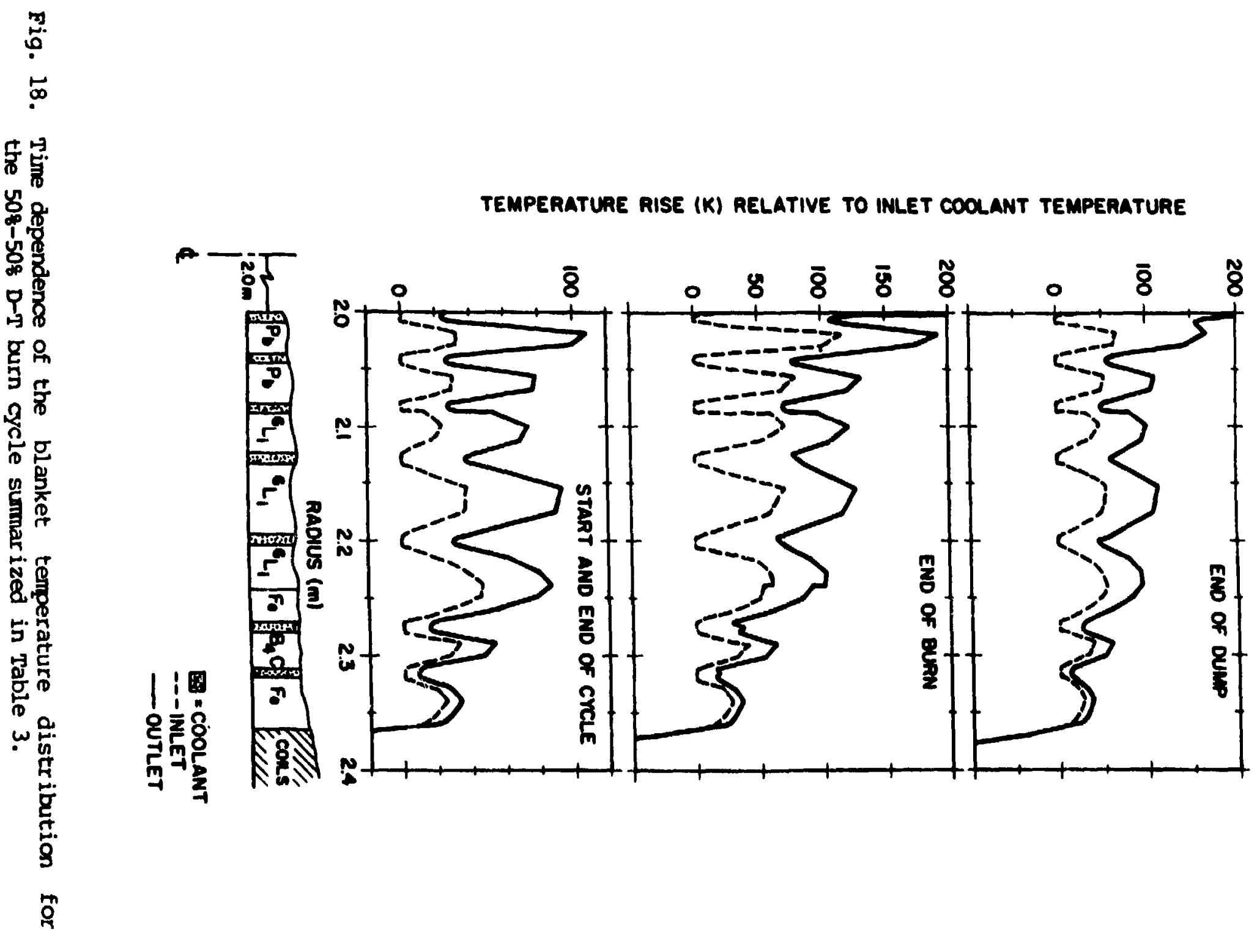


an overall tritium breeding ratio of 1.10 , and a combination of iron and boron carbide for attenuation of gamma rays and slow neutrons. Efficiency of the blanket in capturing neutron energy is to be near 1008 resulting in a total thermal energy of $18 \mathrm{MeV} /$ neutron. Division of the blanket into 30 azimuthal sections (Fig. 17) reduces the eddy-current Iosses.

The colant-flow response shown in Fig. 19 and resultant temperature profile shown in Fig. 18 use parameters from the 508-508 D-T fuel mixture case where the numbered coolant flow curves correspond to the flow channels in the blanket also shom schematically in Fig. 16. During the burn (when magnetic field is present) the lithium flow is very small, and the heat transfer to the coolant is primarily by conduction. During the quench phase (plasma dump) the net plasma current is electrically forced to zero resulting in a wall-confined plasma with no field outside the reacting volume which allows the coolant to Elow.

The required image currents for plasma stability (see Sec. IL.A) are assumed to be provided by the first wall and blanket on short time scales $\left(\tau \sim \delta^{2} /\left(0.5 \times 10^{6} n\right)\right.$ where $\eta=2 \times 10^{-6} \Omega-\mathrm{m}$ for $1000 \mathrm{~K}$ Li gives $\tau \sim 0.1 \mathrm{~s}$ for the $\delta \sim 0.4-m-t h i c k$ blanket) and external windings for longer times. This is speculative and further investigation may lead to the inclusion of a low resistivity material near the first wall. A prime candidate would be copper near room temperature which would require a blanket that thermally isolated a cool copper region (immediately outside the first wall at $800-1000 \mathrm{~K}$ ) from the remainder of 


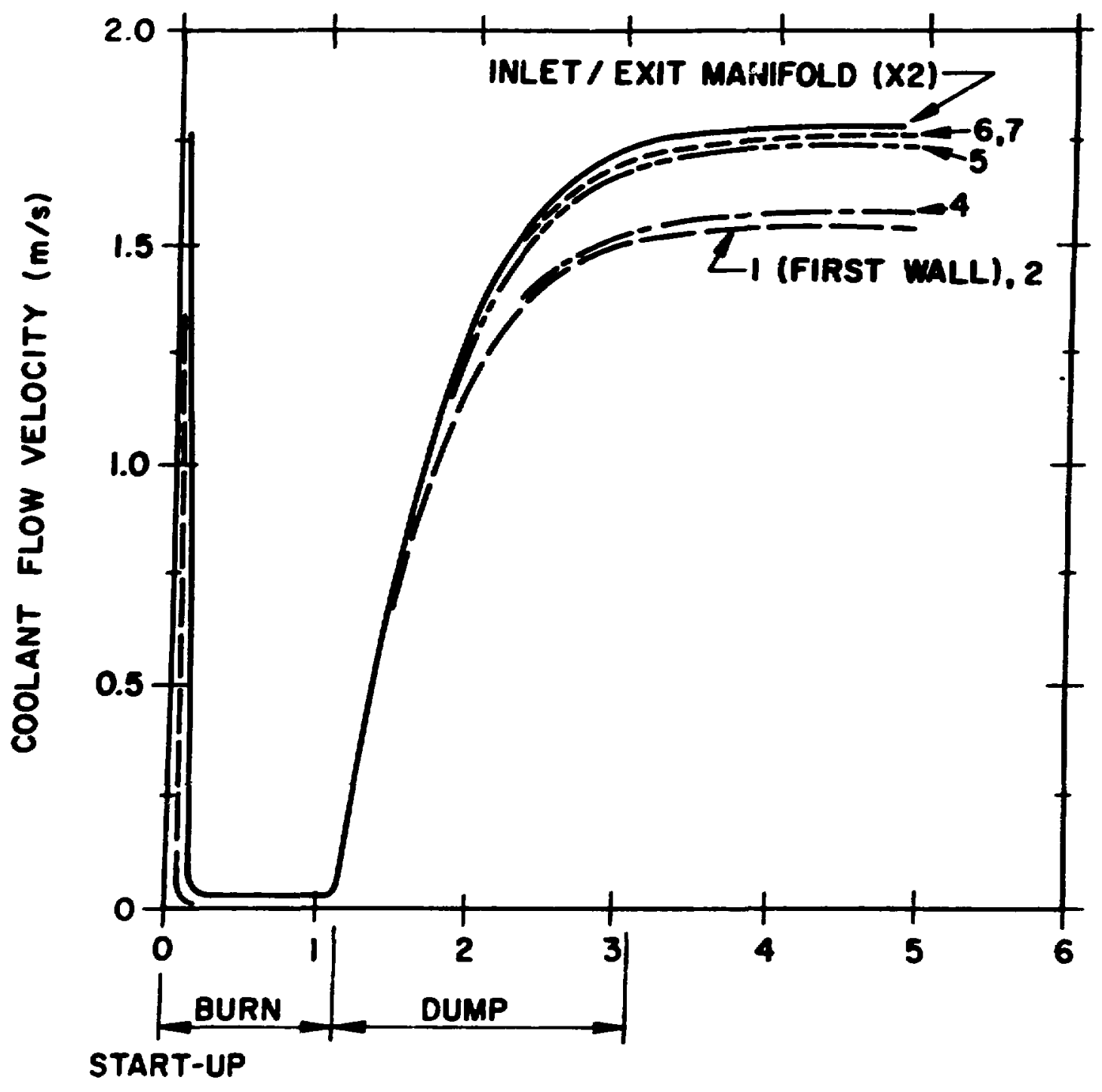

TIME (s)

Fig. 19. Time dependence of lithium coolant flow in the RFPR blanket for the 508-508 D-T fuel mixture case. 
the blanket. The additional energy loss and complexity of this system is much less favorable than the blanket used in this design.

A first wall consisting of a low-z ceramic coating bonded to a structural metal is used as the reference design. For both cases given in Sec. IV. a $(0.3 \mathrm{~mm}) \mathrm{Al}_{2} \mathrm{O}_{3} /(1.0 \mathrm{~mm}) \mathrm{Nb}-1 \mathrm{Zr}$ laminated wall is found to be adequate. A one-dimension heat transfer calculation in cylindrical geometry is performed vs time by the plasma burn oode for the composite wall using the aforementioned lithium flow rates. Thermophysical properties are taken from Ref. 14. Tangential stresses for a conposite cylinder under plane-strain conditions (14) are simultaneously calculated vs time and radial position using the temperature profiles. For all calculations the bremsstrahlung, cyclotron, and thermal conduction is taken as a surface heat flux, while the neutron-gamma heating (73) is assumed uniform. Figures 20 and 21 give the time dependence of tenperature and tangential stresses at key locations within the first wall for the 508-508 D-T case and 908-108 D-T case, respectively. The 508-508 D-T case has a $1.14 \mathrm{~s}$ burn followed by a quench phase when the trapped field $W_{B}^{T N}$ and plasma internal energy is uniformly deposited at the first wall over a time period of $3 \mathrm{~s}$. The lithium coolant starts to flow after the thermonuclear burn is complete. The 908-108 D-T case shom in Fig. 21 has a $6.44 \mathrm{~s}$ burn and a $2 \mathrm{~s}$ quench phase. The ultimate compressive and tensile strength of $\mathrm{Al}_{2} \mathrm{O}_{3}$ is $-7 \times 10^{8} \mathrm{~Pa}$ and $1.6 \times 10^{8} \mathrm{~Pa}$, respectively. The stresses in the alumina are mostly compressive and a factor of at least three less than the ultimate stress. The first-wall composite has been experimentally (76) cycled in excess of a hundred 

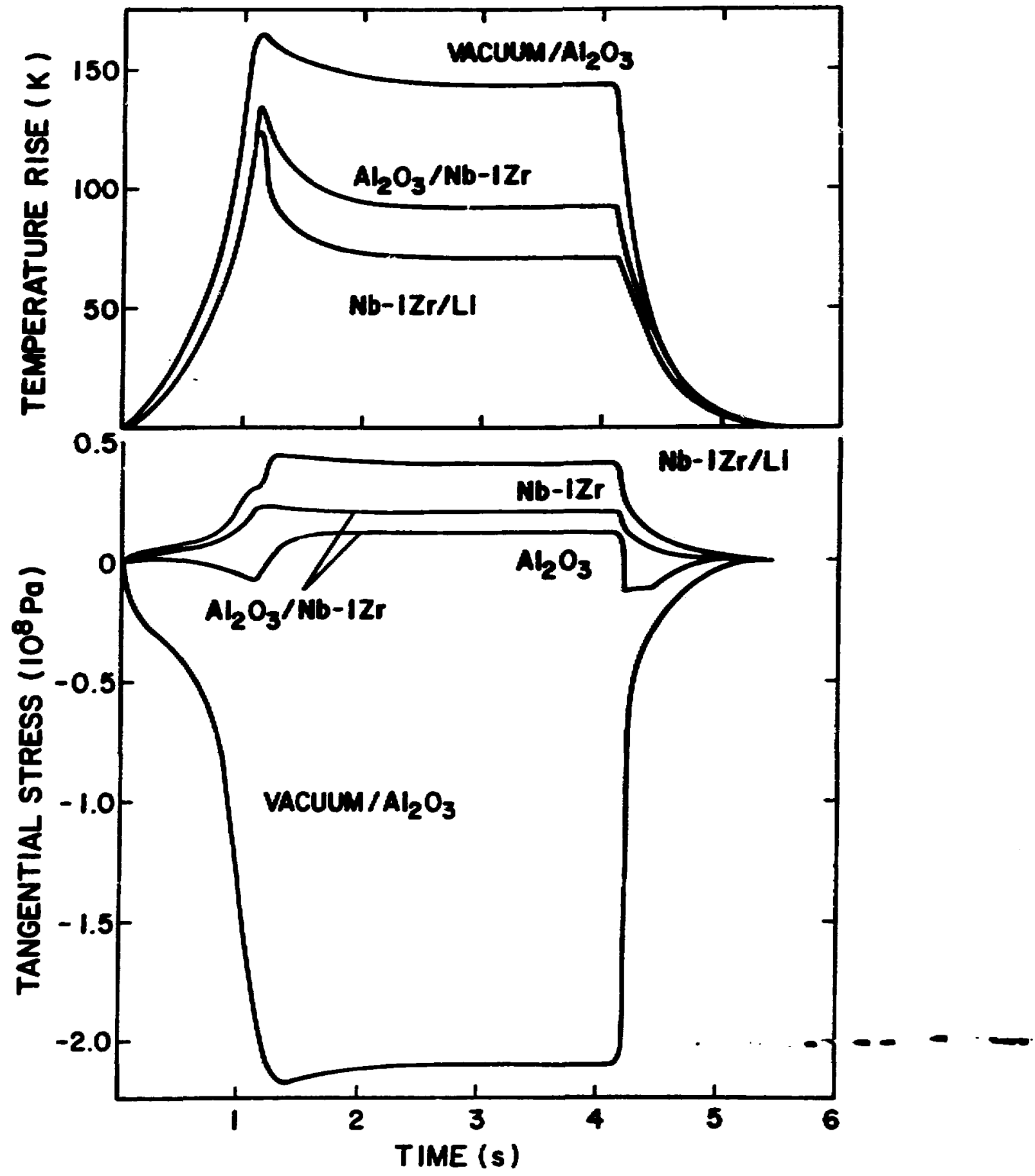

Fig. 20. Dependence of first-wall temperature and stress during the ignition, burn, quench, and plasma coling periods associated with the 508-508 D-T burn cycle given in Table 3. 


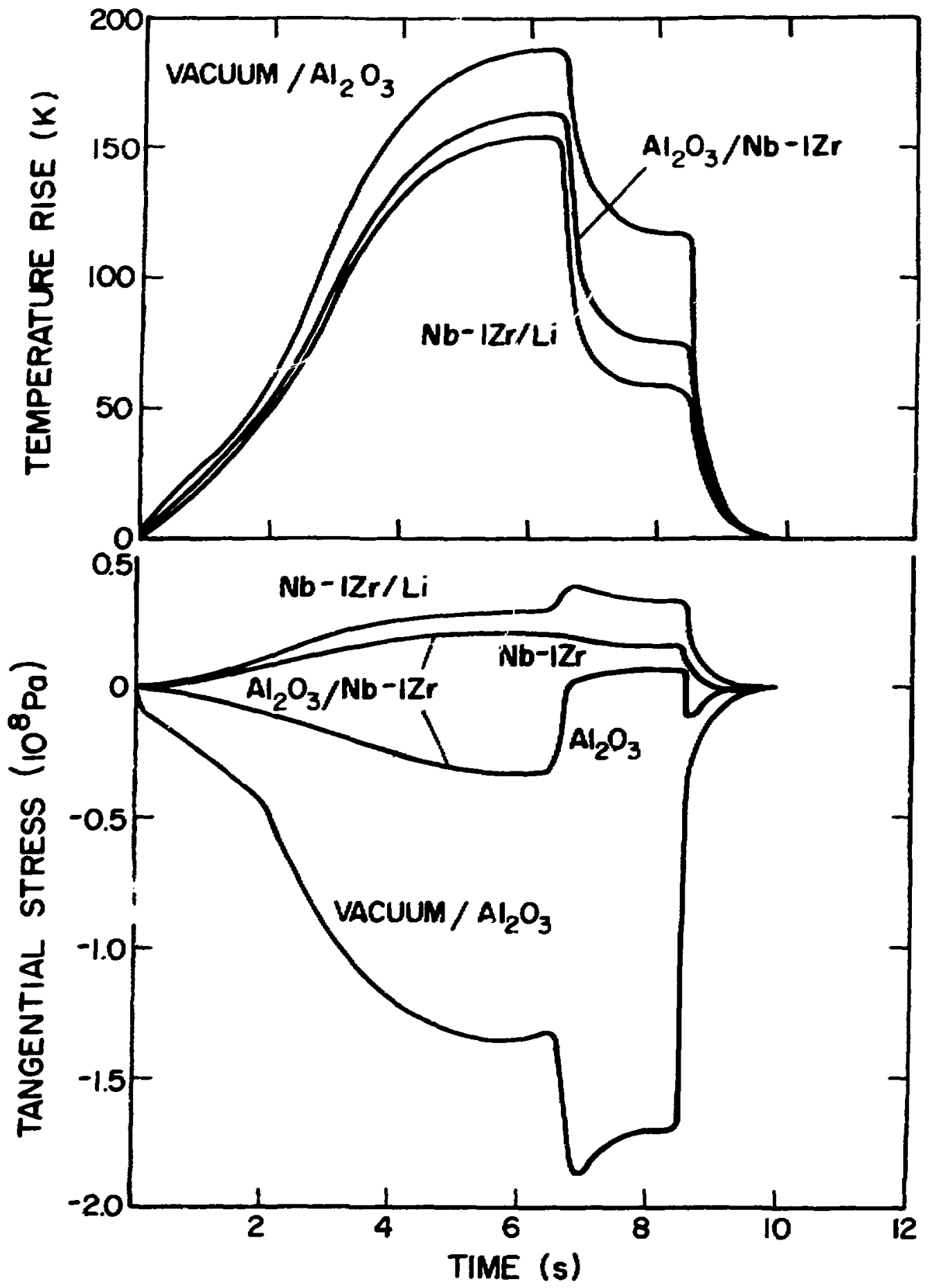

Fig. 21. Dependence of first-wall temperature and stress during the ignition, burn, quench, ard plasma cooling periods associated with the 908-108 D-T burn cycle given in Table 3. 
times using a surface heat flux (pulsed electron beam). The resultant temperature excursions produced compessive stresses (computer simulation) at the alumina surface of $-6 \times 10^{8} \mathrm{~Pa}$ and tensile stresses of $1.4 \times 10^{8} \mathrm{~Pa}$ in the alumina at the $\mathrm{Al}_{2} \mathrm{O}_{3} / \mathrm{Nb}-1 \mathrm{Zr}$ interface. The actual stresses experienced by the RFPR first wall are well below these experimental values and appear to provide a reasonable margin of safety. The lifetime of the $\mathrm{Nb}-12 \mathrm{r}$ structural material is determined by thermal fatigue considerations. The maximum stress occurring in the $\mathrm{Nb}-12 \mathrm{r}$ is three times less than the yield strength of the material $\left(1.4 \times 10^{8} \mathrm{~Pa}\right)$ at the operating temperature which should provide an adequate engineering safety factor, however, radiation damage is not considered.

The elements of the electrical system include a number of homopolar machines, switches, the toroidal/poloidal field coils and an iron core arranged in a toroidal configuration. The electrical circuit is a basic LC or tank circuit wherein the homopolar machine acts as a capacitor. The current/field relationships vs time are shown in Fig. 22. The poloidal and toroida? field systems are electrically separate (although inductive coupling will occur).

Opening and closing of switch $S_{1}$ is in effect performed by the homopolar brushes. Closure of switch $S_{1}$ (i.e., lowering the brushes) at time $-\tau_{R} / 2$ connects the homopolar machine (1008 speed and voltage) to the toroidal field $\infty$ il. The current $r$ ises to a maximum producing the initial bias field $\mathrm{B}_{\mathrm{zO}}$. Preionization of the plasma now cocurs and the analogous switch $s_{1}$ on the poloidal field system is closed. The current $I_{2}$ rises to a maximum as the $B_{2}$ field continues to inductively "ring", 

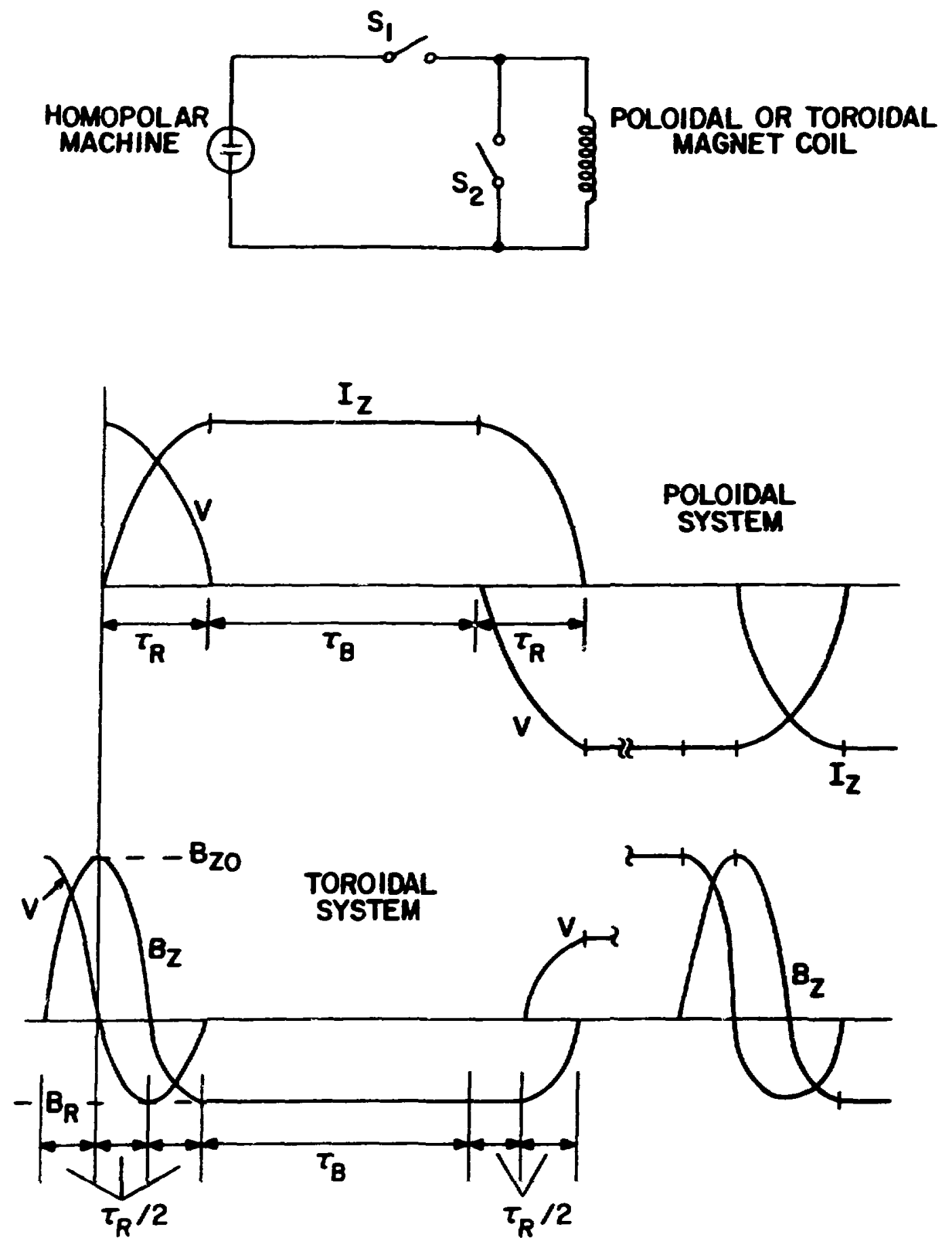

Fig. 22. Schenatic diagram of hamopolar-generator driven circuit for both TFC and PFC systems. The voltage $V \sim 4-5 \mathrm{kV}$, the rise time $\tau_{R} \sim 100 \mathrm{~ms}$, and $\tau_{B} \sim 1-6 \mathrm{~s}$. 
ultimately yielding the desired reversed field $-B_{R^{*}}$ At time $\tau_{R}$ switch $S_{2}$ is closed and the current $I_{z}$ and reverse field $-B_{R}$ is maintained at a near constant value during the burn $\tau_{B^{*}}$. The homopolar machine remains at rest during the period $\tau_{B}$.

Following the burn, the switch $\mathrm{S}_{2}$ is opened and the respective currents for each system are transferred back to the howopolar machine which motors up to 1008 speed and voltage (neglecting losses). The above cycle is then repeated at the desired rate. The direction of rotation and the voltage of the homopolar machine in the poloidal system reverses ouring each cycle. If this results in stability problems, the field may be maintained in a uniform direction by the introduction of reversing switches.

The toroidal field ooil, located inmediately outside the blanket (Fig. 17), consists of 30 separate coils of 15 turns each (corresponding to a 2.1-m module) arranged electrically in parallel resulting in a voltage comparable to that of the poloidal system. The single-toroidal bus is then driven by two hamopolar machines acting in series which are center grounded to minimize the machine voltage above the ground potential. The single-turn poloidal field coil is divided into 30-wedge-shaped segments (Fig. 17) in the azimuthal direction. These wils are then further divided into 4-m-long sections fed by a single electrical lead where $1 / 15$ of the coinluctors in each wedge are energized at each lead resulting in a single-turn transformer coil when the 15 sections are connected. The upper and lower hemicylinder of 4-m-long onductor is constructed as a unit with a single lead disconnect. Each 
poloidal field is driven by two center-grounded homopolar machines. The poloidal field coil wedges and each turn of the toroidal field oil are contained within a stainless steel vessel providing a colant path for the helium gas which maintains the coils at near roan temperature to minimize ohnic losses. These coils would be constructed from $\sim 7 \mathrm{~mm}$ copper bars that are litzed and transposed to produce a uniform current density in the magnet coils.

An equivalent circuit for the poloidal field system is the parallel connection of a capacitor (homopolar generator) and the inductors $L_{i}$ and $\mathrm{L}_{\mathrm{e}}$ associated with the regions internal and external to the poloidal field coil, respectively. The internal inductance is

$$
L_{i}=\mu_{o} R\left[0.5+\ln \frac{r_{C p}}{r_{p}}\right] H \quad
$$

while the external inductance is

$$
L_{e}=\mu_{o} R\left[\ln \frac{B R}{r_{C Q}}-2\right] H
$$

for an air core, and is considered to be infinite for an iron core. Thus, the iron core ideally couples the current in the poloidal coil ( $I_{c}$ ) to the plasma current $\left(I_{c}=I_{z}\right)$ and requires a total stored energy in the homopolar generators of

$$
\mathrm{W}_{\text {IRON }}=0.5 \mathrm{~L}_{\mathrm{i}} \mathrm{I}_{\mathrm{z}}^{2}
$$

For an air core the current swing in the poloidal field ooil is $I_{e} \wedge I_{c}=$ $\left(L_{e}+L_{i}\right) I_{z}$ (equating flux change) which yields $\Delta I_{c}=97.5 \mathrm{MA}$ for the 
508-508 $\mathrm{D}-\mathrm{T}$ case in Table $3 \mathrm{II}_{\mathrm{z}}=40 \mathrm{MA}, \mathrm{L}_{\mathrm{e}}=1.6 \times 10^{-5} \mathrm{H}$, and $\mathrm{L}_{\mathbf{i}}=$ $2.3 \times 10^{-5} \mathrm{H}$ ). Swinging the current in the coil from 0 to $97.5 \mathrm{MA}$ increases the ohmic losses a factor of $6\left(\propto \mathrm{I}_{c}^{2}\right)$ and requires a total stored energy of

$$
W_{A I R}=0.5 L_{e}\left(I_{c}-I_{z}\right)^{2}+0.5 L_{i} I_{z}^{2}
$$

(evaluated at maximum $I_{z}$ ) or nearly 2.5 times the iron core case. By swinging the primary $\infty$ il current from $-48.75 \mathrm{MA}$ to $+48.75 \mathrm{MA}$ the ohmic losses are only 1.5 times and the stored energy required nearly equal to the iron core case. This appears favorable, however, the extraction of the field energy from the poloidal coil at the end of the burn is exceedingly difficult. The coil current is swing from plus to minus 48.75 MA which drives the plasma current to zero. If the external circuit now attempts to drive the ooil current to zero, the flux change induces a current in the hot conducting plasma which implies that the coil current cannot be extracted until after the quench $(2-3 \mathrm{~s})$. In this case the current should simply be left in the coil; using the hamopolar generator as a transfer capacitor to symmetrically swing the current fran plus to minus now only requires an energy store equal to half that needed by the iron core case. Gperating in this mode greatly increases the ohmic losses in the coil when campared to an iron core system.

An iron core is assumed herein for all cases, which reduces the coil ohmic losses and required stored energy (maximizes $Q_{E}$ ) when coupared to an air core system (excluding minus to plus poloidal current swings due 
to the aforementioned field energy extraction problems). The cross sectional area, $A$, of iron required is

$$
2 B_{S} A=I_{i} I_{z} \text { Wb }
$$

where $B_{S}$ is the saturation flux taken as $2 \mathrm{~T}$, and the factor of two accounts for back biasing the iron before each pulse. Requirements of $\sim 920(690)$ Wb for the 508-508 (908-108) D-T fuel mixture cases results in $230(170) \mathrm{m}^{2}$ of iron which repressents about 3-4 times the amount of iron shown in Figs. 15 and 17. This additional amount of iron could be put around the torus, however diminishing space and added maintenance problems may be prohibitive. A second poloidal coil may be inserted outside the iran core to drive a fraction of the flux and reduce the iron requirements, although additional energy storage and chmic losses are again incurred. This study has used the engineering Q-value $Q$ as the object function for system optimization. The large anount of iron required represents an additional constraint which may alter the design point ance an economic analysis is performed, which is beyond the scope of this work.

Conceptual designs of homopolar machines (16) for the Reference Theta Pinch Reactor provide the engineering basis for the RFPR energy storage system. Machines using low inertia rotors constructed of hollow, radially thin, cylinders allow increases in diameter, speed, and magnetic field with superconducting windings. These properties yield low energy storage costs and high efficiency.

The machine voltage is

$$
\mathrm{v}=\mathrm{v} \overline{\mathrm{B}}_{\mathrm{R}} \mathrm{L}
$$


where the maximum allowable peripheral velocity $\mathrm{v}$ is taken as $277 \mathrm{~m} / \mathrm{s}$ and the average field between collectors $\bar{B}_{R}$ is $3 \mathrm{~T}$. The voltage is then specified by the active length $L$ of the machine. The energy stored in a cylindrical rotor riachine is

$$
w_{s}=\frac{\pi}{4} \rho L r_{0}^{2} v^{2} f_{i}
$$

where the density $\rho$ of the aluminum-graphite fiber rotor is $2300 \mathrm{~kg} / \mathrm{m}^{3}$. Taking the fraction $f_{i}$ of the flux intercepted by the rotor as 0.61 then defines the rotor radius $r_{0}$ for the required machine energy $w_{S}$. This value of $f_{i}$ is dependent upan a rotor length to diameter ratio of 0.75 . This value is closely maintained in the design of the poloidal field system which is the major energy store. For the toroidal field system, length to diameter ratios of $0.5-0.75$ are favorable. Size optimization leads to rotcr diameters of $1.5-3 \mathrm{~m}$ with energy transfer efficiencies of $\sim 958$ and energy storage costs of $\sim 0.6 \% / J o u l e$. These considerations lead to the homopolar parameters listed in Table 4.

The system requires the interruption of $\sim 3 \mathrm{MA}$ from two series connected homopolar generators. Using $\sim 200 \mathrm{kA}$ switches then requires a parallel set of 15 switches with the associated problem of current isolation during switching. The rapidly varying impedance of a switching element may result in one switch carrying all the current, unless precautions are taken. This may involve keeping the parallel circuits electrically separate (although inductive coupling will ocur) and paralleled only at the brushes of the homopolar which also reduces circulating currencs in the coils. 
Table 4. Homopolar specifications

\begin{tabular}{|c|c|c|c|c|c|c|c|}
\hline $\begin{array}{l}\text { Energy } \\
\text { Storage } \\
\text { System }\end{array}$ & $\begin{array}{l}\text { Riset ime } \\
\text { (s) }\end{array}$ & $\begin{array}{c}\text { Voltage } \\
\text { (kV) }\end{array}$ & $\begin{array}{l}\text { Total } \\
\text { Active } \\
\text { Length } \\
\text { (m) }\end{array}$ & $\begin{array}{l}\text { Diameter } \\
\text { (m) }\end{array}$ & $\begin{array}{c}\text { Number } \\
\text { of } \\
\text { Rotors }\end{array}$ & $\begin{array}{l}\text { Number } \\
\text { of } \\
\text { Machines }\end{array}$ & $\begin{array}{c}\text { Energy } \\
\text { Per } \\
\text { Machine } \\
\text { (MJ) }\end{array}$ \\
\hline $\begin{array}{l}\text { Poloidal } \\
\text { (908-108 } \\
\text { DT) }\end{array}$ & 0.1 & 4.5 & 5.42 & 2.35 & 4 & 20 & 635 \\
\hline $\begin{array}{l}\text { Toroidal } \\
\text { (908-108 } \\
\text { DT) }\end{array}$ & 0.05 & 4.5 & 5.42 & 1.45 & 6 & 2 & 242 \\
\hline $\begin{array}{l}\text { Poloidal } \\
\text { (508-508 } \\
\text { DT) }\end{array}$ & 0.1 & 5.5 & 6.62 & 2.27 & 4 & 30 & 720 \\
\hline $\begin{array}{l}\text { Toroidal } \\
\text { (50-508 } \\
\text { DT) }\end{array}$ & 0.05 & 5.5 & 6.62 & 1.73 & 6 & 2 & 418 \\
\hline
\end{tabular}

Solid state switching may be used for this system. The rating of these devices is about $200 \mathrm{kA}$ at $4-6 \mathrm{kV}$ and many of them are paralleled to give the desired current rating. The cost of this type of switching element is, however very high and probably prohibitive. The present price estimates (77) are $\$ 10^{4}$ MVA with total requirements on the order of $5 \times 10^{4} \mathrm{MVA}$. This may be alleviated by using mechanical breakers or the A.E.G. air blast breaker to be used in JET (77). These breakers interrupt $\sim 100 \mathrm{kA}$ and cost $\sim \$ 0.5 \mathrm{M}$ which still results in a high cost considering 300-400 are needed. This problem may be alleviated by using hydraulic (oil) breakers (78) which can interrupt $\sim 100 \mathrm{kA}$ and may cost only $\sim \$ 2000$, although the reliability of these switches must be resolved. 


\section{SUMMARY AND CONCLUSIONS}

The physics model used herein predicts a wide range of possible operating points for the reversed-field pinch reactor. The operating range is, however, greatly reduced when considering first-wall thermal constraints and imposing an upper limit on the achievable current density. The ohmically ignited pulsed system must have a radius greater than about $3.5 \mathrm{~m}$ to minimize the recirculating power fraction which results in a reactor system of moderate power output $(750 \mathrm{me})$. The reactor system that evolves from this model achieves an overall plant efficiency of 30-338 using a lithium-sodium-steam heat transport system which will use much of the technology developed from the Liquid-Metal Fast-Breeder Reactor. Preliminary consideration of major reactor subsystems reveals no major "flaws" although considerable technological development will. be required before the reactor described herein could be fully realized.

Relatively slow startup is necessary to be oompatible with the rotating machinery (homopolar generators) which provides the field energy. Estabiishing the RFP profiles may require the plasma to pass through many unstable states resulting in turbulence. For risetimes of $0.1 \mathrm{~s}$ the required voltages $(5-6 \mathrm{kV})$ are achievable with homopolar generators. Electron runaway can be avoided during the early phases of breakdown and is not a problem when greater than 108 of the fuel is ionized. Laboratory experimentation must, however, reveal the true plasma behavior during long ( 0.1 s) startup tine periods. 
The evaluation of various burn cycles must be based on the resultant recirculating power fraction and first-wall thermal constraints such as stress and thermal fatigue. Recirculating power fractions of $\sim 0.25$ are achievable in 508-50\% D-T systems in which the temperature $r$ ises uncontrollably until beta limits are achieved and the plasma must be quencher. Temperature control by heat loss from the plasma implies an enhanced surface heat flux at the first wall which imposes severe onnstraints in a pulsed high-density system. Using a 908-108 D-T fuel mixture provides automatic temperature control by tritium burnup and results in recirculating power fractions of -0.15 . The feasibility of these burn cycles must ultimately be investigated with a MD burn code.

The operation of a RFPR in a pulsed mode is contingent upon extracting the plasma current at the end of the burn. This may require the reacting olume to be flooded with neutral gas during the quench phase in order to avoid a short-circuit current path at the first wall. The flux trapped in the wall-confined plasma at the end of the burn is assumed thermally lost to the wall. To replace this last flux requires 508 of the recirculating electric power, which demonstrates the importance of the plasma quench and the need for detailed calculations to better quantify the actual amount of flux lost.

Stability of the plasma during the burn cycle is assumed. Constraints are imposed on the maximum poloidal beta, minimum plasma radius, and achievable current densities (experimentally determined); however, the conducting wall needed for complete stability would be too thick for a reactor system. The image currents necessary for stability 
could be provided by the external ooils for slowly growing modes $(\sim 0.01 \mathrm{~s})$ in conjunction with a thin $(1 \mathrm{~cm})$ conducting wall to stabilize the rapidly growing modes. The need to prevent a slowly growing helical deformation is questionable. The large field trapped inside the plasma will prevent any large energy loss from the plasma even if in close proximity to the wall (as a tokamak). Much theoretical work is needed to determine the required thickness of the conducting wall.

The RFPR is a medium aspect ratio system which results in a low dipole field (1-2 T) in the center of the torus allowing the use of an unsaturated iron core to minimize the recirculating power fraction (maximize $Q_{E}$ ) although the large amount of iron required may ultimately change the design point due to restrictions on space and cost. The use of normal field coils requires only 10-208 of the recirculating electrical energy and greatly simplifies the construction and maintenance of the system when compared to superconducting $\infty$ ils.

Among the most difficult engineering problems of this system are the required high efficiency ( 908$)$ energy transfer and storage. Homopolar generators provide a realistic solution to the energy storage problem; however, these devices require a significant technological development. The reliable switching of large amounts of energy (10-20 GJ) every $\sim 10 \mathrm{~s}$ is perhaps the most formidable problem. Solid state switching is possible; however, the cost may prove to be prohibitive. The development of reliable mechanical switches at low cost may be necessary. 
The study of a pulsed RFPR has revealed physics operating points that are compatible with realistic engineering systems. The desirability of these systems must await an economic assessment and is contingent upon favorable physics scaling. 


\section{TOPICS FOR FURTHER STWY}

The reactor design generated by this thesis represents a basis from which a more comprehensive and realistic engineering system may be developed. The present design describes a plausible reactor scenario that is contingent on many physics and engineering assumptions that warrant further study.

Plasma behavior is subject to much conjecture due to the limited experimental work that has been perfocmed on the RFP. Theoretical work dealing with startup, field reversal, stability/-quilibrium and the associated need for a flux conserving first wall, transport loss, and a neutral-gas blanket (plasma quench) could provide insight into the behavior of a RFP plassa. The actual response of the plasma must be investigated through further experimentation, although "reactor-like" plasmas will not be available for many years.

A final design point will ultimately be dictated by economics which must be the underlying consideration in future parameter studies of the RFPR. This will also allow a refinenent in the engineering design of major subsystems such as the first wall, blanket, toroidal/poloidal field coil, iron core, energy storage/transfer system, vacum/fueling, and the balance of plant. This work should ultimately lead to a consistent engineering design of a RFPR that will operate at minimum cost. 
l. Kruskal, M.D. 1954. Large-Scale Instability in the Stellarator. USAEC Rept. NYO-6045.

2. Shafranov, V.D. 1956. The Stability of a Cylindrical Gaseous Conductor in a Magnetic Field. Atomnaiia Energiia (English Translation) $1: 709-713$.

3. Artsimovich, L.A. 1972. Tokamak Devices. Nuclear Fusion 12:215-252.

4. Dean, S.O., chairman. 1973. Status and Objectives of Tokamak Systems for Fusion Research. USAEC Rept. WASH-1295.

5. Toyama, H., et al. 1976. Experiments on Noncircular Tokamak and Related Topics. Sixth International Conference on Plasma Physics and Controlled Nuclear Fusion Research, Berchtesgaden, West Germany 6:IAEA-CN-35/Al0-4.

6. Plasma Theory Section Staff. 1976. Tokamak Plasma Magnetics. Sixth International Conference on Plasma Physics and Controlled Nuclear Fusion Research, Berchtesgaden, West Germany $6:$ IAEA-CN-35/B10.

7. Chu, C.K., et al. 1975. Initial Dynamics, Equilibrium, and Heating of Toroidal Belt Pinches. Third Topical Conference on Pulsed High Beta Plasmas, Culham, United Kingdom 3:553-556.

8. Hoekzema, J.A. 1975. Toroidal Equilibrium of Non-Circular Sharp Boundary Plasmas Surrounded by Force-Free Fields. Third Topical Conference on Pulsed High Beta Plasmas, Culham, United Kingdom 3:535-539.

9. Hirano, Kei-ichi. 1975. Screw Pinches and High Beta Tokamak with Circular Cross-Section. Third Topical Conference on Pulsed High Beta Plasmas, Culham, United Kingdom 3:87-9l.

10. Bobeldijk, C., et al. 1975. Results of SPICA. Third Topical Conference on Pulsed High Beta Plasmas, Culham, United Kingdom $3: 493-496$.

11. Bodin, H.A.B. 1975. Reversed Field Pinches. Third Topical Conference on Pulsed High Beta Plasmas, Culham, United Kingdom $3: 39-57$.

12. Baker, D. A., R. L. Hagenson, R. A. Krakowski, and K. I. Thomassen. 1977. Summary of the Reversed-Field Z-Pinch Concept. USERDA Rept. LA-UR-77-459. (Los Alamos Scientific Laboraciory, Los Alamos, NM) 
13. Baker, D.A. and J.N. DiMarco. 1975. The LASL Reversed-Field Pinch Program Plan. USERDA Rept. LA-6177-MS. (LOS Alamos Scientific Laboratory, Los Alamos, NM)

14. Krakowski, R.A., R. L. Hagenson, and G.E. Cort. 1976. First Wall Wall Thermal-Mechanical Analyses of the Reference Tneta-Pinch Reactor. Nuclear Technology $34(2): 217-241$.

15. Krakowski, R.A., et al. 1976. CTR-DOT Quarterly Report for the Period July 1 - September 30, 1976. (Los Alamos Scientific Laboratory, Los Alamos, NM)

16. Thomassen, K.I., et al. 1976. Conceptual Engineering Design of a One-GJ Fast Discharging Homopolar Machine for the Reference Theta-Pinch Fusion Reactor. EPRI ER-246, Project 469. (Electric Power Research Institute)

17. Glasstone, S. and R.H. Lovberg. 1960. Controlled Thermonuclear Reactions. Van Nostrand Reinhold Company, New York, N.Y. 523 pp.

18. Rose, D.J. and M. Clark, Jr. 1965. Plasmas and Controlled Fusion. 2nd ed. The M.I.T. Press, Massachusetts Institute of Technology, Cambridge, Massachusetts. 493 pp.

19. Kruskal, M.D. and M. Schwarzschild. 1954. Some Instabilities of a Complecely Ionized Plasma. Proceedings of the Royal Society of London A223: 348-360.

20. Tayler, R.J. 1957. Hydromagnetic Instabilities of an Ideally Conducting Fluid. Physical Society B70:31-48.

21. Rosenbluth, M.N. 1956. Stability of the Pinch. USAEC Rept. LA-2030. (LOS Alamos Scientific Laboratory, Los Alamos, NM)

22. Shafranov, V.D. 1957. On the Stability of a Cylindrical Gaseous Conductor in a Magnetic Field. J. Nuclear Energy 5:86-9l.

23. Tayler, R.J. 1958. The Stability of a Constricted Gas Discharge. Proceedings of the Second United Nations International Conference on the Peaceful Uses Atomic Energy, Geneva, Switzerland 2(31): 160-170.

24. Kruskal, M. and J. L. Tuck. 1958. The Instability of a Pinched Fluid with a Longitudinal Magnetic Field. Proceedings of the Royal Society of London A245:222-237.

25. Suydam, R.B. 1958. Stability of a Linear Pinch. Proceedings of the Second United Nations International Conference on the Peaceful Uses of Atomic Energy, Geneva, Switzerland $2(31): 157-159$. 
26. Newcomb, W.A. 1960. Hydromagnetic Stability of a Diffuse Linear Pinch. Annals of Physics 10:232-267.

27. Furth, H.P. 1960. Sufficient Conditions for Hydromagnetic Stability of a Diffuse Linear Pinch. Physics of Fluids 3:977-981.

28. Suydam, B.R. 1960. Stability of a Linear Pinch, Part II. USAEC Rept. LAMS-2381. (Los Alamos Scientific Laboratory, Los Alamos, $N M$ )

29. Baker, D.A. and L.W. Mann. 1974. Progresss Report of the LASL Controlled Thermonuclear Research Program. USERDA Rept. LA-5656-PR. (LOS Alamos Scientific Laboratory, Los Alamos, NM)

30. Baker, D.A., et al. 1971. Z-Pinch Experiments with Shock Heating. Proceedings of the IAEA Conference on Plasma Physics and Controlled Nuclear Fusion Research, Madison, Wisconsin $4(1): 203-216$.

31. Robinson, D.C. 1971. High- $\beta$ Diffuse Pinch Configurations. Plasma Physics 13:439-462.

32. Mercier, C. 1960. A Necessary Criteria of Hydromagnetic Stability for a Plasma with Symmetry of Revolution. Nuclear Fusion $1: 47-53$.

33. Baker, D.A. and L.W. Mann. 1972. MED Studies of Numerically Obtained Toroidal Equilibria. Proceedings of the Second Topical Conference on Pulsed High Beta Plasmas, Munich, West Germany $2: 69-72$.

34. Haberstich, D.A., et al. 1975. Stability and Diffusion of the ZT-I Reversed Field Pinch. Third Topical Conference on Pulsed High Beta Plasmas, Culham, England 3:249-253.

35. Crow, J.E., J. Kileen, and D.C. Robinson. 1973. Resistive Instabilities in Diffuse Pinches. Proceedings of the Sixth European Conference on Controlled Fusion and Plasma Physics, Moscow USSR $6(1): 269-272$.

36. Diabiase, J.A. 1974. Numerical Studies of Resistive Instabilities in Diffuse Pinches. USERDA Rept. UCRL-51591. (Lawrence Livermore Laboratory, Livermore, CA)

37. Butt, E.P., et al. 1974. Confinement and Stability of High Beta Plasma in a Reversed Field Pinch. Proceedings of the Fifth International Conference on Plasma Physics and Controlled Nuclear Fusion Research, Tokyo, Japan 5(3):417-429. 
38. Turner, L. 1977. Vlasov-Fluid Theory of Short Wavelength Instabilities of a Sharp-Boundary Screw Pinch. Phys. Fluids $20(4): 662-674$.

39. Taylor, J.B. 1974. Relaxation of Toroidal Plasma and Generation of Reverse Magnetic Fields. Phys. Rev. Letts. 33(19): 1139-1141.

40. Ortolani, S. and G. Rostagni. 1975. Reverse Field Configurations with Minimum Potential Energy. Third Topical Conference on Pulsed High Beta Plasmas, Culham, UK 3:335-339.

41. Baker, D.A. and J.A. Phillips. 1974. Pressure-Balance Limitations in Z-Pinches with Diffusion Heating. Phys. Rev. Letts. $32(5): 202-205$.

42. Sgro, A.G. and C.W. Nielson. 1975. Hybrid Model Studies of Magnetic Field Diffusion in High- $\beta$ Pinches. Third Topical Conference on Pulsed High Beta Plasmas, Culham, UK 3:329-334.

43. Burkhardt, L.C. 1975. Partial Chronology of Z-Pinch Studies at Los Alamos Scientific Laboratory, 1952-1975. USERDA Rept.

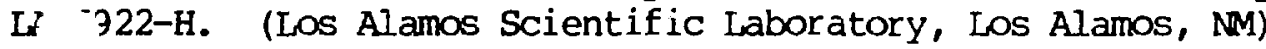

44. Ohkawa, T., H.K. Forsen, A.A. Schupp, Jr., and D.W. Kerst. 1963. Toroidal Discharge Experiments with Rapid Programming. Phys. Fluids $6(6): 846-857$.

45. Butt, E.P., et al. 1958. The Design and Performance of ZETA. Proceedings of the Second United Nations International Conference on the Peaceful Uses of Atomic Energy, Geneva, Switzerland $32: 42-64$.

46. Burton, W.M., et al. 1962. Plasma Loss in ZETA. Nuclear Fusion, Supplement 3:903-919.

47. Butt, E.P., et al. 1965. Conditions for Improved Stability in ZETA. Proceedings of the Conference on Plasma Physics and Controlled Nuclear Fusion Research, Culham, UK 1:751-764.

48. Robinson, D.C. and R.E. King. 1968. Factors Influencing the Improved Stability of ZETA. Proceedings of the Third International Conference on Plasma Physics and Controlled iNuclear Fusion Research, Novosibirsk, USSR 3(1):263-276.

49. Butt, E.P. and A.A. Newton. 1975. New Results from ZETA. Third Topical Conference on Pulsed High-Beta Plasmas, Culham, UK $3: 425-429$. 
50. Verhage, A.J.L. and D.C. Robinson. 1975. Stability of Pinches with a Reversed Field in HBTX I. Third Topical Conference on Pulsed High Beta Plasmas, Culham, UK 267-271.

51. Bunting, C.A., A.A. Newton, and M.R.C. Watts. 1975. Studies of the Ion Temperature and Total Radiated Energy from Pinches in HBTXI. Third Topical Conference on Pulsed High Beta Plasmas, Culham, UK 3:437-441.

52. Buffa, A., S. Costa, G.F. Nalesso, and G. Malesani. 1975. Experiments on Programed and Naturally Relaxing RFP Configurations. Third Topical Conference on Pulsed High Beta Plasmas, Culham, UK 3:261-265.

53. Buffa, A., et al. 1976. Heating, Diffusion, and Stability of Reverse Field Pinch Configurations. Sixth International Conference on Plasma Physics and Controlled Nuclear Fusion Research, Berchtesgaden, West Germany 6:IAFA-CN-35/E3.

54. Ogawa, K., et al. 1975. High Beta Plasma Confinement in Reversed Field Pinch (ETL TPE-1). Third Topical Conference on Pulsed High Beta Plasmas, Culham, UK 3:255-259.

55. Shimada, T., et al. 1976. Toroida: Pinch Experiments in ETL. Sixth International Conference on Plasma physics and Controlled Nuclear Fusion Research, Berchtesgaden, West Germany 6: IAEA-CN-35/E4.

56. Hirano, K., et al. 1976. Plasma Confinement of Nagoya High Beta Toroidal Pinch Experiments. Sixth International Conference on Plasma physics and Controlled Nuclear Fusion Research Berchtesgaden, West Germany 6:IAEA-CN-35/E7.

57. Baker, D.A., et al. 1971. Z-Pinch Experiments with Shock Heating. Proceedings of the IAEA Conference on Plasma Physics and Controlled Nuclear Fusion Research, Madison, Wisconsin $1: 203-216$.

58. Burkhardt, L.C., et al. 1972. Recent Results from the Shock Heated Toroidal Z-Pinch Experiment ZT-I. Proceedings of the Second Topical Conference on Pulsed High Beta Plasmas, Munich, West Germany 2:33-36.

59. Bodin, H.A.B., T.E. James, and A.A. Newton. 1969. A Pulsed Fusion Reactor Based on the Toroidal Pinch. Proceedings of the BNES Nuclear Fusion Reactor Conference, Culham, UK 1:3.4.

60. Bodin, H.A.B., et al. 1975. The Pulsed Reverse Field Pinch Reactor. Plasma Physics and Controlled Nuclear Fusion Research, Vienna, Austria 1:IAEA-CN-33/G5. 
61. Yeung, B.C., J.W. Long and A.A. Newton. 1975. Reactor Burning Calculations for a Model Reversed Field Pinch. Third Topical Conference on Pulsed High Beta Plasmas, Culham, UK 3:575-579.

62. Hancox, R., et al. 1977. A $600 \mathrm{MW}(\mathrm{e})$ Reversed Field Pinch Reactor Study. IAEA Workshop on Fusion Reactor Design, Madison, Wisconsin, 1:CLM-P501.

63. Newton, A.A., Li Yin-An, J.W. Long, and B.C. Yeung. 1975. Numerical Investigation of Reversed Field Pinches. Third Topical Conference on Pulsed High Beta Plasmas., Culham, UK 3:323-328

64. Thamassen, K. I., et al. 1977. Ohunic Heating Systems Study for a Tokamak EPR. USERDA Rept. LA-UR-77-398. (LOS Alamos Scientific Laboratory, Los Alamos, NM)

65. Rrajcik, R.A. 1973. The Effect of a Metallic Reflector upon Cyclotron Radiation. Nuclear Fusion 13:7.

66. Burnett, S.C., W.R. Ellis, T. A. Oliphant, and F. L. Ribe. 1972. A Reference Theta Pinch Reactor (RTPR). USAEC Rept. LA-5121-MS. (LOS Alamos Scientific Laboratory, Los Alamos, NM)

67. Oliphant, T.A. 1969. Fuel Burnup and Direct Conversion of Energy in a D-T Plasma. USAEC Rept. IA-DC 10528. (LOS Alamos Scientific Laboratory, Los Alamos, NM)

68. Papoular, R. 1976. The Genesis of Toroidal Discharges. Nuclear Fusion 16:37-45.

69. Bernstein, W., F.F. Chen, M.A. Heald, and A.Z. Kranz. 1958. "Runaway" Electrons and Cooperative Phenomena in B-1 Stellarator Discharges. Physics of Fluids $1(5): 430-437$.

70. Coor, T., et al. 1958. Experiments on the Ohmic Heating and Confinement of Plasma in a stellarator. Physics of Fluids $1(5): 411-420$.

71. Berger, J.M., I.B. Bernstein, E.A. Frieman, and R.M. Kulsrud. 1958. on the Ionization and Ohmic Heating of a Helium Plasma. Physics of Fluids $1(4): 297-300$.

72. Gurevich, A.V. 1961. On the Theory of Runaway Electrons. Soviet Physics JETP 12(5): 904-912.

73. Krakowski, R.A., F.L. Ribe, T.A. Coultas and A.J. Hatch. 1974. An Engineering Design of a Reference Theta-Pinch Reactor (RTPR). USAEC Rept. LA-5336/ANL-8019. 
74. Dushman, S. and J.M. Lafferty. 1965. Scientific Foundations of Vacuum Technique. John Wiley and Sons, Inc., New York, NY. 806 pp.

75. Cort, G.E. and R. A. Krakowski. 1978. Heat Transfer in LithiumCooled Blanket of the Reference Theta-Pinch Reactor. To be presented at the Sixth International Heat Transfer Conference, Toronto, Canada.

76. Armstrong, P.E. and R.A. Krakowski. 1977. Thermal Shock Experiment (TSEX) : A "Proof-of-Principle" Evaluation of the Use of Electron Beam Heating to Simulate the Thernal Mechanical Environment Anticipated for the First wall of the Reference Theta-Pinch Reactor (RTPR). USERDA Rept. LA-6861-MS. (LOS Alamos Scientific Laboratory, Los Alamos, NM)

77. Heck, F.M., E.I. King, Jr., and R.E. Stillwagon. 1976. Experimental Power Reactor Ohmic Heating Energy Storage Study. WFPS-TME-038 (Westinghouse Electric Corporation, Fusion Power Systems Department).

78. Vogel, H.F. 1977. personal communication, Los Alamos Scientific Laboratory, Los Alamos, NM.

79. Spitzer, L. 1962. Physics of Fully Ionized Gases. Interscience Publishers, Inc., New York, NY. 105 pp.

80. Braginskii, S.I. 1965. Reviews of Plasma Physics Vol. 1. Consul tants Bureau, New York, NY. 326 pp. 


\section{ACKNOWLEDGMANS}

The performance of this research at the Los Alamos Scientific Laboratory has proved to be a very rewarding experience. I am especially grateful to Drs. Keith Thamassen, Robert Krakowski, and Zeinab Sabri for making this research arrangement possible, providing encouragement and support while supervising this research, and reviewing this manuscript. I also wish to acknowledge my appreciation to the many people who gave assistance and advice, including Celina Ortiz for her help in preparing this manuscript. 


\section{APPENDIX}

The classical plasma resistivities used in this study are given by Spitzer (79) as

$$
\begin{aligned}
& \eta_{11}=\frac{9.62 \times 10^{-10} z_{\text {eff }} \ln \Lambda}{\gamma_{E} T_{e}^{3 / 2}} \quad(\Omega-m) \\
& n_{+}=n_{11} / 0.51
\end{aligned}
$$

where the value of $\gamma_{E}$ is approximately

$$
\gamma_{E} \simeq 0.582+0.418\left(\frac{z_{\text {eff }}^{-1}}{z_{\text {eff }}}\right)^{2}
$$

and

$$
\begin{aligned}
& \Lambda=\frac{4.907 \times 10^{17}}{\mathrm{Z}_{\text {eff }}} \frac{\mathrm{T}_{\mathrm{e}}^{3 / 2}}{\mathrm{n}_{\mathrm{e}}^{1 / 2}}, \mathrm{~T}_{\mathrm{e}}<0.0362 \mathrm{keV} \\
& \Lambda=\Lambda\left(\frac{0.0362}{\mathrm{~T}_{\mathrm{e}}}\right)^{1 / 2}, \mathrm{~T}>0.0362 \mathrm{keV} .
\end{aligned}
$$

The classical thermal conductivity perpendicular to field lines is given by Braginskii (80) as

$$
k_{+}=5.07 \times 10^{-39} \frac{a_{i}^{1 / 2} n_{i}^{2} \ln \Lambda}{T_{i}^{1 / 2} B^{2}}(\mathrm{~W} / \mathrm{m} \mathrm{keV})
$$

where $a_{i}$ is the atomic mass of the ions $\left(a_{i}=2.5\right.$ for DT fuel) and $B$ is somewhat arbitrarily taken as $\mathrm{B}_{\mathrm{O}}$ at the radius $\mathrm{r}_{\mathrm{p}}$. 